\title{
The Continuous Slope-Area Method for Computing Event Hydrographs
}

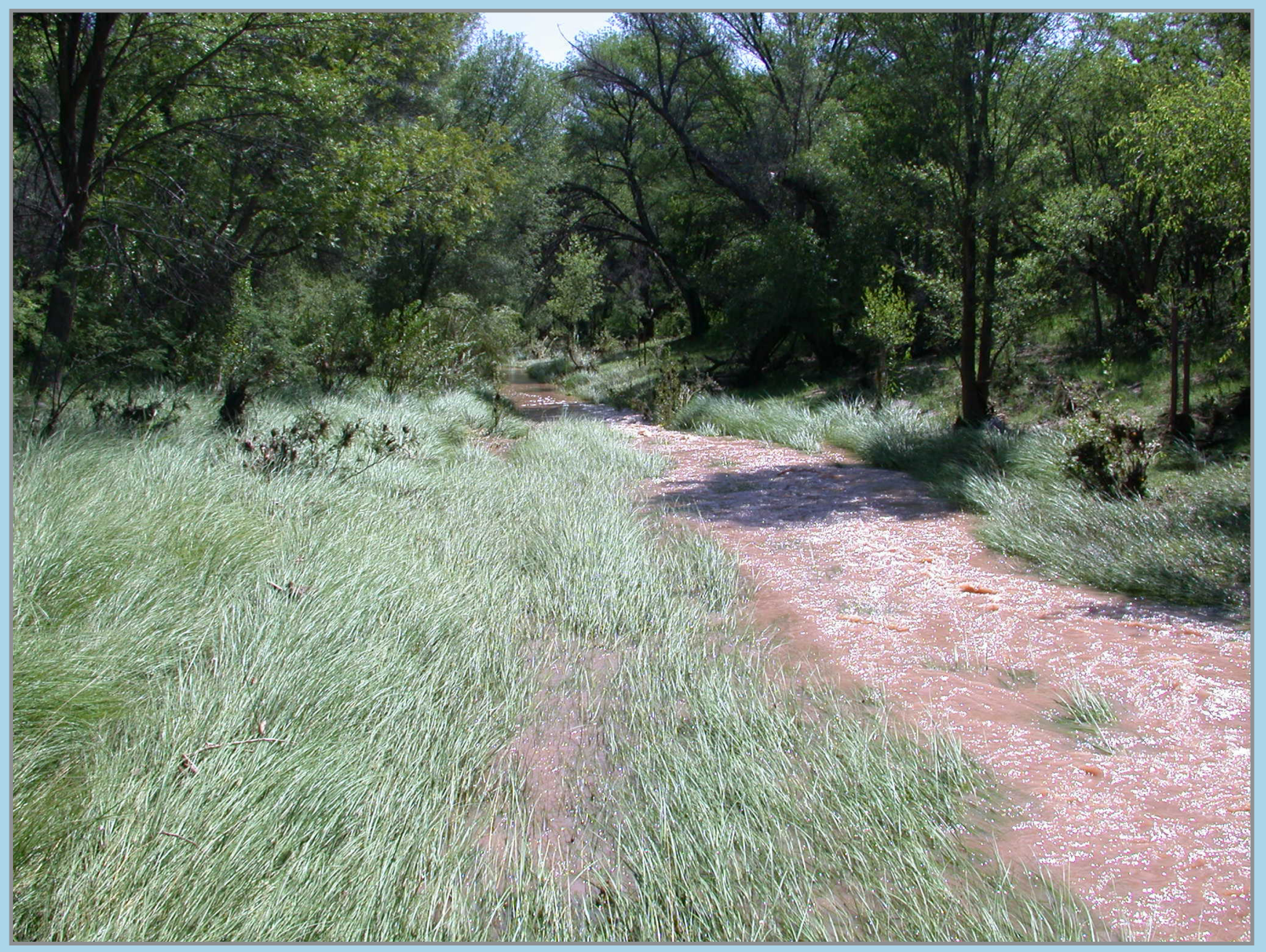

Scientific Investigations Report 2010-5241 
Cover. Babocomari River in southern Arizona, looking downstream during a summer flow event (photograph by J.T. Cordova). 


\section{The Continuous Slope-Area Method for Computing Event Hydrographs}

By Christopher F. Smith, Jeffrey T. Cordova, and Stephen M. Wiele

Scientific Investigations Report 2010-5241 


\section{U.S. Department of the Interior KEN SALAZAR, Secretary}

\section{U.S. Geological Survey Marcia K. McNutt, Director}

\section{U.S. Geological Survey, Reston, Virginia: 2010}

This report and any updates to it are available online at:

http://pubs.usgs.gov/sir/2010/5241/

For more information on the USGS - the Federal source for science about the Earth, its natural and living resources, natural hazards, and the environment:

World Wide Web: http://www.usgs.gov/

Telephone: 1-888-ASK-USGS

Any use of trade, product, or firm names in this publication is for descriptive purposes only and does not imply endorsement by the U.S. Government.

Although this report is in the public domain, it may contain copyrighted materials that are noted in the text. Permission to reproduce those items must be secured from the individual copyright owners.

Library of Congress Cataloging-in-Publication Data

Suggested citation:

Smith, C.F., Cordova, J.T., and Wiele, S.M., 2010, The continuous slope-area method for computing event hydrographs: U.S. Geological Survey Scientific Investigations Report 2010-5241, 37 p. 


\section{Contents}

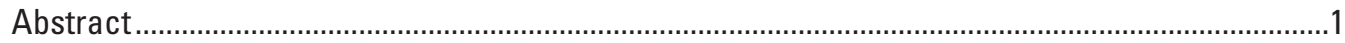

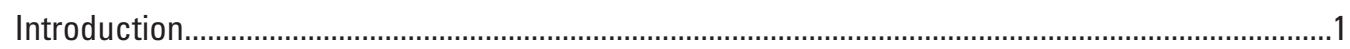

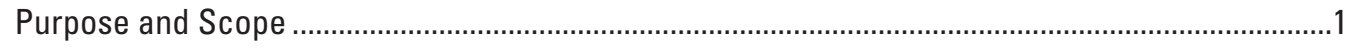

Discharge Measurements Using the Slope-Area Method ............................................................

The Slope-Area Computation Program .................................................................................

Sensitivity of Indirect Discharge Computations to Slope …….................................................2

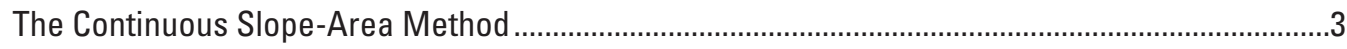

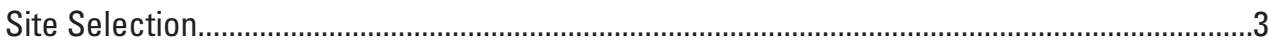

Evaluation of Pressure-Transducer Data and Calculated Hydrographs ..................................4

Comparison of Pressure-Transducer Peaks to Crest-Stage Gage Peaks.................4

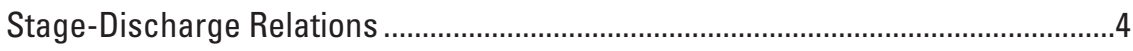

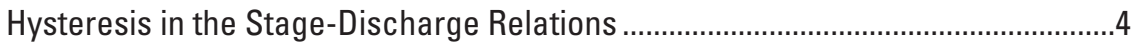

Evaluation of Channel Geometry..........................................................................

The Effect of Unsteadiness on Discharge Computation Accuracy............................5

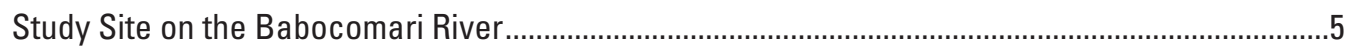

Description of Channel Conditions along the Slope-Area Reach and Roughness Coefficient

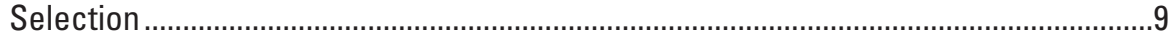

Application of the Continuous Slope-Area Method on the Babocomari River ................................11

Installation of Pressure Transducers ................................................................................11

Collection and Reduction of Pressure-Transducer Data ....................................................12

Calculation of Hydrographs Using the Continuous Slope-Area Method...................................13

Batch-Processing Discharge Computations.........................................................................13

Development of Stage-Discharge Relations ..................................................................

Major Flows on the Babocomari River 2002-2006 ……….................................................

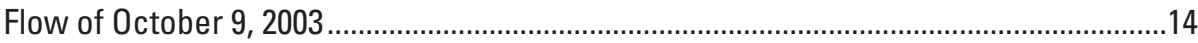

Channel Geometry ........................................................................................14

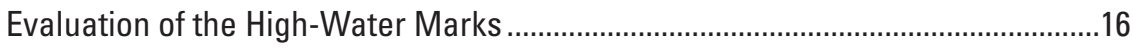

Conventional Slope-Area Computation and Analysis.............................................17

Evaluation of the Pressure-Transducer Data..........................................................18

Continuous Slope-Area Discharge Computations and Analysis .............................18

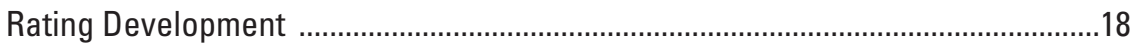

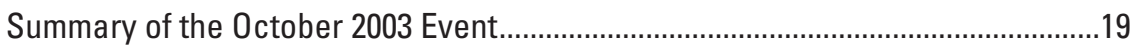

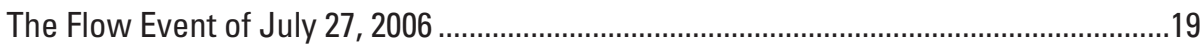

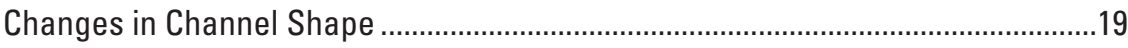

Evaluation of the High-Water Marks .....................................................................20

Slope-Area Computation and Analysis of High-Water Marks ...............................20

Slope-Area Computation of Peak Discharge using PT Data and Analysis of PT

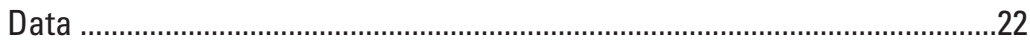

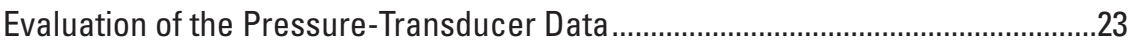

Development of Stage-Discharge Relation ............................................................24

Transfer of the CSA Stage-Discharge Relation to the Babocomari River near Tombstone

Streamflow-Gaging Station .......................................................................................

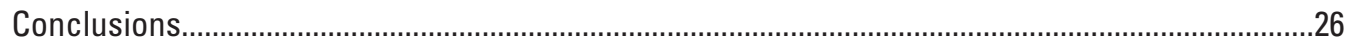

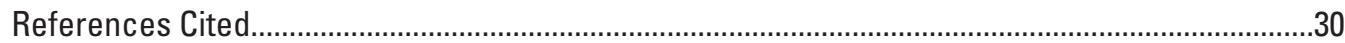




\section{Figures}

1. Error in discharge calculated with equation 2, caused by errors in measured reach drop. The sample calculation shown is for a true drop in the reach of $0.5 \mathrm{ft}$.

2. Percent error in the St. Venant momentum equation as a result of neglecting the unsteady term as a function of change in velocity for three reach slopes..

3. Velocity and du/d0 as function of discharge for a trapezoidal channel with a bed width of $50 \mathrm{ft}$, slope of 0.001 , and a Manning's $n$ of 0.035 . The bank width was specified as two times the depth

4. Hydrograph computed with the Continuous Slope-Area method and the normalized unsteady term from the momentum equation (du/dt)/(gS) during the July 27, 2006, event on the Babocomari River.

5. Histogram of the absolute value of the normalized unsteady term in equation 4 for the Babocomari River hydrograph shown in figure 4......................................................7

6. Map showing the study area on the Babocomari River.................................................

7. View looking downstream from cross section 1. Note the dense grass where trees are sparse...

8. View looking upstream from cross section 4. Ash trees grow along the low-flow channel.

9. Views from cross section 1 looking upstream (left), downstream (center), and downstream (right).

10 Views from cross section 2 looking upstream (left), downstream (center), and downstream (right)

11. Views from cross section 3 looking upstream (left), downstream (center), and downstream (right)

12. Views from cross section 4 looking upstream (left), downstream (center), and downstream (right)

13. Installation of the crest-stage gage (left). The pressure transducer is clamped to the bottom of the crest-stage gage board (center and right)

14. Plan view of the cross sections and eight pressure transducers in the Babocomari River continuous-slope-area reach....

15. Pressure-transducer-pin elevations (dry with no flow)................................................13

16. Peak streamflows recorded on the Babocomari River during the study period, 2002-2006.

17. Stage hydrographs from the October 9,2003 , flow event on the Babocomari River .....15

18. Channel surveys in cross section 1 before and after the 0 ctober 9,2003 , event. The blue dashed line shows the water-surface elevation at the peak discharge.

19. Channel surveys in cross section 2 before and after the October 9, 2003, event. The blue dashed line shows the water-surface elevation at the peak discharge.

20. Channel surveys in cross section 3 before and after the 0 ctober 9, 2003, event. The blue dashed line shows the water-surface elevation at the peak discharge.

21. Channel surveys in cross section 4 before and after the October 9, 2003, event. The blue dashed line shows the water-surface elevation at the peak discharge.

22. Average left- and right-bank pressure-transducer-stage hydrographs during the October 9, 2003, event 
23. Discharge values computed with the average pressure-transducer and creststage gage data for the October 9, 2003, event.

24. Stage-discharge relation determined with discharges computed from the averaged pressure-transducer data and crest-stage gage data for the October 9, 2003, event

25. July 27, 2006, stage hydrographs for six pressure transducers. Right-bank pressure transducers are indicated by $R$ in the legend label; left-bank pressure transducers are indicated by $\mathrm{L}$ in the legend label; the number in the legend label corresponds to the cross-section number.

26. Right-bank pressure transducer in cross section 1 (PTR1) after the July 27, 2006, flow event.

27. View looking upstream from cross section 3 on the right bank after the July 27, 2006, event. The floodway is mostly clear of obstacles

28. Channel surveys in cross section 1 before and after the July 27, 2006, event. The blue line shows the water-surface elevation at the peak discharge. At the peak discharge, the difference in cross-section areas is 2 percent

29. Channel surveys in cross section 2 before and after the July 27, 2006, event. The blue line shows the water-surface elevation at the peak discharge. At the peak discharge, the difference in cross-section areas is 8 percent

30. Channel surveys in cross section 3 before and after the July 27, 2006, event. The blue line shows the water-surface elevation at the peak discharge.

At the peak discharge, the difference in cross-section areas is 0.5 percent

31. Channel surveys in cross section 4 before and after the July 27,2006 , event. The blue line shows the water-surface elevation at the peak discharge. At the peak discharge, the difference in cross-section areas is 4 percent

32. Debris pile near left bank in cross section 3 after the July 27, 2006, event ....................26

33. Stage hydrographs of the four pressure transducers that were used to compute discharge for the July 27, 2006, event

34. Stage values from the left-bank pressure transducer in cross section 1 and the corresponding discharge computed with stage data in X1-X4 during the July 27, 2006, event are shown as dots. All stage and discharges shown occurred prior to the rotation of the pressure transducers. The solid line is a cubic polynomial fitted to the stage-discharge relation

35. Reach below the Babocamari River near the Tombstone stream gage was heavily vegetated prior to the July 27, 2006, event (left). Much of that vegetation was gone after the event (right). The rock in the right foreground of the left photograph is the same as the rock occupying the right lower quadrant of the right photograph

36. Stage hydrographs from the Babocomari River near Tombstone gage and the left bank pressure transducer in cross section 1 (PTL1) during the July 27, 2006, event Stages from the two sites were adjusted to coincide on the rising limb

37. Stage-discharge relations before and after the July 27, 2006, event. The blue line represents conditions prior to the peak and included the effects of the dense vegetation. The red curve represents the condition after vegetation was scoured. 


\section{Tables}

1. Elevation difference between crest-stage and pressure-transducer datums (dry)......13

2. Peak stages recorded by the crest-stage gages and by the pressure transducers during the October 9, 2003, event.

3. Peak discharge for cross sections $1-4$, based on average of left- and right- stage data from the pressure transducers and crest-stage gage from 0 ctober 9, 2003, event...

4. Water-surface elevations from surveyed high-water marks and pressure transducers from the July 27, 2006, event

5. Peak discharge computed using surveyed left-bank high-water marks for the July 27, 2006, event.......

6. Peak discharges computed using surveyed right-bank high-water marks for the July 27, 2006, event.

7. Peak discharge computed with the left-bank pressure transducers for the July 27, 2006, event.

8. Peak discharge computed with the right-bank pressure transducers for the July 27, 2006, event.

\section{Appendices}

1. Stage data and computed discharge for five runoff events in the Babocomari

River

2. Input files to the SAC program used in the continuous slope-area calculations of discharge for five events on the Babocomari River. 


\section{Conversion Factors}

\begin{tabular}{ccc} 
Inch/Pound & & \\
\hline Multiply & By & To obtain \\
\hline & Length & \\
\hline $\begin{array}{c}\text { foot } \\
(\mathrm{ft})\end{array}$ & 0.3048 & meter (m) \\
& Flow rate & meter (m) \\
$\begin{array}{c}\text { foot per second } \\
(\mathrm{fts} / \mathrm{s})\end{array}$ & 0.3048 & \\
\hline
\end{tabular}

Temperature in degrees Celsius $\left({ }^{\circ} \mathrm{C}\right)$ may be converted to degrees Fahrenheit $\left({ }^{\circ} \mathrm{F}\right)$ as follows: ${ }^{\circ} \mathrm{F}=\left(1.8 x^{\circ} \mathrm{C}\right)+32$

Temperature in degrees Fahrenheit $\left({ }^{\circ} \mathrm{F}\right)$ may be converted to degrees Celsius $\left({ }^{\circ} \mathrm{C}\right)$ as follows: ${ }^{\circ} \mathrm{C}=\left({ }^{\circ} \mathrm{F}-32\right) / 1.8$

Vertical coordinate information is referenced to the insert datum name (and abbreviation) here for instance,

"North American Vertical Datum of 1988 (NAVD 88)."

Horizontal coordinate information is referenced to the insert datum name (and abbreviation) here for instance,

"North American Datum of 1983 (NAD 83)."

Altitude, as used in this report, refers to distance above the vertical datum. 
This page intentionally left blank 


\title{
The Continuous Slope-Area Method for Computing Event Hydrographs
}

\author{
By Christopher F. Smith, Jeffrey T. Cordova, Stephen M. Wiele
}

\section{Abstract}

The continuous slope-area (CSA) method expands the slope-area method of computing peak discharge to a complete flow event. Continuously recording pressure transducers installed at three or more cross sections provide water-surface slopes and stage during an event that can be used with cross-section surveys and estimates of channel roughness to compute a continuous discharge hydrograph. The CSA method has been made feasible by the availability of low-cost recording pressure transducers that provide a continuous record of stage. The CSA method was implemented on the Babocomari River in Arizona in 2002 to monitor streamflow in the channel reach by installing eight pressure transducers in four cross sections within the reach. Continuous discharge hydrographs were constructed from five streamflow events during 2002-2006. Results from this study indicate that the CSA method can be used to obtain continuous hydrographs and rating curves can be generated from streamflow events.

\section{Introduction}

The U.S. Geological Survey (USGS) operates about 7,500 stream gages throughout the Nation. The rating curves that relate stage to discharge at these gaging stations are formulated from periodic measurements of discharge at known stages. Stages are recorded at regular intervals, typically $15 \mathrm{~min}$, and the discharge is computed from stage using the stage-discharge rating curve. A well-defined rating curve typically requires many discharge measurements at a range of discharges. Obtaining discharge measurements over a wide range of stage is not always possible as a result of remoteness of the streamflow-gaging stations, inaccessibility due to flooding, flashy events, or limited resources.

If a direct measurement of discharge is not obtained at a high flow, the USGS routinely uses slope-area method to estimate discharge (Dalrymple and Benson, 1967). A slopearea measurement is a discharge calculated using measured cross sections, estimations of channel roughness, and a water-surface slope derived from field evidence, such as debris lines. The Manning equation, in which the slope is the energy slope, is used to calculate discharge.

The use of a water-surface slope derived from field evidence to calculate the discharge in slope-area measurements has two potential drawbacks. First, the high-water marks used to infer the water-surface slope may not be well defined and may not accurately represent the water-surface slope in the main part of the flow. Debris lines are subject to wave action, downslope creep, and diffusion by rainfall and gravity that produce inaccuracies or an apparent irregularity in the water-surface slope. Smaller peaks following a large event can add to the difficulty in identifying the relevant high-water marks. Bank roughness can generate real variability in the water-surface slope that poorly represents the slope near the center of the channel. The resulting scatter in the water surface that is used in the slope-area calculations can be a source of error. Second, the use of high-water marks allows only for the calculation of the peak discharge. The event hydrograph cannot be estimated from peak discharge calculations.

This report presents an extension of the slope-area method for obtaining peak discharges to a method for recording continuous time series stage at multiple cross sections, development of stage discharge relationships, and computation of discharge hydrographs for the slope-area reach. The method requires some foresight - slope-area reaches must be identified and instrumented prior to events - and, because the method depends on estimates of channel roughness and reaches with desirable properties for slope-area measurements may not be available, it cannot consistently achieve the level of accuracy characteristic of standard USGS stream gages with rating curves that are well defined by many direct discharge measurements. The method can produce more complete discharge records than would otherwise be possible, where the resources are not available to install and maintain stream gages or the required measurements are not possible due to logistical obstacles.

\section{Purpose and Scope}

The CSA method for computing hydrographs has been under development by the USGS Arizona Water Science Center Data Program since the summer of 2002. This report 
describes the installation of crest-stage gages (CSG) with continuously recording pressure transducers (PT), data acquisition and analysis, and computed results from the Babocomari River continuous slope-area reach that was operated over a 5-yr period from 2002 to 2006, as well as the basics of the method and its implementation. Additional sections cover implementation of the method in the Babocomari River. Five significant flows occurred during the study period and the CSA method was used to determine a hydrograph for each of them; the application of the CSA method to two of these events is described in this report, and the stage data, computed discharges, and channel shape and roughness for all five events are available in appendices 1 and 2. Although the study lasted 5 years, the southeastern Arizona climate combined with drought conditions during the study period limited the total time of recorded flow to only about 9 hours. Thus, this report should be considered an initial application of the method and not a comprehensive techniques and methods manual. Other applications are ongoing (for example, Stewart and others, 2008) and will aid in refining field methods and the analysis of stage records.

\section{Discharge Measurements Using the Slope-Area Method}

A slope-area discharge measurement uses channel surveys, estimates of water-surface slopes, and estimates of channel roughness to calculate peak discharge. Benson and Dalrymple (1967) and Dalrymple and Benson (1967) explain the practical and theoretical components of slope-area discharge measurements. Channel geometry of the reach is important in producing accurate slope-area computations of discharge. Large changes in the shape of the channel along a reach, for example, should be avoided due to uncertainties in energy losses. Ideally, cross sections selected in the slope-area reach will be uniform and have nearly the same shape and area for a given discharge. In addition, the reach should be long enough and the fall large enough that errors associated with interpretations in the high-water profile are small. In reality, some compromises between logistical considerations and desirable channel properties are typically required. The length of the indirect reach is often limited by the geometry of the channel and the practical difficulties of surveying long reaches of a river channel, and a uniform channel may be difficult or impossible to find.

\section{The Slope-Area Computation Program}

The Slope-Area Computation (SAC) Program (Fulford, 1994) has greatly improved the ease of the computation. Input files to SAC supply all required information and the program automates the indirect peak discharge calculation. SAC output includes discharges computed for all cross-section combinations and warnings for reach length, drop, and other parameters that affect or help evaluate the accuracy of the result.

\section{Sensitivity of Indirect Discharge Computations to Slope}

The calculation of accurate discharges using the slopearea method depends on the accuracy of the water-surface elevations, and thus the reach slope, supplied in the input to SAC. Unlike step-backwater calculations, in which the watersurface elevation is specified as a boundary condition at the downstream end (for subcritical flow) and the upstream water surface profile is calculated, the slope-area method for computing discharge imposes a water-surface slope (modified by streamwise changes in velocity head) on the calculation that is used to directly calculate discharge. The sensitivity of the calculated discharge to errors in the reach water-surface drop can be determined by finding the ratio of discharges calculated using the true water-surface slope and the water-surface slope estimated from surveys of reach length and apparent drop in the water surface. The Manning equation is used to compute discharge,

$$
Q=\frac{1}{n} A R^{2 / 3} S^{1 / 2},
$$

where $Q$ is the discharge, $n$ is the Manning roughness coefficient, $A$ is the cross-section area, $R$ is the hydraulic radius, and $S$ is the water-surface slope. Equation 1 is used with metric units; with Imperial units, the $1 / n$ is replaced by $1.49 / n$. Representing the surveyed water-surface drop in the reach used to calculate the discharge as the true drop plus an error, the ratio of the true and calculated discharges can be represented by,

$$
\frac{Q_{c}}{Q_{t}}=\left(1+\frac{e_{c}}{d_{t}}\right)^{1 / 2},
$$

where $Q_{c}$ is the discharge calculated with the measured water surface drop, $Q_{t}$ is the true discharge, $e_{c}$ is the error in the measured drop in the reach used to calculate $Q_{c}$, and $d_{t}$ is the true drop in the reach. Note that reach length is not represented in equation 2. Small differences in the cross-sectional area and hydraulic radius related to differences in water-surface drops are neglected in equation 2. An example application of equation 2 over a range of errors in reach drop (fig. 1) shows that an error in reach drop of a few tenths of a foot can lead to a calculated discharge that is off by about 25 percent. Equation 1 shows that the discharge is linearly related to crosssectional area and roughness but is related to the square root of the slope, thus indicating greater sensitivity to channel shape and roughness than slope. Channel shape is well defined by surveys if the channel does not change significantly during a flow event, however, and roughness is generally well defined by published methods for estimating roughness or verified roughness in similar channels. 


\section{The Continuous Slope-Area Method}

The CSA method expands the slope-area method of computing peak discharge to a complete flow event. Continuously recording pressure transducers (PTs) installed at three or more cross sections provide water-surface slopes and stage during an event that can be used along with cross-section surveys and estimates of channel roughness to compute a continuous-discharge hydrograph. The method, as demonstrated by the applications described in this report, can also reveal complexities during significant flows that are not evident from peak-flow estimates derived from post-flow evidence.

The CSA method has been made feasible by the availability of low-cost recording PTs that provide a continuous record of stage at each cross section. In addition to the applications described in this report, such devices have been used at crest-stage gages to record continuous stage in ephemeral streams (Waltemeyer, 2005). Crest-stage gages were used in this experiment to incorporate standard USGS equipment and methods.

\section{Site Selection}

Information about the channel required for the slope-area method is also required for application of the CSA method. A minimum of variability between cross sections and a sufficient drop in the channel are desirable properties. Channel roughness may be estimated using published methods or derived from direct measurements of discharge and water-surface slope. A detailed guide to the slope-area method of discharge is presented by Dalrymple and Benson (1967).

Dalrymple and Benson (1967) indicate that the selection of cross-section locations should be determined by breaks in slope of the water surface profile determined from surveys of debris lines. This method of determining cross-section locations can be difficult to apply where debris lines are poorly defined and is not possible prior to a flow, as would typically be the case for an initial CSA application. Consequently, cross sections for a CSA reach can be located initially, depending on resources available, based on a visual assessment or survey of the reach to identify changes in bed slope or channel width. If sufficient resources are available, a step-backwater model of

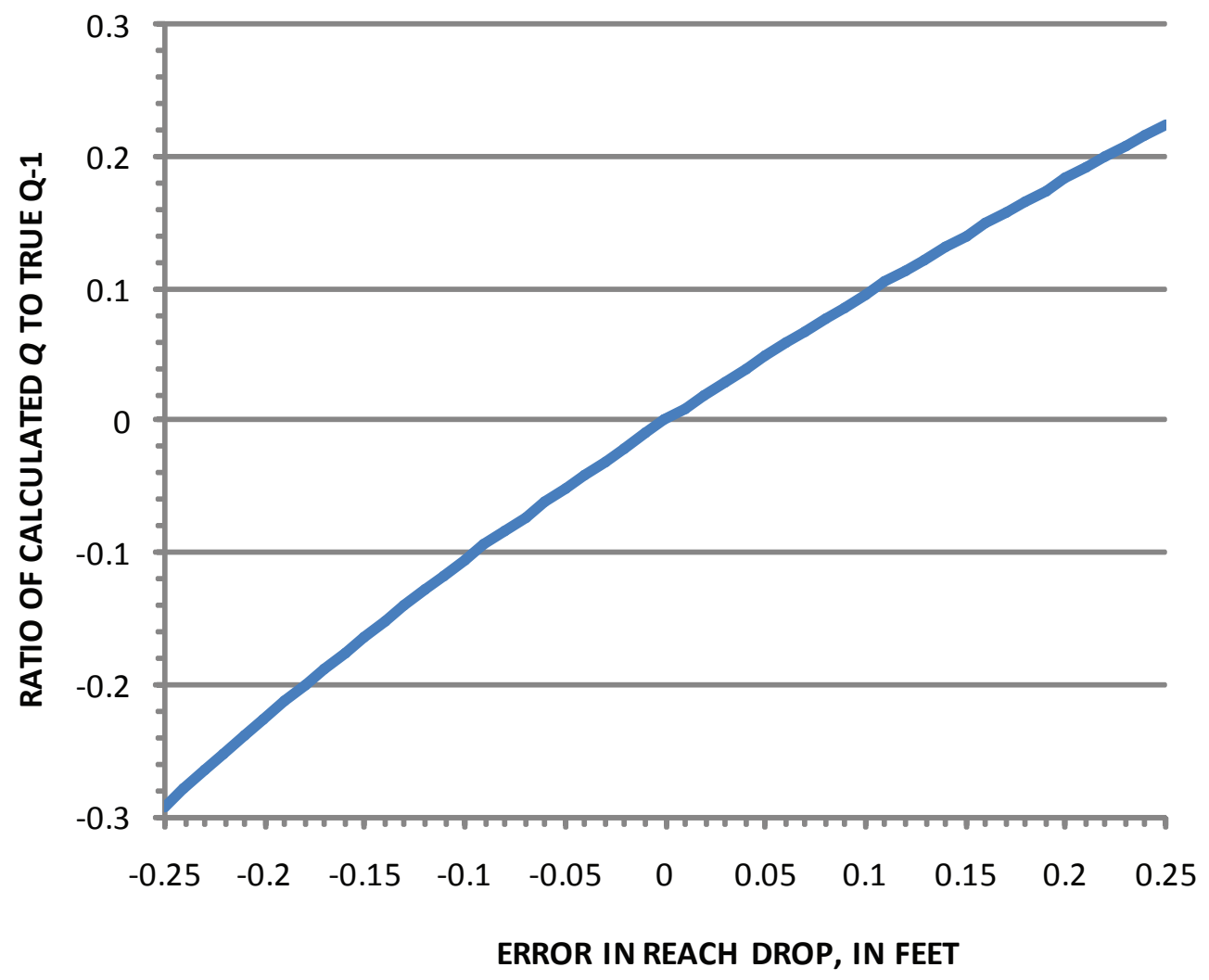

Figure 1. Error in discharge calculated with equation 2, caused by errors in measured reach drop. The sample calculation shown is for a true drop in the reach of $0.5 \mathrm{ft}$. 
the reach would provide an estimated water surface profile that could be used in accordance with the criteria of Dalrymple and Benson (1967) for cross-section location. After a significant flow has occurred in the reach, cross-section location could be adjusted according to the methods of Dalrymple and Benson (1967) if debris lines are adequate.

\section{Evaluation of Pressure-Transducer Data and Calculated Hydrographs}

The calculation of discharge using the slope-area method, on which the CSA method is based, could be accomplished with only two PTs at two cross sections, but at least three cross sections are considered minimum for obtaining reasonably accurate results. The redundancy of multiple cross sections, and possibly more than one PT per cross section, can be an important aid in interpreting stage data and choosing the best sequence of cross sections and stage hydrographs for the discharge calculation and can be critical if instruments malfunction. Including more cross sections in the discharge calculation also increases confidence in the computed discharges.

Irregularities in the calculated-discharge hydrographs can be a result of errors in the PT data, changes in the channel during the flow event, or accurate PT readings that are affected by local conditions such as debris piles, wave action, or isolation from the main flow. The errors in the stage data can come from PT errors, such as time drift and loss of calibration, or CSG errors that can occur from burial or plugging by sediment or from accumulation of local debris. Loss of calibration can be detected by comparing the PT readings with high-water marks on the bank, if clear marks are available, or peak stage was recorded by the CSG. A PT water-surface elevation higher than the high-water marks may indicate a problem with the PT. Changes in the channel during runoff events can include scour, fill, and changes in vegetation along the slope-area reach. Scour may occur at one cross section while fill conditions may affect another cross section during the same flow event. Channel roughness can be modified during floods, if vegetation is bent over or scoured out or if debris collects on trees. All of these conditions need to be identified during the channel survey after the runoff event and considered when evaluating the accuracy of the computed discharge.

\section{Comparison of Pressure-Transducer Peaks to Crest-Stage Gage Peaks}

If reliable CSG peak stages or other indicators of maximum stage are available, as in the Babocomari River study reach, they can be compared to the peak stages indicated by the PTs. Differences between the two do not necessarily indicate error in the PT stage, however. The PTs, for example, may miss the peak stage even if they are recording at 5-min intervals.

If the CSG peak stages are recorded in enough cross sections, a slope-area calculation can be made to determine the event-peak discharge. Water-surface elevations from CSGs at cross-section locations is not as comprehensive as a continuous water surface derived from surveyed debris lines, as is typically used in a conventional slope-area measurement, but CSGs, which are constructed and widely used by the USGS to obtain accurate records of peak stage, may provide more accurate water-surface elevations at cross sections than those inferred from debris lines. The computation can be used to help identify the most favorable cross-section combination for the CSA calculations, and the event peak computed with CSG data can also be compared with the peak discharge calculated with the CSA method to test the accuracy of the CSA method. Because the 5-min recording interval used in the stage recorders may miss the instantaneous peak stage during a flashy event, the CSA peak stage could be less than the event peak. The CSA peak stage can equal the CSG peak stage, but the CSA peak stage should never exceed the CSG peak, unless the CSG is overtopped.

\section{Stage-Discharge Relations}

Stage-discharge plots derived from the CSA hydrograph are an effective tool for examining PT performance. The computed discharge is sensitive to the measured fall in the reach. If one or more PTs do not function properly, the computed discharge as a function of stage will be erratic, and a tight relation will not be possible. A tight fit does not assure the accuracy of the stage-discharge relation, but it is an important indicator of the quality of the stage data. If the channel was stable and the instruments performed normally during an event, plots of the calculated discharges against the corresponding stages from each of the pressure transducers should form a tight, consistent plot. If the plot is widely scattered, it likely indicates faulty data or channel instability. A tight plot for medium and high discharge may be accompanied by considerable scatter at low discharges, especially in sand-bedded channels. In this case, the lower discharges may be affected by small-scale channel features that are not significant at higher discharges.

\section{Hysteresis in the Stage-Discharge Relations}

The CSA method can be used to make indirect measurements during the rise and fall of the event hydrograph. The data may be used to evaluate differences in hydraulic conditions on the rising and falling limbs of a hydrograph which can cause a loop in the stage-discharge rating curve commonly referred to as hysteresis. Hysteresis in rating curves can be caused by an increase or decrease in the steady-discharge water-surface slope related to the passing of a discharge wave. On the rising limb, the water-surface slope is increased and lowers the stage at a given discharge with respect to the steady-discharge water-surface slope. The opposite occurs on the falling limb of the hydrograph. The magnitude of the hysteresis can be estimated by scaling the terms in the momentum equation using reasonable values for wave speed (which can be estimated from $d Q / d A$ ), the rate at which the stage rises or falls, and the steady-discharge water-surface slope (for example, Wiele and Smith, 1996). Changes in roughness or shape 
during an event can also cause a loop in the rating curve. In ephemeral channels or channels with low base flow, such as the Babocomari River, vegetation commonly grows within the channel between significant flow events. Channel roughness can be reduced significantly during a large discharge, if vegetation is uprooted and washed downstream or if flexible vegetation, such as grass, is bent over. Conversely, uprooted vegetation can form dams that cause significant backwater effects. Scour or deposition can also contribute to changes in the stage-discharge relation during an event.

Apparent hysteresis can potentially be caused by instrument error or weaknesses in its installation. If the PT position is not firmly fixed, the reference elevation used in the conversion of pressure to stage can change, introducing error into the stage.

\section{Evaluation of Channel Geometry}

Changes in channel shape can be determined by comparing cross sections that were surveyed before and after the flow event. After each event, the cross sections should be evaluated to determine if they should be resurveyed. Many small and medium events produce little or no change to the channel and will not require the channel to be resurveyed. High flows, however, can significantly modify the channel, making new surveys necessary. Accuracy of computed peak or continuous discharges can be degraded if significant channel change occurred.

\section{The Effect of Unsteadiness on Discharge Computation Accuracy}

The slope-area computation used for indirect discharge measurements and the CSA method is based on an assumption of steady flow. For indirect measurements, this is not an issue because the change in velocity over time is zero at the peak discharge. For computing continuous hydrographs, as in the CSA method, the change in velocity over time is nonzero except at the peak. The significance of neglecting the unsteadiness of the flow can be estimated by considering the relative magnitudes of the terms in the one-dimensional St. Venant equation for momentum,

$$
\frac{\partial u}{\partial t}+u \frac{\partial u}{\partial x}+g\left(\frac{\partial e}{\partial x}-S\right)+\frac{u_{*}^{2}}{R_{h}}=0,
$$

where $x$ is the streamwise dimension, $g$ is gravity, $d e / d x$ is the additional water-surface slope due to a varying flow field, $S$ is the steady-flow water-surface slope, $u_{*}$ is the shear velocity, and $R_{h}$ is the hydraulic radius. Dividing equation 3 by the driving term, $g S$, normalizes the equation and reduces the driving term to unity,

$$
\frac{1}{g s} \frac{\partial u}{\partial t}+\frac{u}{g s} \frac{\partial u}{\partial x}+\frac{\partial e / \partial x}{s}-1+\frac{u^{2}}{g R_{h} s}=0,
$$

Taking gravity as a constant, the first term in equation 4 indicates that the significance of the error, induced by using steady-flow equations to model unsteady flow in the CSA method, is a function of the change of velocity over time and the reach slope. Reaches with steeper slopes are less sensitive to changes in velocity over time than reaches with lower slopes (fig. 2). In the flows on the Babocomari River discussed below, the discharge, and consequently velocity, changes rapidly, but the slope of the reach was about 0.01 , which tends to reduce the significance of the unsteadiness on discharge calculations.

Sample calculations with a hypothetical trapezoidal channel (slope $=0.001$, bed width $=50 \mathrm{ft}$, Manning's $n=0.035$, bank width $=$ two times the depth) illustrate that the velocity and $d u / d Q$ tend to change most rapidly with respect to discharge at lower discharges (fig. 3). At the medium and high discharges at which the CSA method is most effective, the relatively muted response of velocity to changes in discharge tends to favor the use of steady-flow equations, but this can be offset by a rapid rise in discharge. During the largest flow on the Babocomari River on July 27, 2006, the normalized unsteady term in equation 4 was not significant (figs. 4, 5), indicating that the accuracy of the computed hydrograph was not significantly affected by the use of steady-flow equations.

\section{Study Site on the Babocomari River}

A reach of the Babocomari River was chosen for the initial application and testing of the CSA method (fig. 6). The Babocomari River is a tributary to the San Pedro River in southeastern Arizona, and the study reach and access to it are on Bureau of Land Management land. The elevation of the study reach is $3,980 \mathrm{ft}$ and the drainage area is about $307 \mathrm{mi}^{2}$. The stream is typically perennial with a base flow during the winter of about $1 \mathrm{ft}^{3} / \mathrm{s}$. Peak flows usually occur during the summer months as a result of local convective storms. The streamflow record of the Babocomari River has been used for groundwater studies of the San Pedro basin and the effects of groundwater development on the San Pedro River, a free flowing river that provides vital habitat in an area undergoing rapid population increases and urban development.

There are two permanent streamflow-gaging stations along the Babocomari River. The USGS stream gage Upper Babocomari River near Huachuca City, AZ (identification number 09471380) measures the runoff from the Huachuca and Mustang Mountains (fig. 6). The USGS stream gage Babocomari River near Tombstone, AZ (09471400) was installed for the primary purpose of measuring base flow from a perennial section of the river where groundwater is discharged to the surface (Pool and Coes, 1999). This section of the river is not accessible for medium to high flow measurements.

Starting in the summer of 2002, a CSA reach was selected and monitored on the Babocomari River. The slopearea reach is approximately $0.25 \mathrm{mi}$ downstream from the Babocomari River stream gage (09471400) near Tombstone, AZ. The study site conforms more closely to the criteria established by Dalrymple and Benson (1967) than other reaches in 


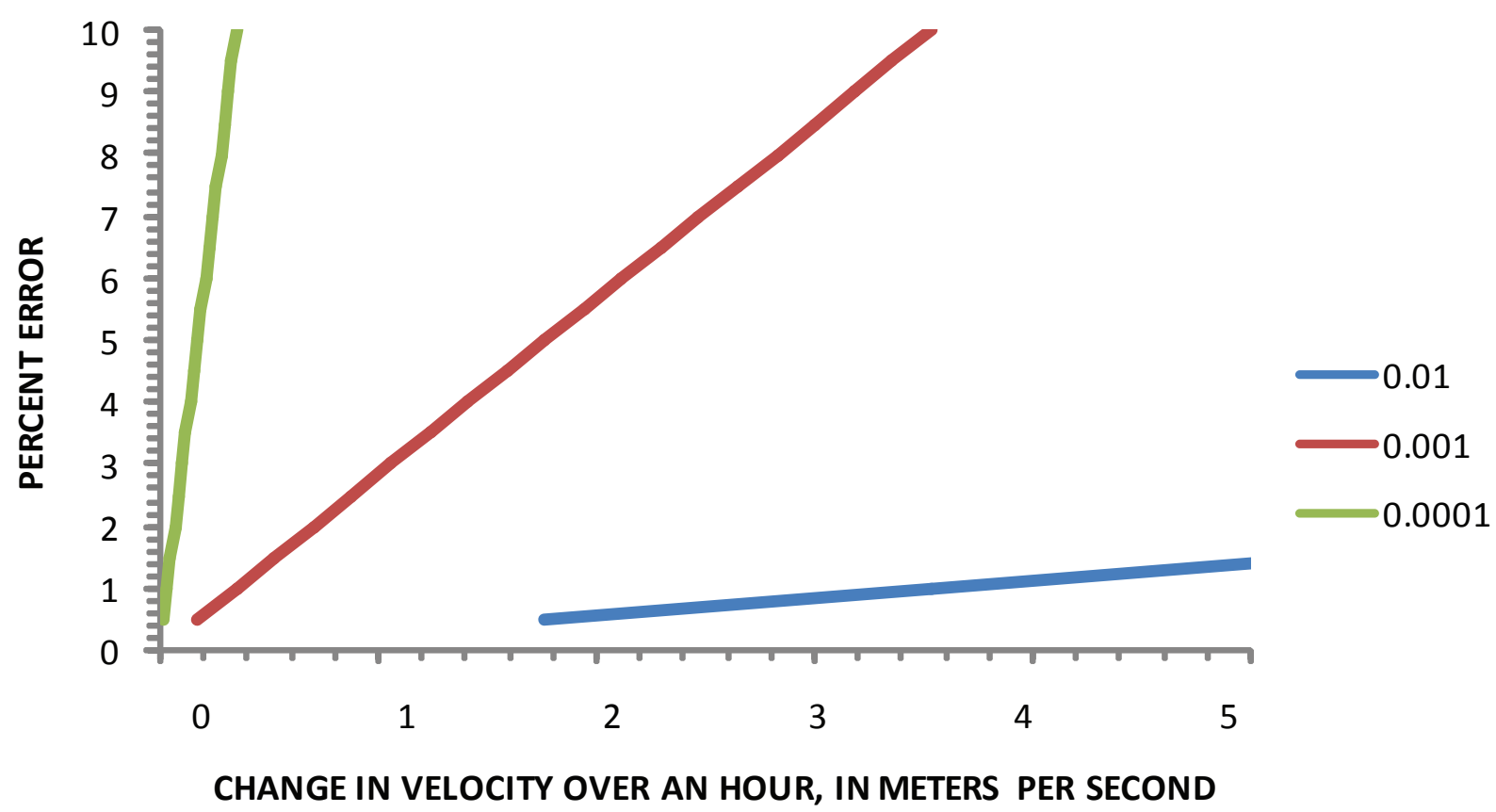

Figure 2. Percent error in the St. Venant momentum equation as a result of neglecting the unsteady term as a function of change in velocity for three reach slopes.

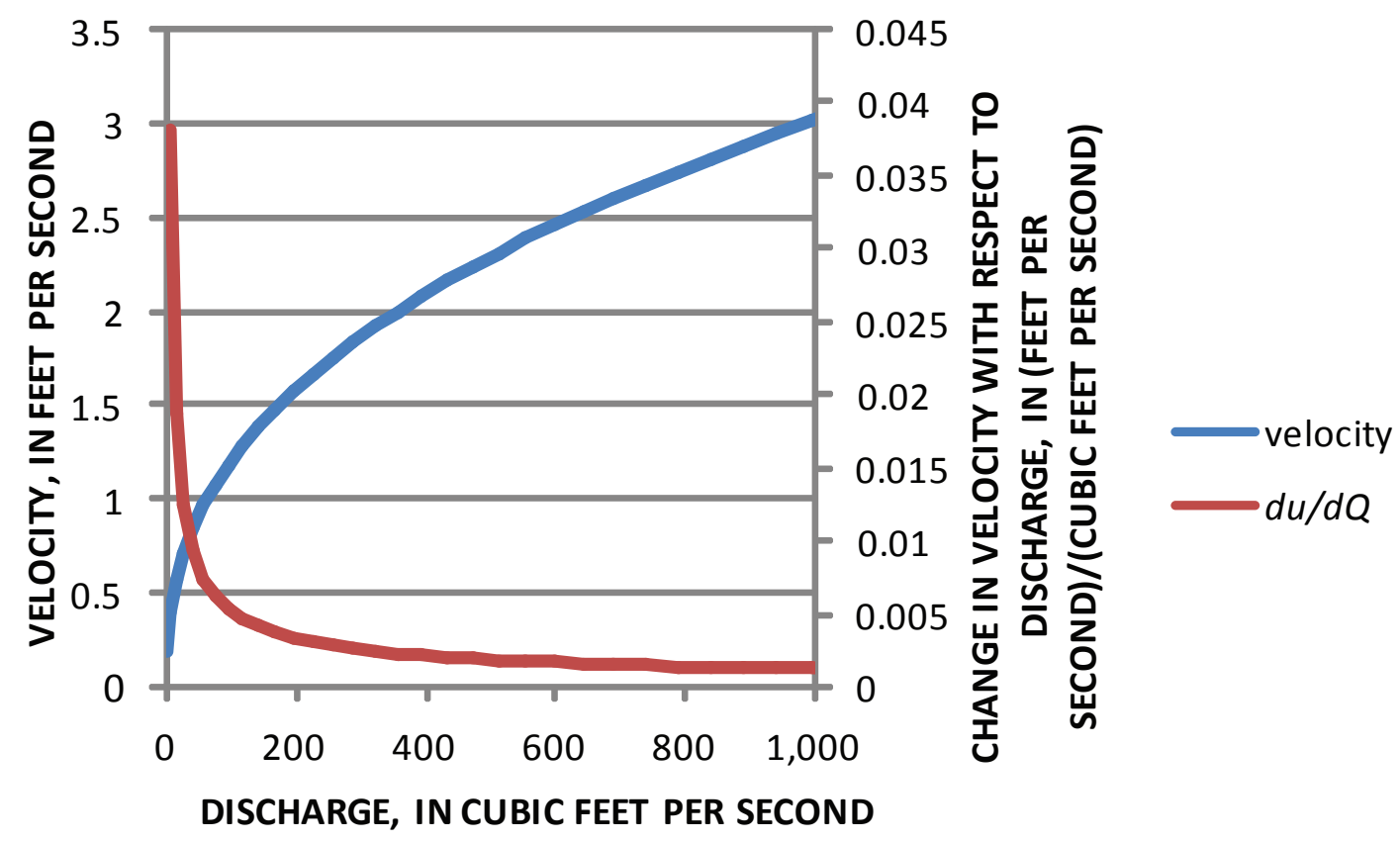

Figure 3. Velocity and $d u / d Q$ as function of discharge for a trapezoidal channel with a bed width of $50 \mathrm{ft}$, slope of 0.001 , and a Manning's $n$ of 0.035 . The bank width was specified as two times the depth. 


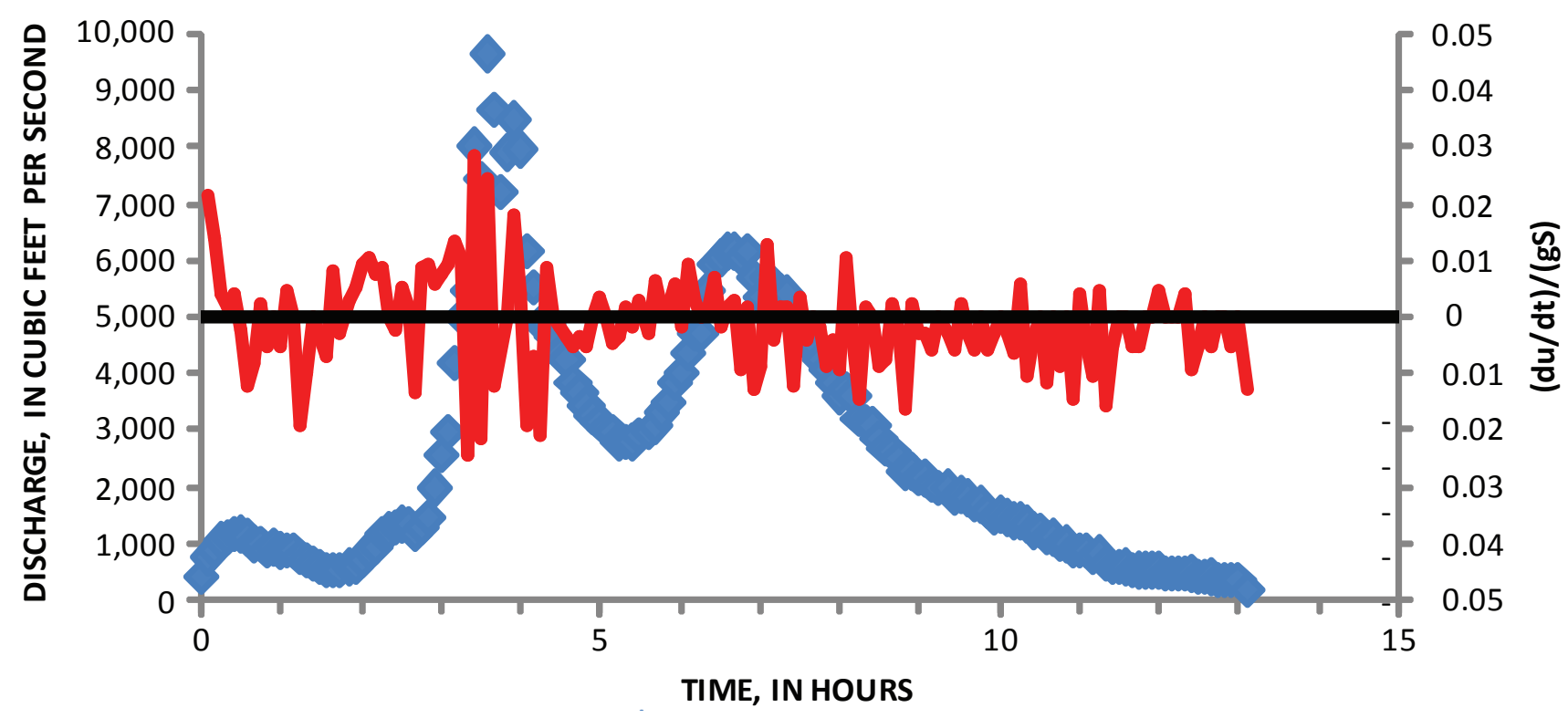

Figure 4. Hydrograph computed with the Continuous Slope-Area method and the normalized unsteady term from the momentum equation (du/dt)/(gS) during the July 27, 2006, event on the Babocomari River.

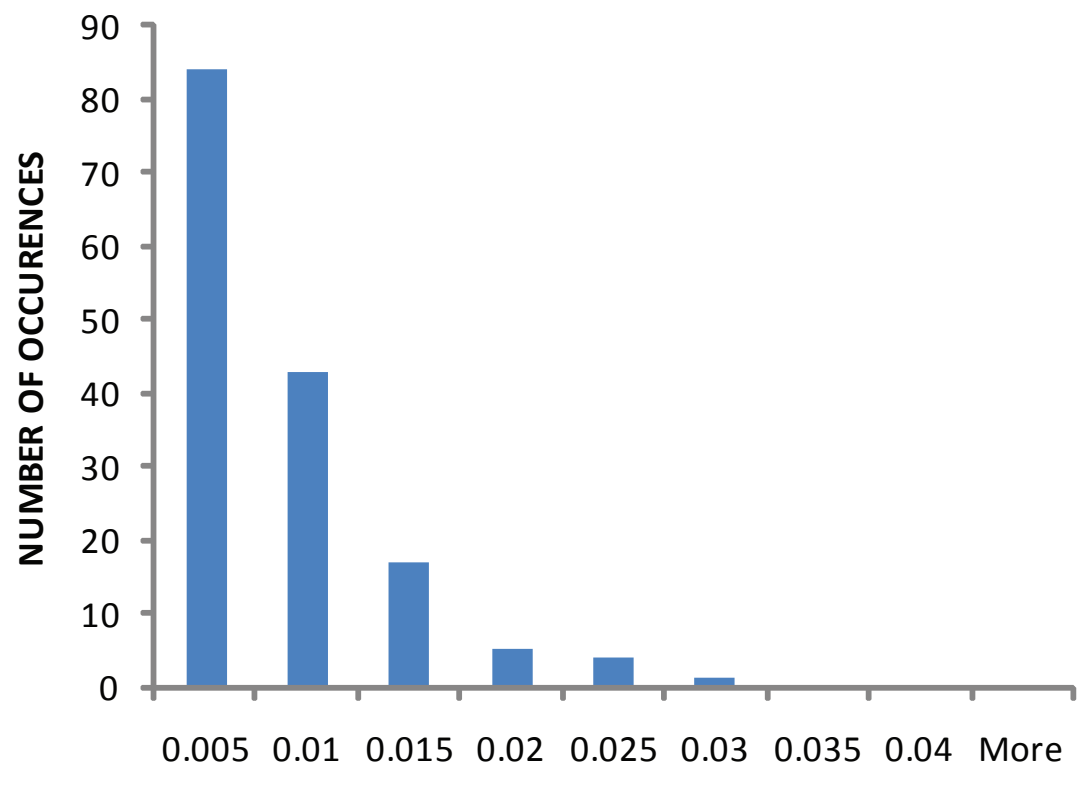

$(d u / d t) /(g S)$

Figure 5. Histogram of the absolute value of the normalized unsteady term in equation 4 for the Babocomari River hydrograph shown in figure 4. 

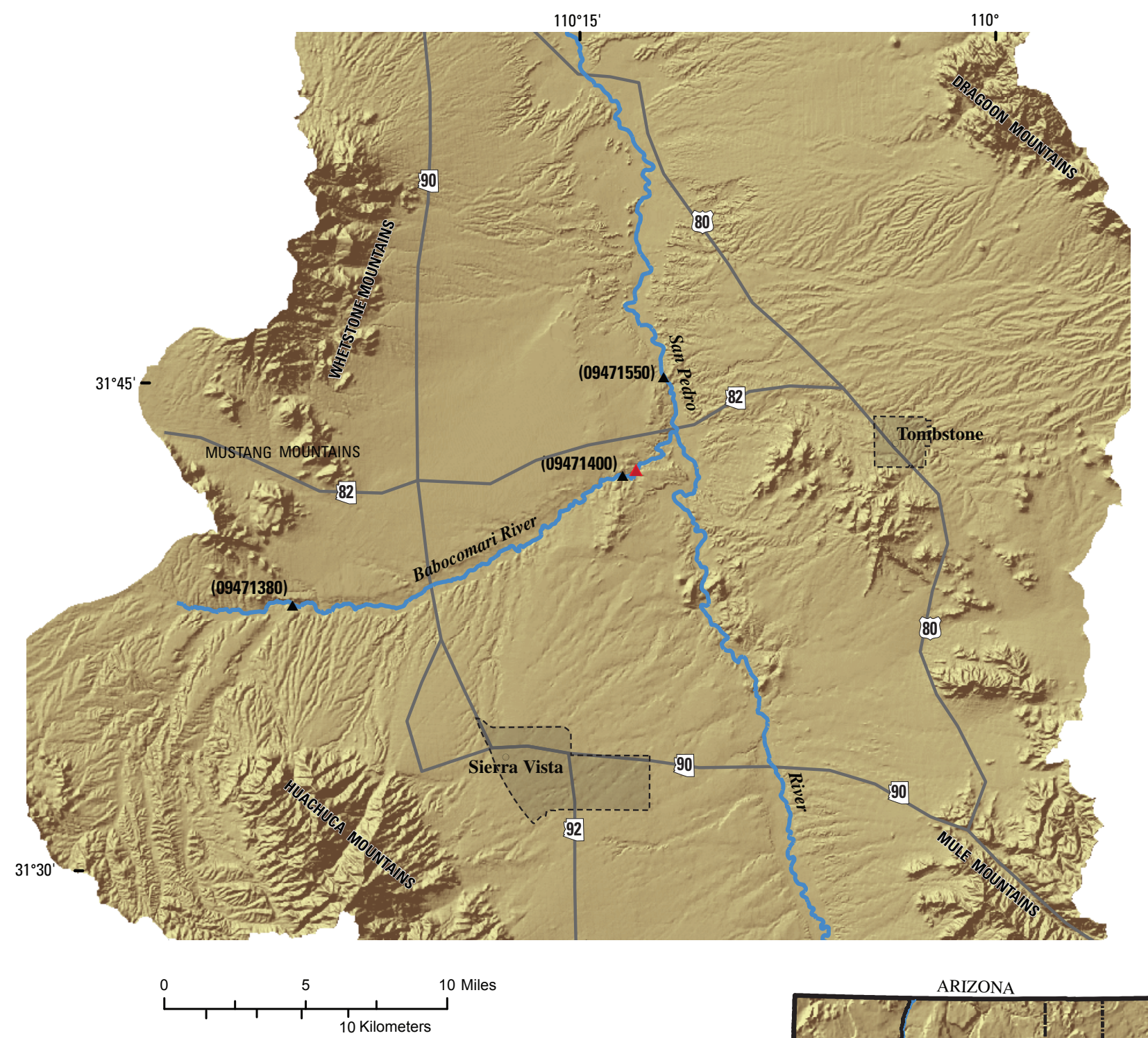

Base from U.S. Geological Survey digital elevation model data, 1:250,000, 1982

Universal Transverse Mercator Projection, Zone 12,

Datum: NAD 27

A STREAMFLOW-GAGING STATIONU.S. Geological Survey

A CONTINUOUS SLOPE-AREA GAGEU.S. Geological Survey

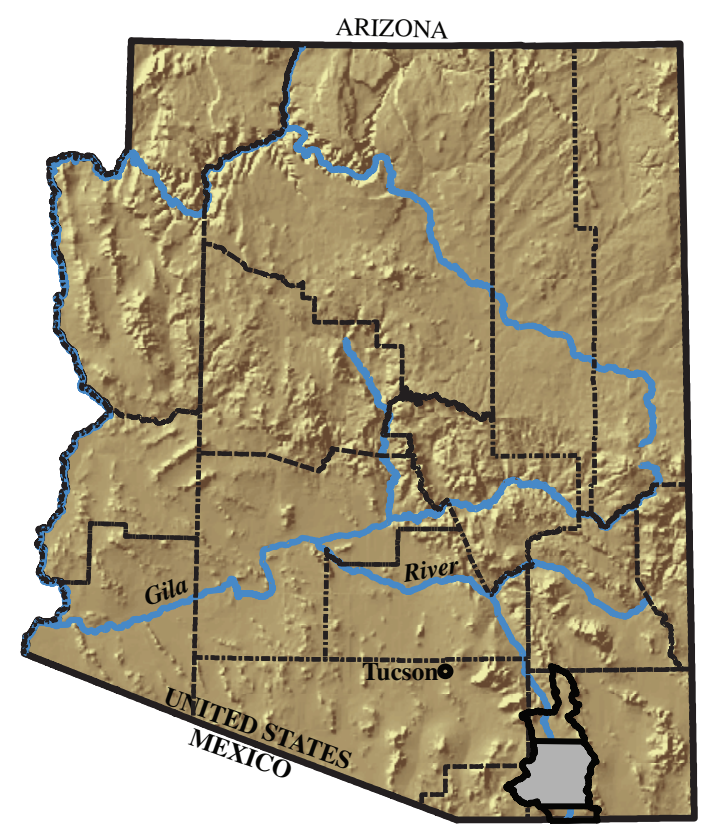

Figure 6. Map showing the study area on the Babocomari River. 
the area. At this downstream location, the flow is confined to one main channel. A tributary that flows intermittently enters the river between the gage and the CSA reach.

\section{Description of Channel Conditions along the Slope-Area Reach and Roughness Coefficient Selection}

The slope-area reach was selected because it was straight and uniform. The reach is about $300 \mathrm{ft}$ long with about a $2.7-\mathrm{ft}$ fall in water-surface elevation over the range of observed flows. The reach is straight and uniform for about $50 \mathrm{ft}$ above the upstream cross section and $50 \mathrm{ft}$ below the downstream cross section. The total length of the reach was limited by a tributary confluence just upstream of the reach and by an expanding channel downstream of the reach. The cross sections were spaced approximately $100 \mathrm{ft}$ apart.

The grass upstream and downstream of cross section 1 (the upstream extent of the study reach) was dense and consistently about $2 \mathrm{ft}$ tall (fig. 7). The grass throughout the rest of the reach during the study period was sparse on the left bank and dense on the right bank. The density of grass in the reach is related to the density of trees growing in the reach; areas of dense grass are areas of sparse trees. The exposure, absence, or burial of grass in the reach was used to determine if scour or fill occurred during a high-flow event.

The trees in the slope-area reach consist of ash, willow, mesquite, and walnut. The ash and willow are the predominant types of trees growing in the slope-area reach. The younger ash trees (6-14 inches in diameter) line the low-flow

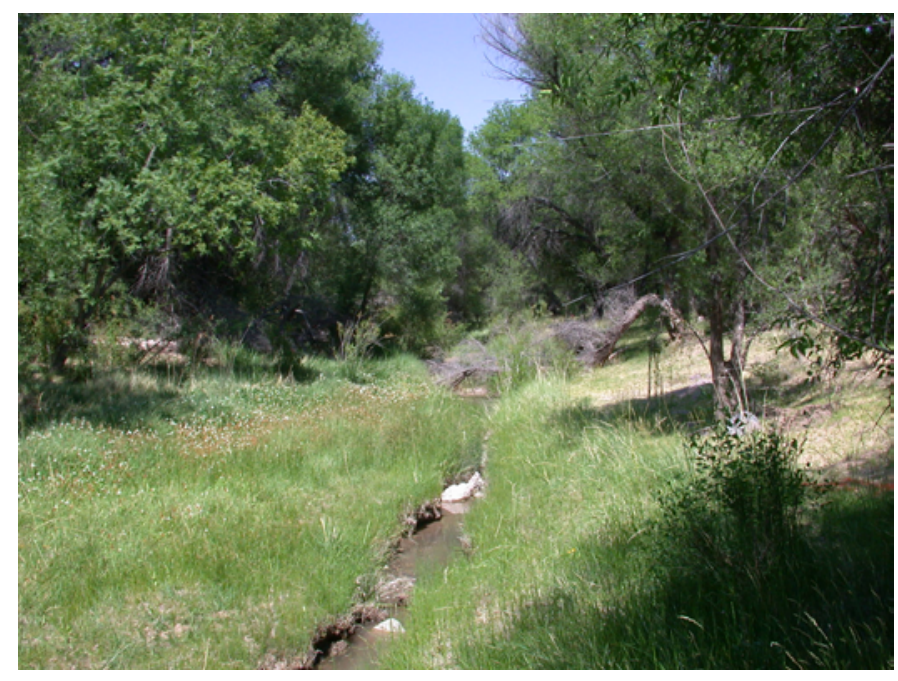

Figure 7. View looking downstream from cross section 1. Note the dense grass where trees are sparse. channel and form a ribbon of trees that create barriers on the left bank of the channel and often collect debris (fig. 8).

The willows are not as numerous as the ash trees but tend to be 14 to 20 inches in diameter. There were a few small willows in the low-flow portion of the channel. The mesquite form dense mesquite bosques in the overbank flow areas. A few walnut trees, 10 to 14 inches in diameter, grew on the left bank between cross sections 1 and 2 .

A small tributary with a drainage area of less than $0.5 \mathrm{mi}^{2}$ flows into the channel between the gage and the slope-area reach. A PT gage was installed to determine whether inflow from the tributary occurred during main-stem events. The flow from this tributary was not significant during the five events that occurred during the study period and was neglected in the discharge calculations.

The flow through all four cross sections during the study period was contained by steep and well-defined embankments. The vegetation in cross section 1 (X1), the most upstream cross section, consists mostly of grass and small trees (fig. 9). At low flow, the water is contained in a narrow 3 -ft-wide channel. The majority of the section is covered with thick grass.

Cross section $2(\mathrm{X} 2)$ is $110 \mathrm{ft}$ downstream of $\mathrm{X} 1$ and has a more incised section of flow where the water is ponded at low flow. The vegetation at X2 consists of grass and sapling trees with some mesquite trees higher on the banks (fig. 10).

Cross section 3 (X3), $79 \mathrm{ft}$ downstream from X2, also has an incised section of channel and has vegetation types similar to X2 (fig. 11). A row of ash trees, located on the lowflow section of the left bank starting in X3, extends downstream through cross section 4 (X4).

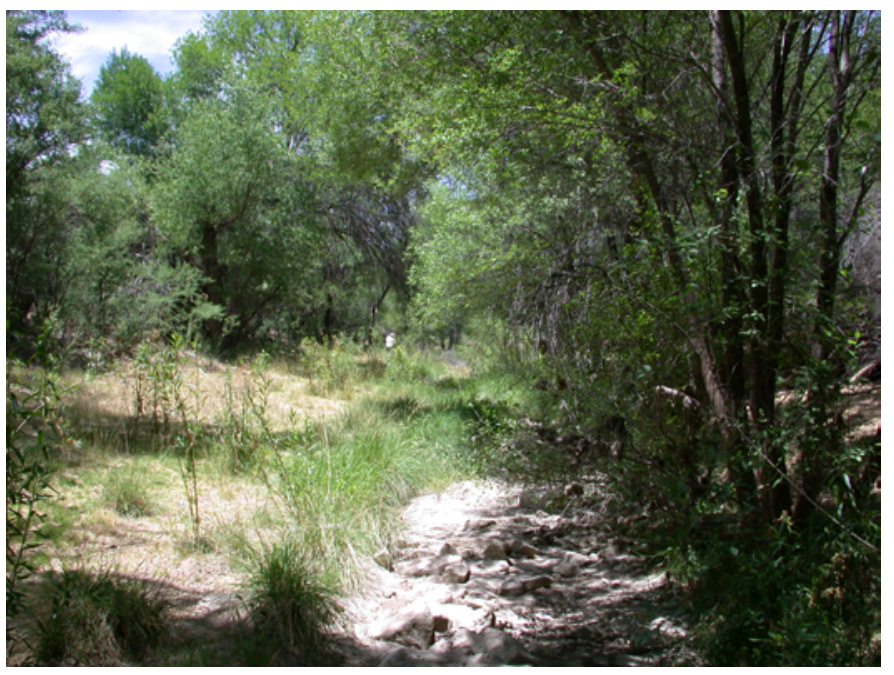

Figure 8. View looking upstream from cross section 4. Ash trees grow along the low-flow channel. 
Cross section 4 (X4), $111 \mathrm{ft}$ downstream of X3, does not have an incised channel but has a wider and shallower section of flow. The main section of flow consists of small cobbles and gravels (fig. 12). At low flow, riffles form at this cross section.

A Manning's roughness coefficient was selected based on the type and density of the vegetation in the slope-area reach. Grass is the predominant natural condition that affects the Manning's roughness coefficient for medium and low flows. For these conditions, a Manning's roughness coefficient of 0.035 was selected for all four cross sections, based on values from reference tables and previous publications (Aldridge and Garrett, 1973; Thomsen and Hjalmarson, 1991; Phillips and Tadayon, 2006). For high flows, the trees along the bank increase the Manning's roughness coefficient to 0.040 , which is also based on reference tables and previous publications (Aldridge and Garrett, 1973; Thomsen and Hjalmarson, 1991; Phillips and Tadayon, 2006).
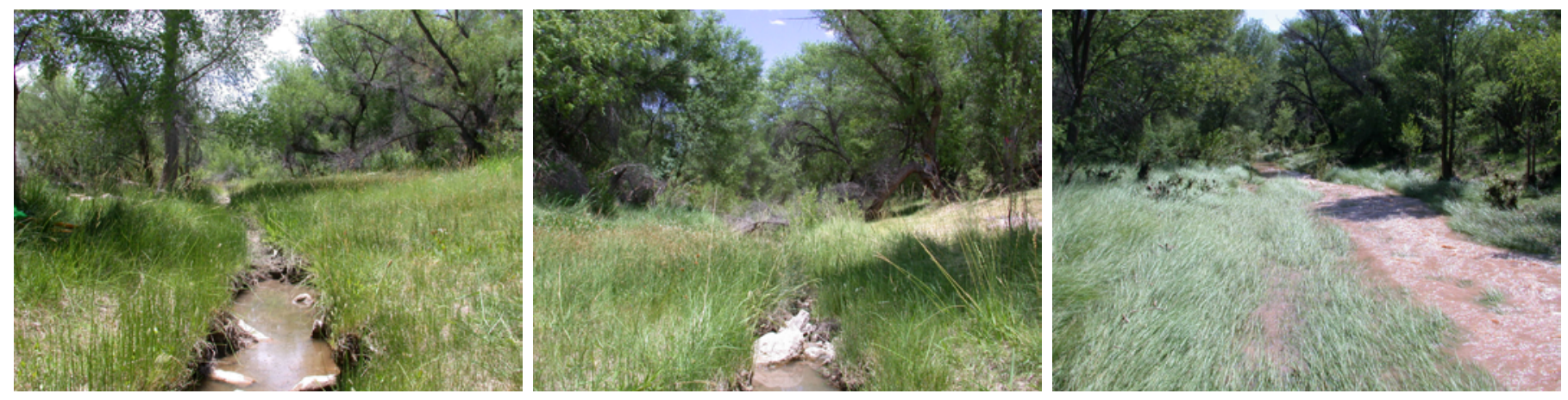

Figure 9. Views from cross section 1 looking upstream (left), downstream (center), and downstream (right).
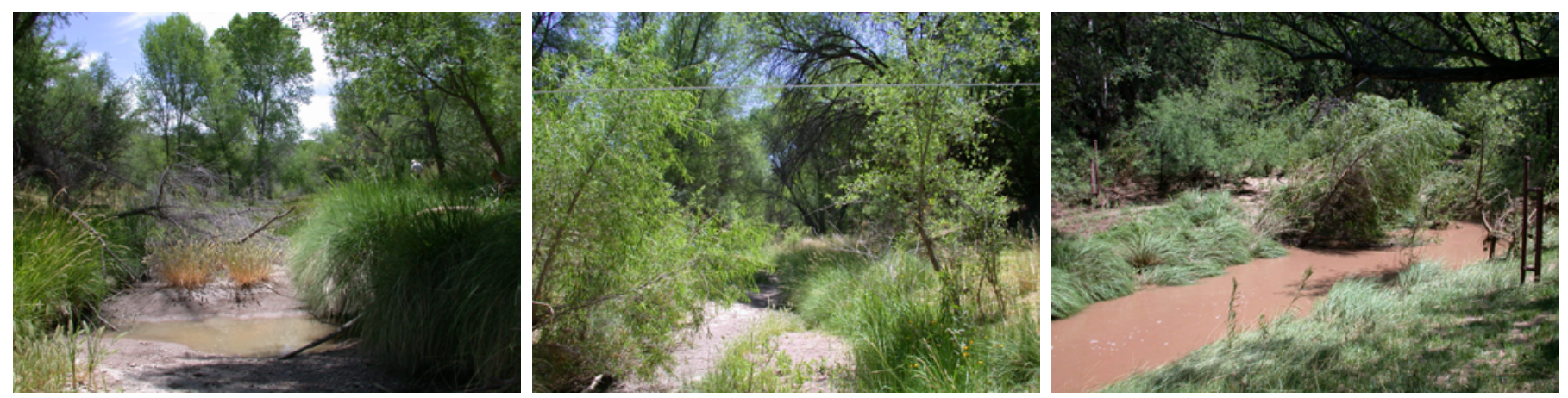

Figure 10. Views from cross section 2 looking upstream (left), downstream (center), and downstream (right).
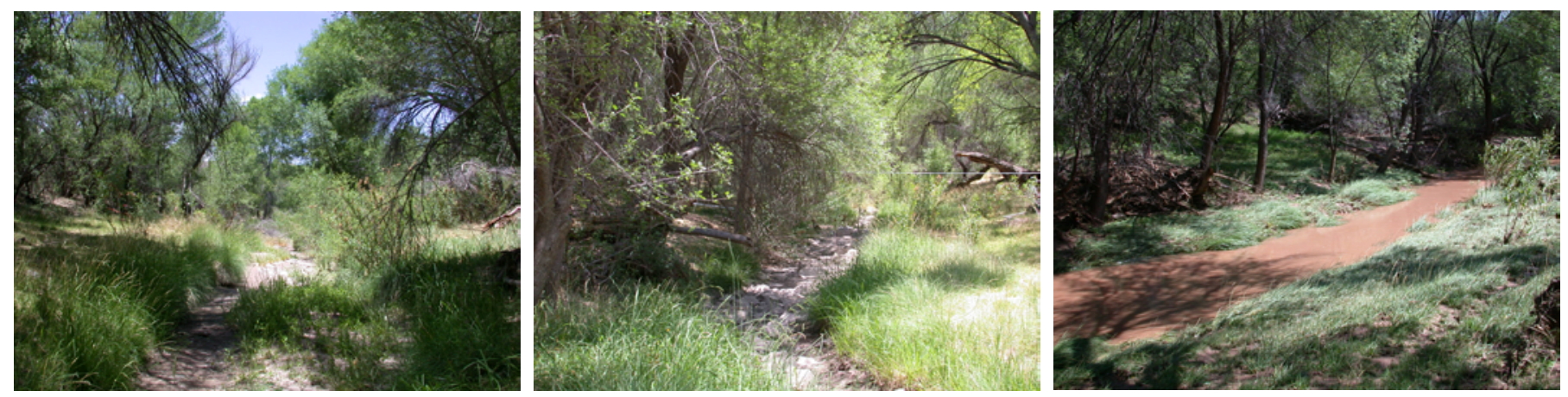

Figure 11. Views from cross section 3 looking upstream (left), downstream (center), and downstream (right). 


\section{Application of the Continuous Slope- Area Method on the Babocomari River}

\section{Installation of Pressure Transducers}

The initial installation of PTs for the continuous slopearea application consisted of a modification of the existing crest-stage gage (CSG) design. The CSGs were made of a 4-ft length of 2-in galvanized pipe with a perforated cap on the bottom (fig. 13). The galvanized pipe contains a narrow wooden stick and granulated cork on the bottom cap. During a streamflow event, the cork rises to the peak elevation of streamflow and remains on the wooden stick after the stage recedes, leaving a mark where the crest occurred. PTs were secured to the bottom of the crest-stage gage sticks with hose clamps.

Eight PTs were installed at four cross sections in the overbank area on both sides of the channel (fig. 14). One additional PT gage was installed in a tributary located about $100 \mathrm{ft}$ upstream from the first cross section to document any inflows between the permanent USGS gage and the CSA reach. Each PT installed in the reach is identified by its location in the reach. For example, PTL2 (pressure transducer 2, left bank) is installed on the left bank and along cross section 2, while PTR2 (pressure transducer 2, right bank) is installed on the right bank. Figure 15 shows the elevations of the CSG pins (used as an elevation reference) on the left and right banks. The streamwise elevation differences between CSG pins on either bank are shown in table 1 . On each bank the elevation difference between the farthest upstream and downstream CSG pins is greater than $2 \mathrm{ft}$. The minimum elevation difference between each CSG pin on the left bank was $0.47 \mathrm{ft}$, and the minimum on the right bank was $0.07 \mathrm{ft}$. The CSG pins on the left bank were installed along the overbank area of the channel and are at a higher elevation than the CSG pins on the right bank. The CSG pins on the right bank were installed closer to the active channel. The fall in the reach and between the CSG pins should be uniform, for example the CSG pin in PTR3 should have been installed at an elevation $0.5 \mathrm{ft}$ lower than the pin in PTR2.

The miniTROLL PTs with a sensor range of 0-30 PSI manufactured by In-Situ Inc. were used for this study. The PTs
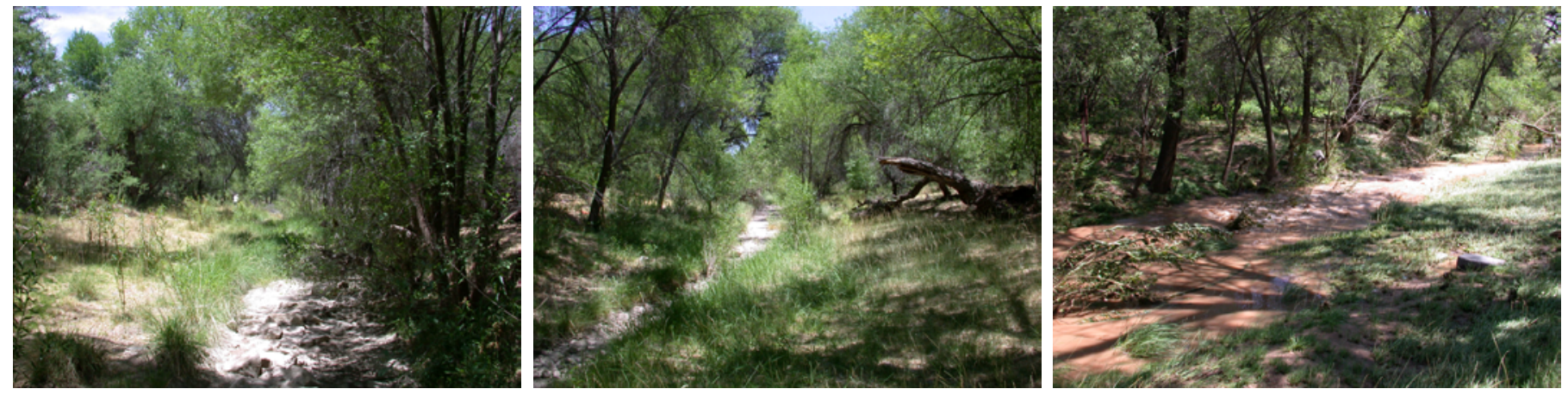

Figure 12. Views from cross section 4 looking upstream (left), downstream (center), and downstream (right).
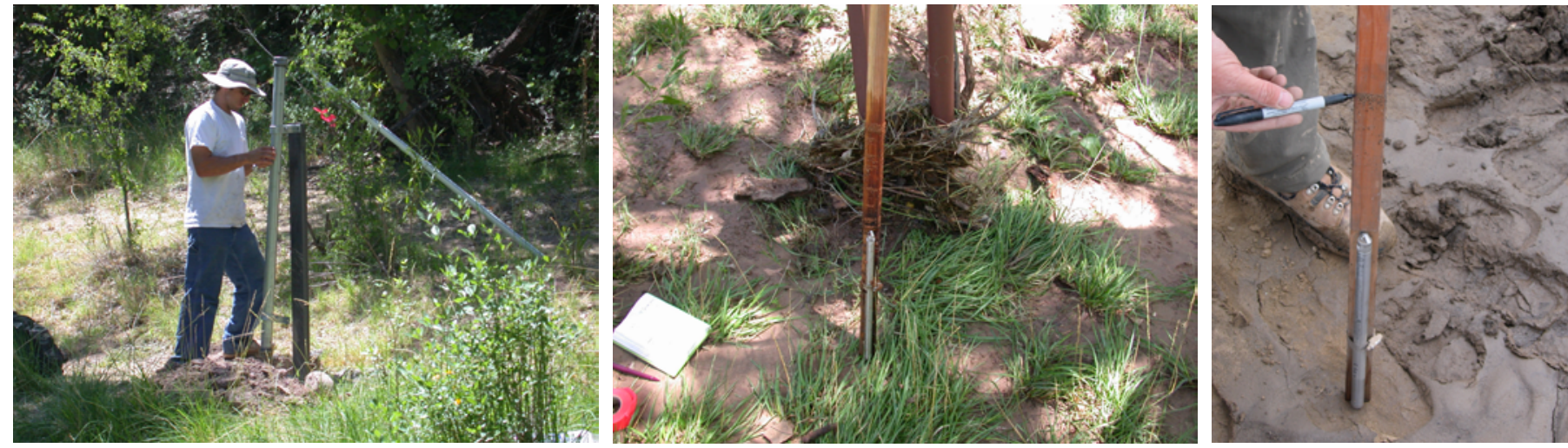

Figure 13. Installation of the crest-stage gage (left). The pressure transducer is clamped to the bottom of the crest-stage gage board (center and right). 
were programmed to record at 5-min intervals regardless of whether the channel was flowing. In the absence of equipment malfunction, the PT's internal data recorders were capable of measuring and recording pressure at this rate for approximately 6 months. The PTs used for this application measured absolute pressure because they are not vented to the atmosphere. Consequently, in addition to measuring the depth of water above the PT, atmospheric pressure was also measured. To remove the effects of atmospheric pressure, a PT measuring the barometric pressure was placed in the gage house, which is located about 0.25 mile upstream from the slope-area reach.

\section{Collection and Reduction of Pressure- Transducer Data}

The stage data were downloaded from the PTs after significant flows. In addition, the cross sections and CSG pin elevations were resurveyed to document any scour or fill in the channel and to ensure the CSG pins had not moved. During each site visit, the CSGs were inspected for high-water marks.
The bottom CSG cap was also removed and inspected to ensure the PT was in connection with the river and not clogged with sediment and debris. After each site visit, fresh cork was added to the CSGs. If high-water marks were present, they were measured and documented. In addition, any other indications of streamflow were noted, such as debris on the base of the CSG and the condition of the vegetation. The PTs were synchronized with atomic clocks to prevent time drift. If time drift was detected, it was documented and the transducer data were corrected. It is imperative that clocks in the PTs are synchronized so that they record water-surface elevations simultaneously during an event.

Each downloaded data set from the PTs was corrected for barometric effects, PT elevation, and CSG pin elevation. The CSG peak was corrected to gage datum by adding the highwater marks from the crest-stage gage to the CSG pin elevation to determine the final peak elevation. After these corrections were applied, both peaks (PT and CSG) were compared for quality control because the PT-recorded peak should not be higher than the CSG high-water mark.

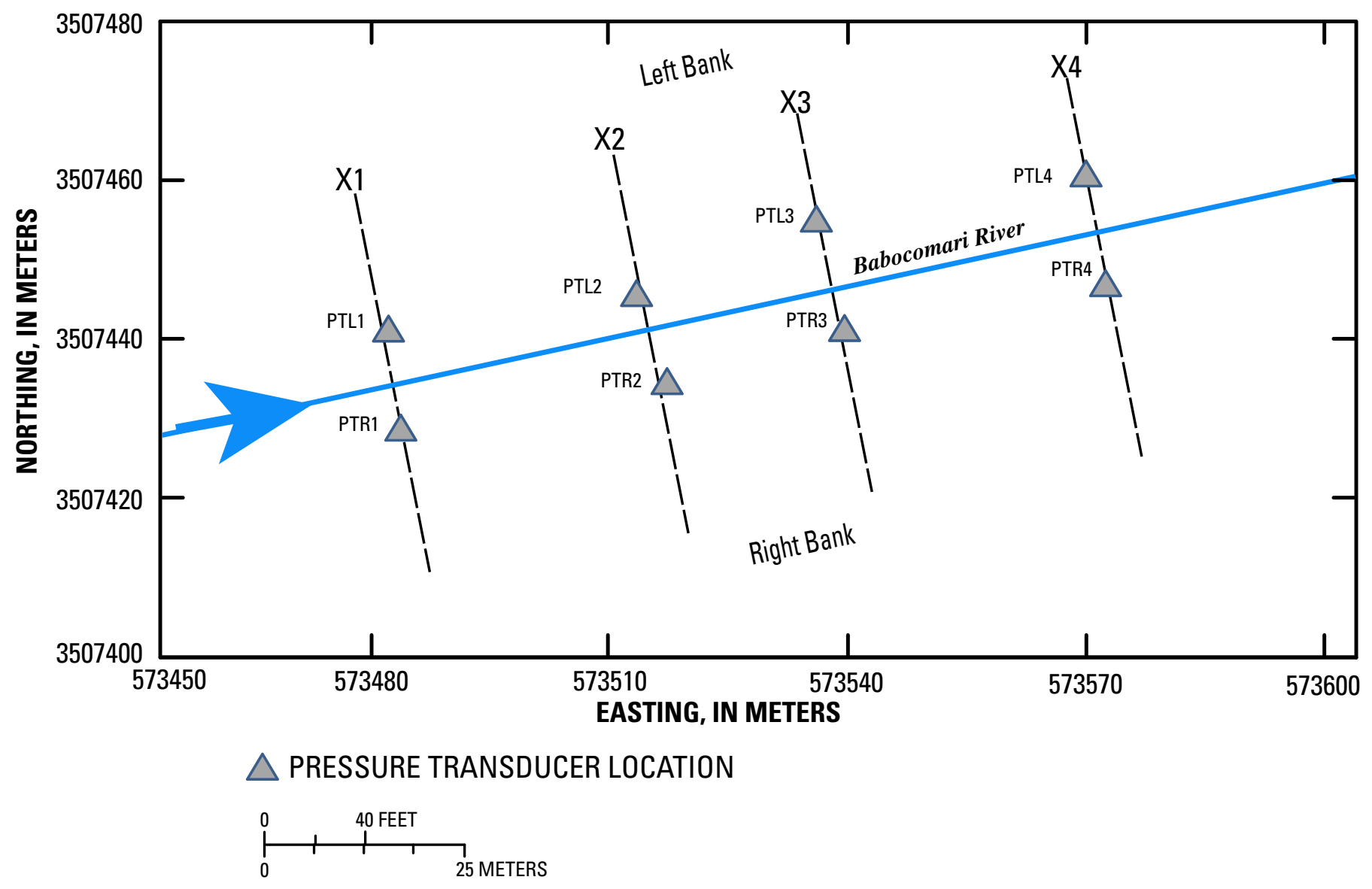

Figure 14. Plan view of the cross sections and eight pressure transducers in the Babocomari River continuous-slope-area reach. 
Table 1. Elevation difference between crest-stage and pressure-transducer datums (dry)

\begin{tabular}{ccc}
\hline Reach & $\begin{array}{c}\text { Right-bank elevation } \\
\text { difference (ft) }\end{array}$ & $\begin{array}{c}\text { Left-bank elevation } \\
\text { difference (ft) }\end{array}$ \\
\hline X1-X2 & 0.52 & 0.92 \\
X2-X3 & 0.07 & 0.69 \\
X3-X4 & 1.59 & 0.47 \\
X1-X3 & 0.59 & 1.61 \\
X2-X4 & 1.66 & 1.16 \\
X1-X4 & 2.18 & 2.08 \\
\hline
\end{tabular}

\section{Calculation of Hydrographs Using the Continuous Slope-Area Method}

After the necessary corrections were applied to the PT data sets, stage hydrographs were produced from the left- and rightbank pressure-transducer data. The water-surface profiles can be evaluated for comparison with the guidelines recommended by Dalrymple and Benson (1967). The water-surface profiles can show insufficient fall between cross sections, which reduces the accuracy and consistency of the results. A similar practice is followed with conventional indirect methods, where highwater marks and cross sections can be removed from the final calculation to improve the quality of discharge computations. Following the initial evaluation of the stage data, discharges are computed with the SAC program.

\section{Batch-Processing Discharge Computations}

The calculation of the continuous discharge is accomplished by applying the SAC program to each step in the

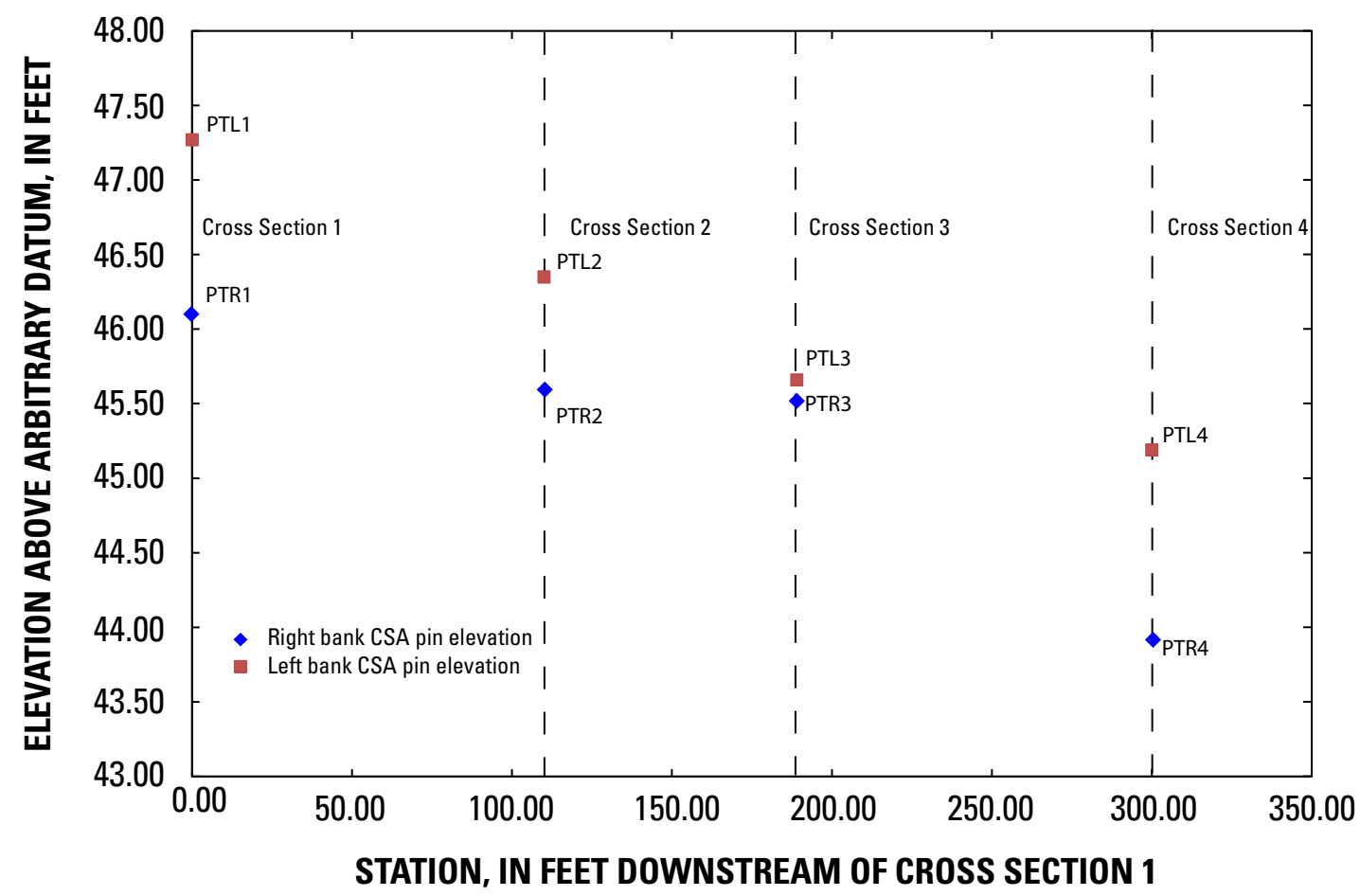

Figure 15. Pressure-transducer-pin elevations (dry with no flow). 
stage-time series. This procedure was automated with a utility program (CSA2SAC) developed for this project that reads in the channel parameters used in the SAC program and the stage data, generates the SAC input files for each time step, runs the SAC program for each time step, reads the SAC output files, and finally generates a separate file containing the computed hydrograph.

\section{Development of Stage-Discharge Relations}

A stage-discharge relation can be created from the stage data collected by any of the PTs and the discharge data computed by the SAC program. The development of stagedischarge relations is generally best achieved by using the discharges computed using more than two cross sections. The multi-section reach computation averages reach conditions, producing a more consistent discharge.

\section{Major Flows on the Babocomari River 2002-2006}

During the five-year study period, Arizona experienced one of the driest periods ever recorded, so medium- and high-flow events were less frequent than normal (Phillips and Thomas, 2005). Five events that inundated the CSG and PT gages occurred during the study period and, as a result, were sufficiently large for the application of the CSA method (table 2; fig. 16). The events between 2002 and 2005 were moderate flows of similar magnitude. The width of flow for these events was about $80 \mathrm{ft}$. During flow in 2006, which was the largest during the study, the width of flow exceeded $150 \mathrm{ft}$ and depths were over $12 \mathrm{ft}$. The following sections describe one of the four moderate events (October, 2003) and the high flow in 2006 to illustrate the CSA application under field conditions. Stage data, computed discharges, and channel shape and roughness for all five events are recorded in appendices 1 and 2 .

\section{Flow of 0 ctober 9, 2003}

A moderate event occurred on October 9, 2003, that was caused by a late-season monsoon. The streamflow event lasted about $1 \mathrm{hr}$, and the water-surface elevations were high enough to submerge all eight PTs for $20 \mathrm{~min}$. The recorded stage hydrographs from each of the PTs are shown in figure 17.

\section{Channel Geometry}

The channel geometry surveyed before and after the October 9, 2003, flow event indicates little channel change during the event (figs. 18-21).

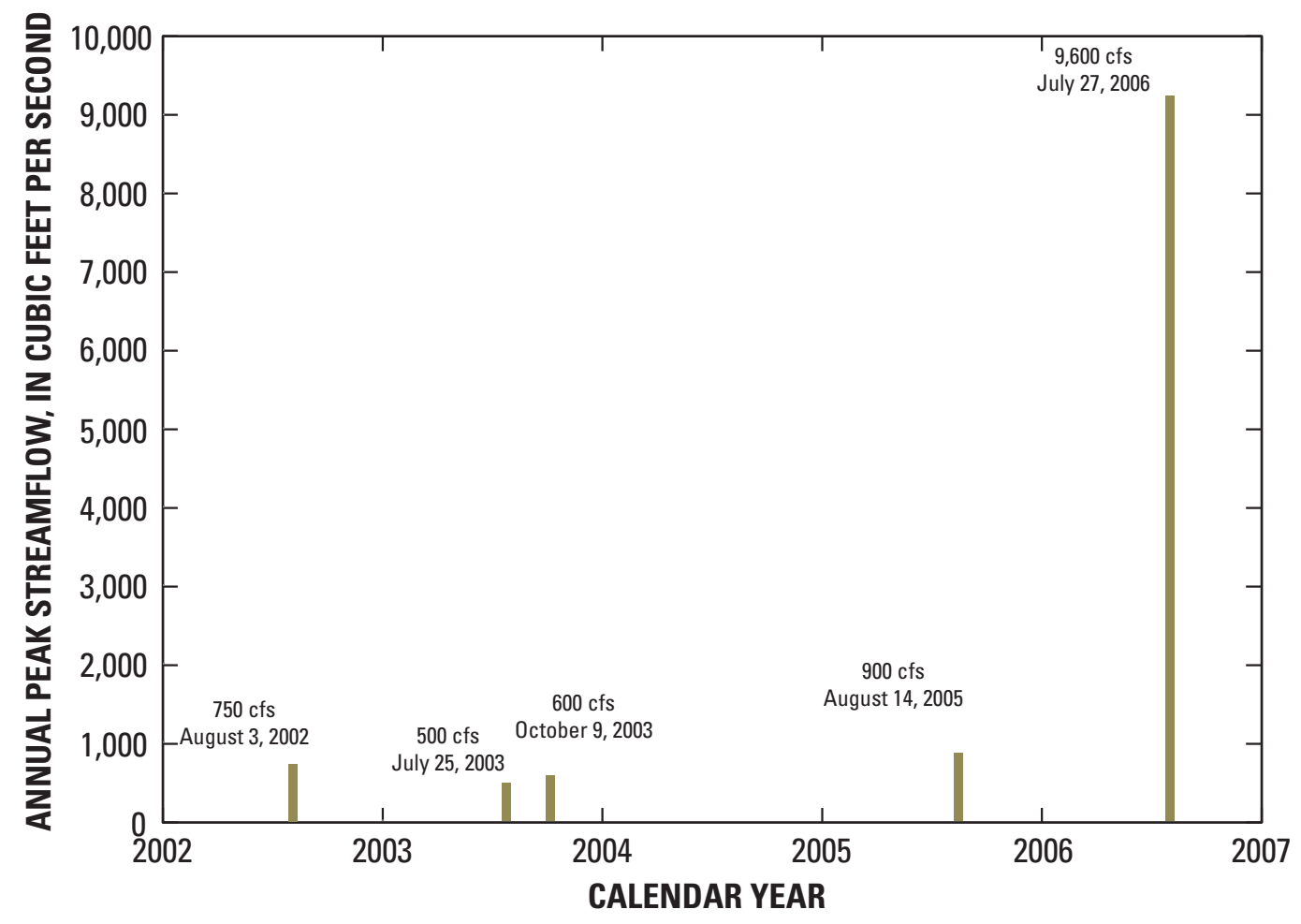

Figure 16. Peak streamflows recorded on the Babocomari River during the study period, 2002-2006. 
Table 2. Peak stages recorded by the crest-stage gages and by the pressure transducers during the October 9, 2003, event.

\begin{tabular}{ccc}
\hline $\begin{array}{c}\text { Pressure transducer (PT) } \\
\text { (R, right; L, left) }\end{array}$ & $\begin{array}{c}\text { Crest-stage gage height } \\
\text { (feet) }\end{array}$ & $\begin{array}{c}\text { Peak (ft) and time } \\
\text { recorded by the PT }\end{array}$ \\
\hline PTR1 & 47.33 & 47.30 at 19:55 \\
PTL1 & 47.54 & 47.49 at 19:55 \\
PTR2 & 47.17 & 47.00 at $19: 55$ \\
PTL2 & 47.22 & 47.10 at $19: 50$ \\
PTR3 & 46.53 & 46.38 at $19: 50$ \\
PTL3 & 46.71 & 46.63 at 19:55 \\
PTR4 & 46.33 & 46.34 at 19:55 \\
\hline
\end{tabular}

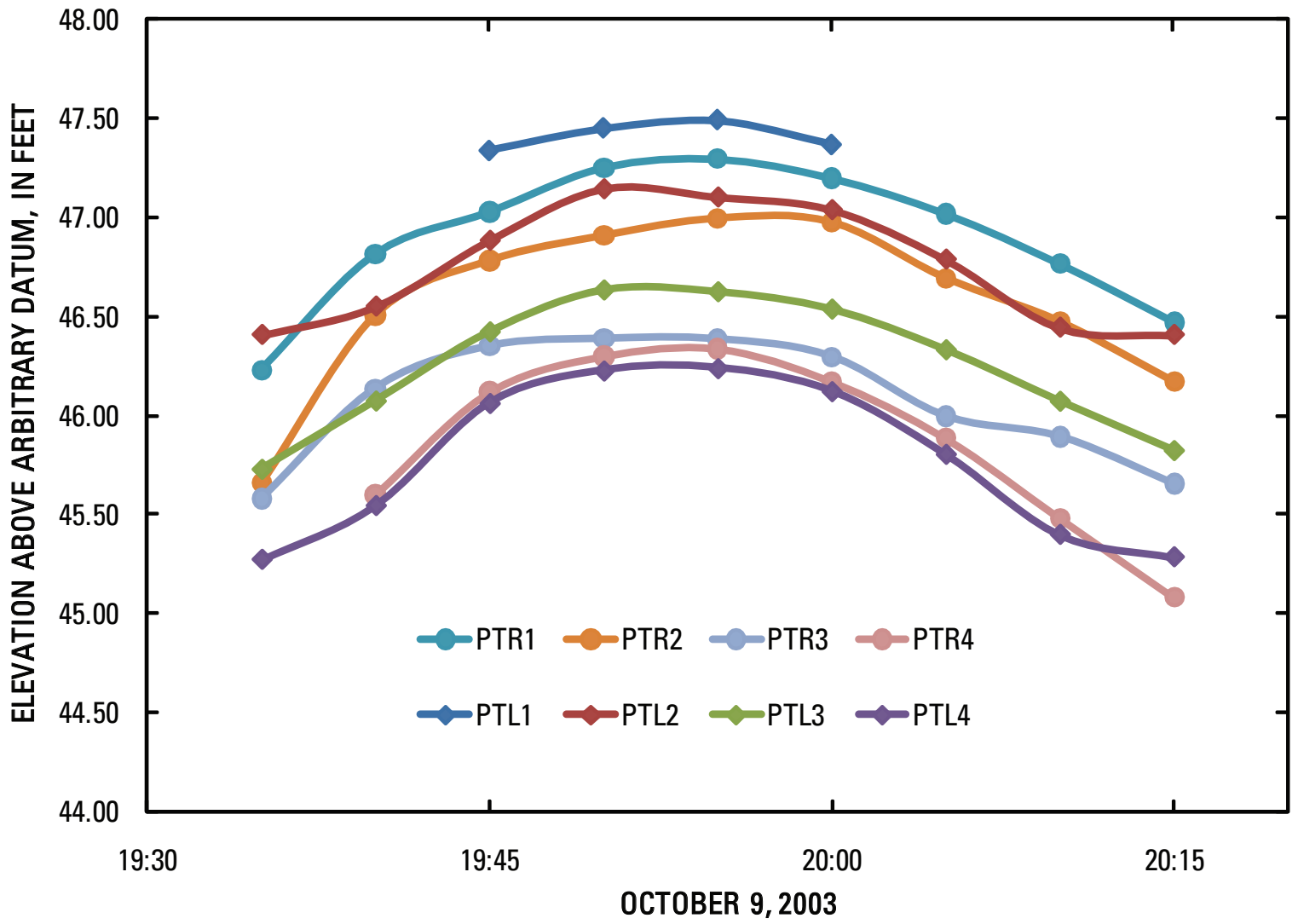

Figure 17. Stage hydrographs from the 0ctober 9,2003 , flow event on the Babocomari River. 


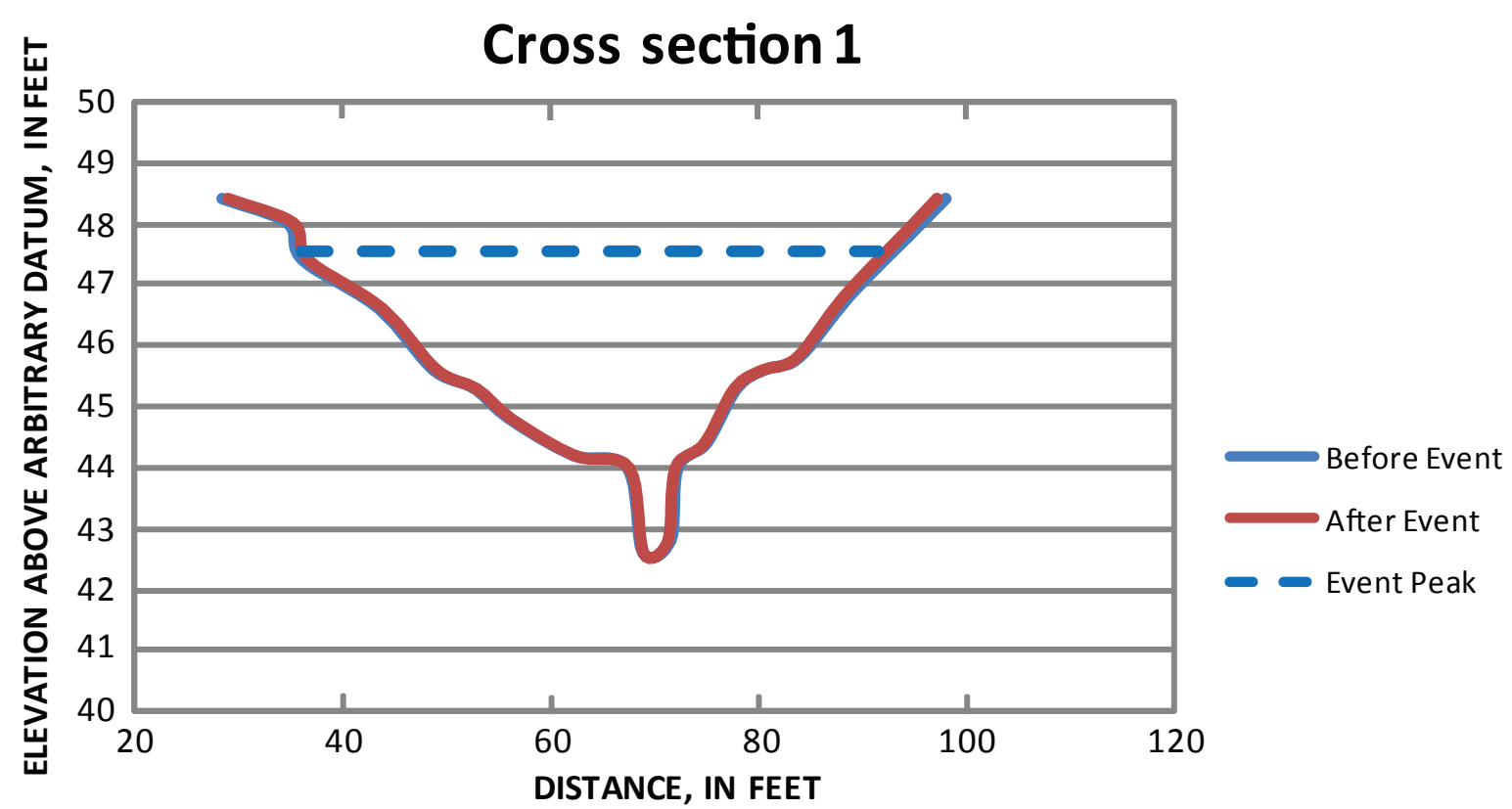

Figure 18. Channel surveys in cross section 1 before and after the 0 ctober 9, 2003, event. The blue dashed line shows the water-surface elevation at the peak discharge.

Evaluation of the High-Water Marks

Crest-stage gage heights representing the crest of the peak were present on all eight of the crest-stage gages following the flow event. The crest-stage gage heights and the
PT-recorded peak values and times associated are shown in table 2. On the left bank, the crest-stage gage heights were higher than the recorded PT peak values; on the right bank, the recorded PT peak values were within $0.01 \mathrm{ft}$ or less than the crest-stage gage heights, with the exception of PTR4 that

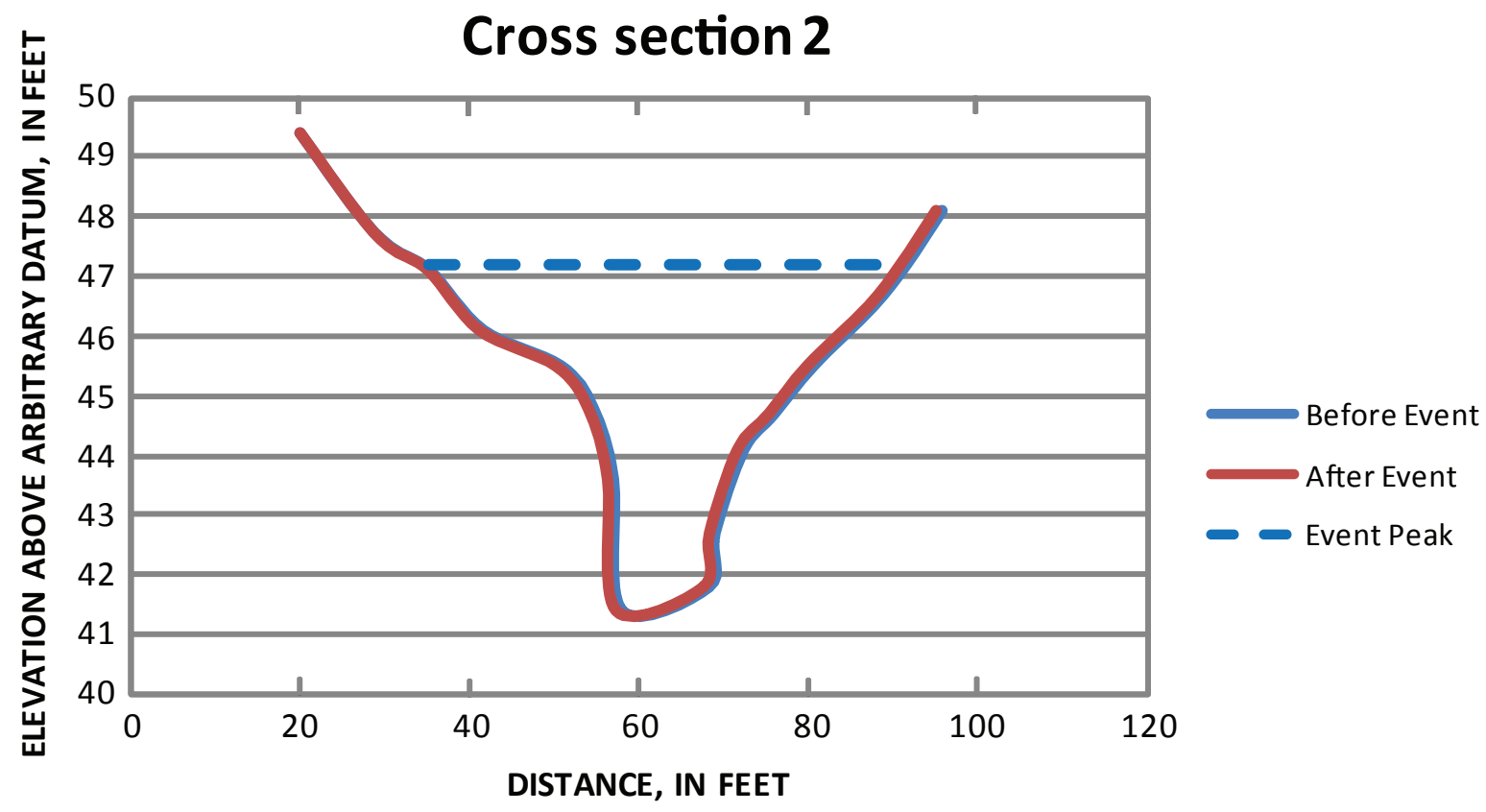

Figure 19. Channel surveys in cross section 2 before and after the October 9, 2003, event. The blue dashed line shows the water-surface elevation at the peak discharge. 


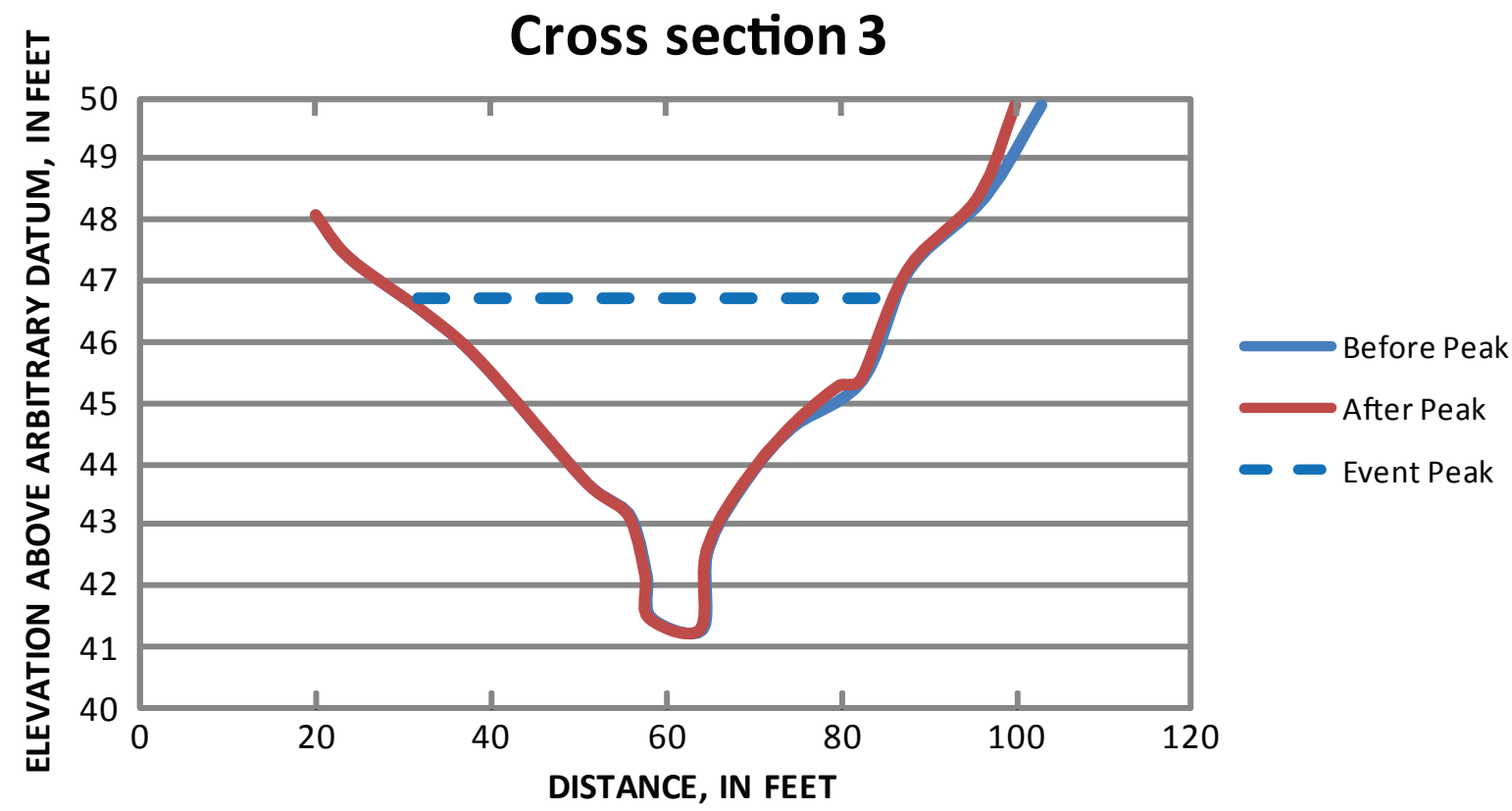

Figure 20. Channel surveys in cross section 3 before and after the 0 ctober 9, 2003, event. The blue dashed line shows the water-surface elevation at the peak discharge.

recorded the same water-surface elevation as PTR3. Six of the eight PTs recorded the peak water surface at 19:55, while two PTs recorded the peak at 19:50. The difference between these peak times could be attributed to splashing or wave action.
Conventional Slope-Area Computation and Analysis

A slope-area calculation using the corrected CSG elevations at four cross sections was performed. A Manning's $n$ value of 0.035 was judged appropriate for each of these four

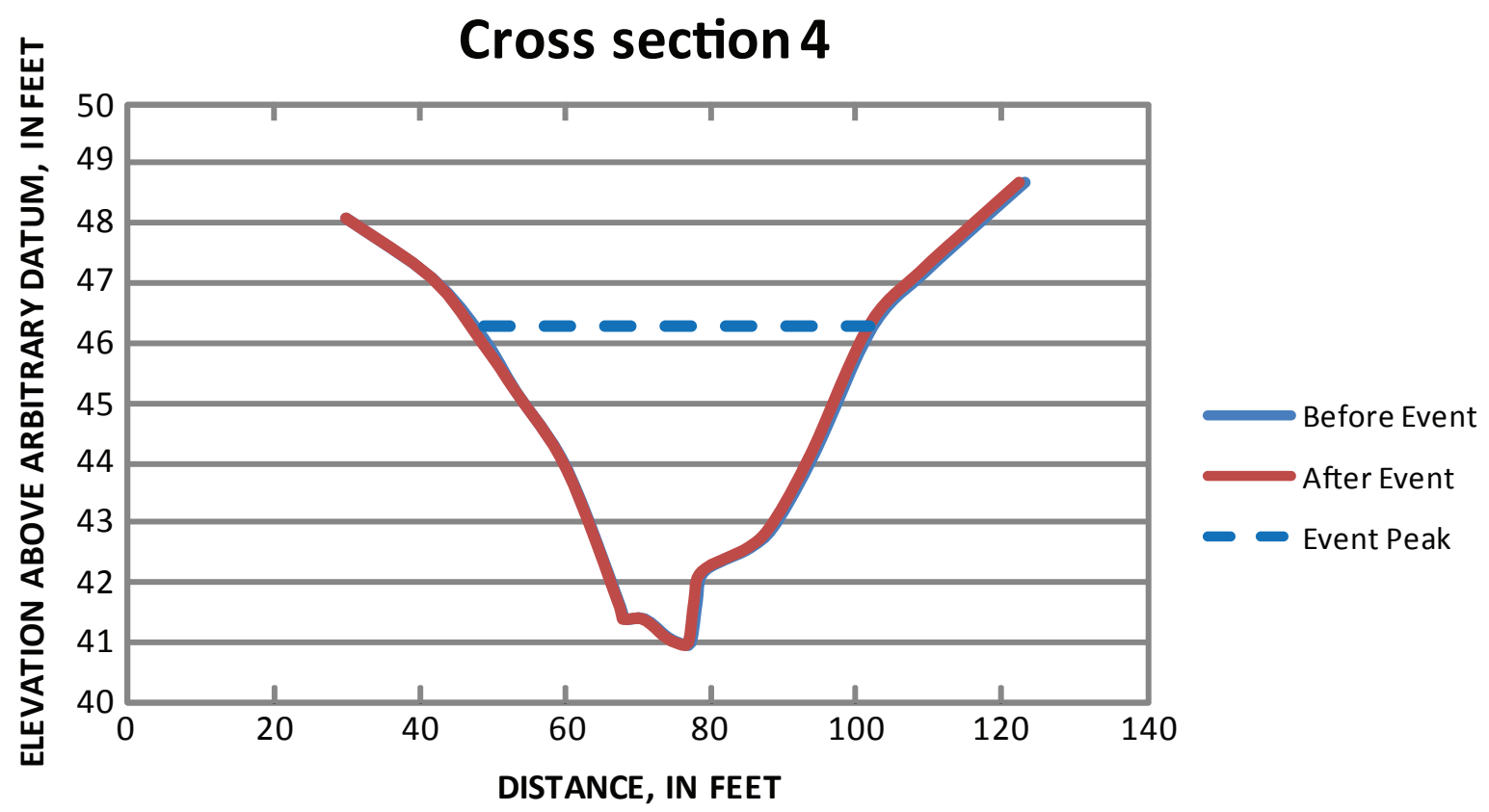

Figure 21. Channel surveys in cross section 4 before and after the 0 ctober 9, 2003, event. The blue dashed line shows the water-surface elevation at the peak discharge. 
Table 3. Peak discharge for cross sections 1-4, based on average of left and right stage data from the pressure transducers and crest-stage gage from the October 9, 2003, event.

\section{Peak discharge computed from the crest- Peak discharge computed from the PT stage gage heights $\left(\mathrm{ft}^{3} / \mathrm{s}\right) \quad$ recorded elevations $\left(\mathrm{ft}^{3} / \mathbf{s}\right)$}

cross sections based on channels with similar conditions in southeastern Arizona (Aldridge and Garrett, 1973; Phillips and Tadayon, 2006). The computed discharge, using the average of the left and right crest-stage gage heights, was $626 \mathrm{ft}^{3} / \mathrm{s}$ (table 3$)$.

\section{Evaluation of the Pressure-Transducer Data}

The left and right averaged PT-stage values used for the CSA computation are shown in figure 22. The average of the left- and right-bank water surfaces results in a hydrograph that represents the water surfaces during the flow event. The four hydrographs contain water-surface elevations recorded nine times during the 40-minute event.
Continuous Slope-Area Discharge Computations and Analysis

The discharge values computed from the average peak left and right CSG heights and the recorded PT-gage heights are shown in table 3 . The CSA-computed discharge values ranged from 340 to $591 \mathrm{ft}^{3} / \mathrm{s}$ during the streamflow event. The computed peak discharge using the CSG heights $\left(626 \mathrm{ft}^{3} / \mathrm{s}\right)$ was $35 \mathrm{ft}^{3} / \mathrm{s}$ greater than the computed peak discharge from the PTs (fig. 23).

\section{Rating Development}

A stage-discharge relation was developed showing the relation between the discharge computed with the CSA

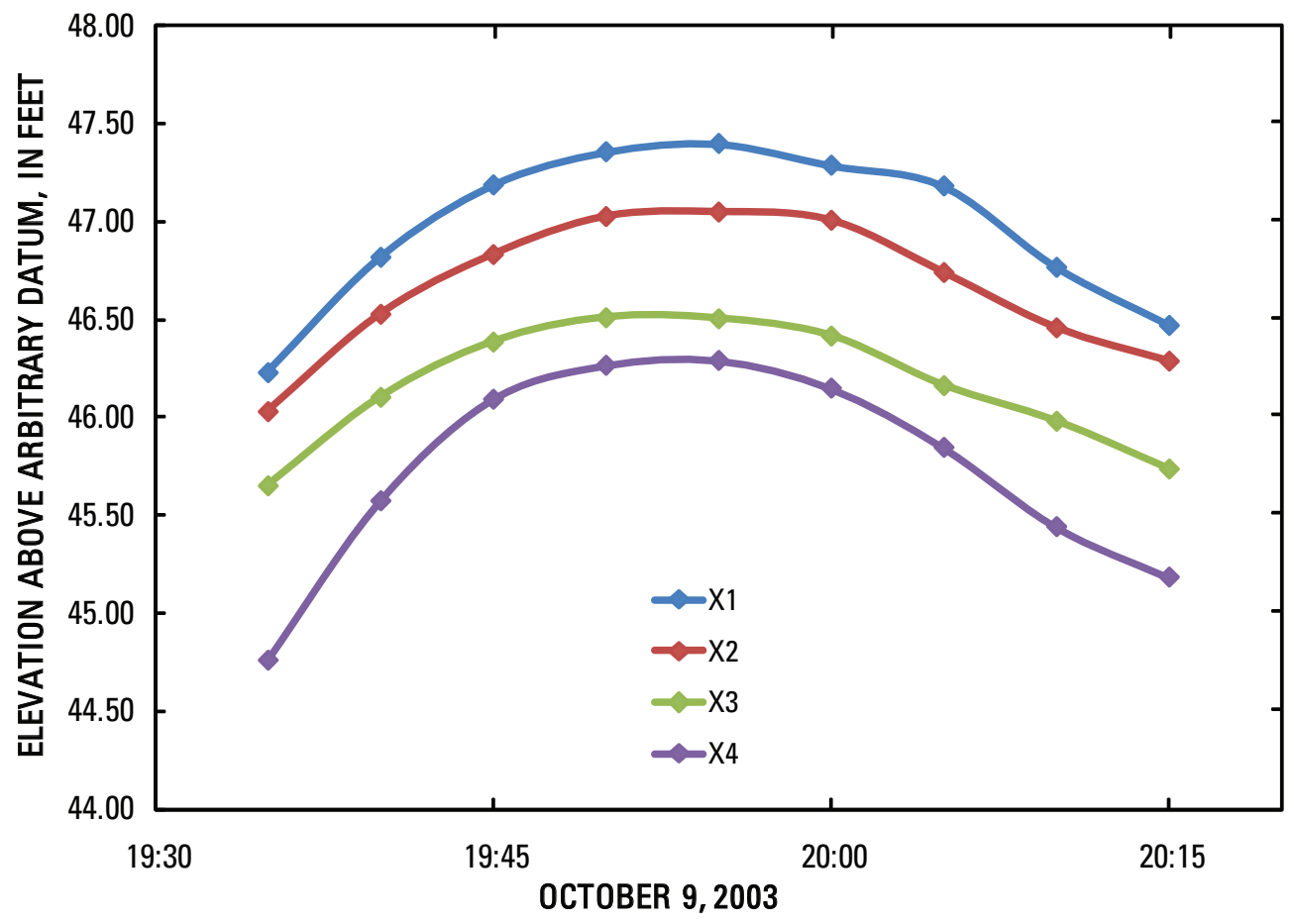

Figure 22. Average left- and right-bank pressure-transducer-stage hydrographs during the October 9, 2003, event. 
method and stage from PTR1 (fig. 24). Stage values from PTR1 were selected over the stage values from the other PTs, because PTR1 stage values produced the closest fit in the stage-discharge relation. The single discharge value calculated from the CSG heights was also included in the plot and is consistent with the CSA results.

\section{Summary of the October 2003 Event}

The third flow event of the study period occurred on October 9, 2003, and all eight of the PTs were submerged and recorded stage during part of the 1-hr event. Crest-stage gage heights were also obtained from eight of the CSGs. Slope-area calculations were performed to determine the peak streamflow using both data from the PTs and the CSG heights. The computed peak discharge value from the CSG heights was about 6 percent higher than the peak discharge value calculated from the peak PT values.

\section{The Flow Event of July 27, 2006}

The July 27, 2006, event produced the peak of record, $9,600 \mathrm{ft}^{3} / \mathrm{s}$, which had an annual exceedance probability of 4 percent. This peak was nearly 10 times greater than any of the previous peaks during the study. Six out of the eight PTs collected data for this event (fig. 25); two PTs (PTR2, PTL4) did not work due to lost battery power. All four cross sections were used in the analysis.

Five of the six PTs that worked for this flow event were rotated about their base shortly after the peak. The pipes supporting PTR1, PTL2, PTR3, PTL3, and PTR4 were all rotated about $45^{\circ}$ (fig. 26) in the downstream direction; only PTL1 remained upright. The five PTs continued to record throughout the event, but only data obtained prior to their displacement were used in the analysis. A sudden shift of about $0.3 \mathrm{ft}$ in stage at each PT indicated the time at which the PTs were displaced.

\section{Changes in Channel Shape}

The only measureable change to the reach during the study period was caused by the July 27,2006 , flood. Two trees were uprooted and deposited near the PTs in X1 and X2 but appeared to have minimal effect on the cross-sectional areas of $\mathrm{X} 1$ and $\mathrm{X} 2$. Vegetation debris accumulated near X3, and sand and gravel were deposited near X4. The changes are generally minor, and their effects on channel hydraulics over the course of the event were neglected in the discharge calculations (fig. 27). The channel changes, however small, introduce additional uncertainty in the computed hydrograph and illustrate another

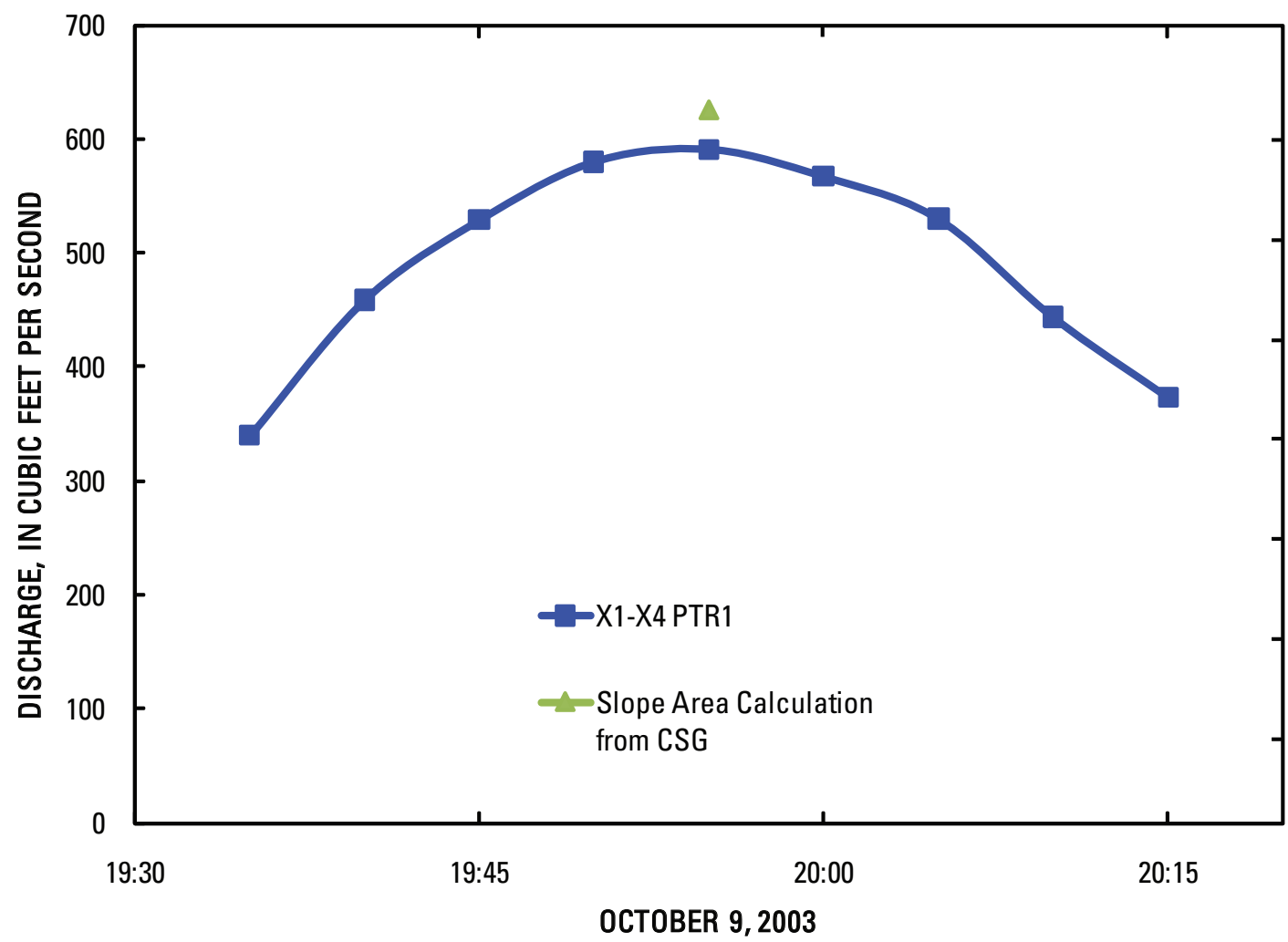

Figure 23. Discharge values computed with the average pressure-transducer and crest-stage gage data for the October 9, 2003, event. 
source of potential error that is present in any kind of hydraulic reconstruction of a significant flow, whether it is step-backwater modeling, multi-dimensional hydraulic modeling, peak-flow indirect measurements, standard stream gaging, or CSA applications. The precise timing of the changes to channel shape is unknown but likely occurred near the peak discharge. Gravel deposited near the right bank in X1 caused a 2 percent decrease in the peak-flow cross-sectional area (fig. 28). Scour in the thalweg and the left side of the channel caused an 8 percent increase in cross-sectional area in X2 (fig. 29). In X3, a 0.5 percent increase occurred as a result of scour in the center of the channel (fig. 30). There was a 4 percent decrease in cross-sectional area in X4, caused by deposition of sand and gravel in the center of the channel (fig. 31).

\section{Evaluation of the High-Water Marks}

High-water marks from the CSGs were not present, because the CSGs were overtopped. Instead, surveyed high-water marks were used in the slope-area computation, although high-water marks were not preserved on the large rocks that dominate the left bank at X1 and X2. The large rocks were present on the left bank $50 \mathrm{ft}$ upstream of $\mathrm{X} 1$ and extended continuously downstream through X2. The surveyed high-water marks combined with the peak stage values from the PTs are shown in table 4. The peak recorded from PTL3 of $56.95 \mathrm{ft}$ was greater than the high-water mark of $55.79 \mathrm{ft}$ surveyed in X3 on the left bank. This may have been caused by debris that accumulated in the center of the channel, which caused an elevated water surface next to PTL3, but did not extend far enough along the bank to elevate the left-bank highwater mark or to affect PTL2.

\section{Slope-Area Computation and Analysis of High-Water Marks}

A slope-area calculation of the peak discharge using the surveyed high-water marks at the four cross sections was performed. A Manning's $n$ of 0.040 was selected, which is greater than the value of 0.035 used in previous flow events. The $n$ value was increased to account for debris that was collected on trees and bushes in the slope-area reach, and the fallen trees that collected deposits of sand and gravel.

The fall between cross sections X3-X4 on the left bank was $0.60 \mathrm{ft}$, and a discharge of 12,044 $\mathrm{ft}^{3} / \mathrm{s}$ was computed (table 5). On the right bank, the subreach $\mathrm{X} 1-\mathrm{X} 2$ had an inverse slope

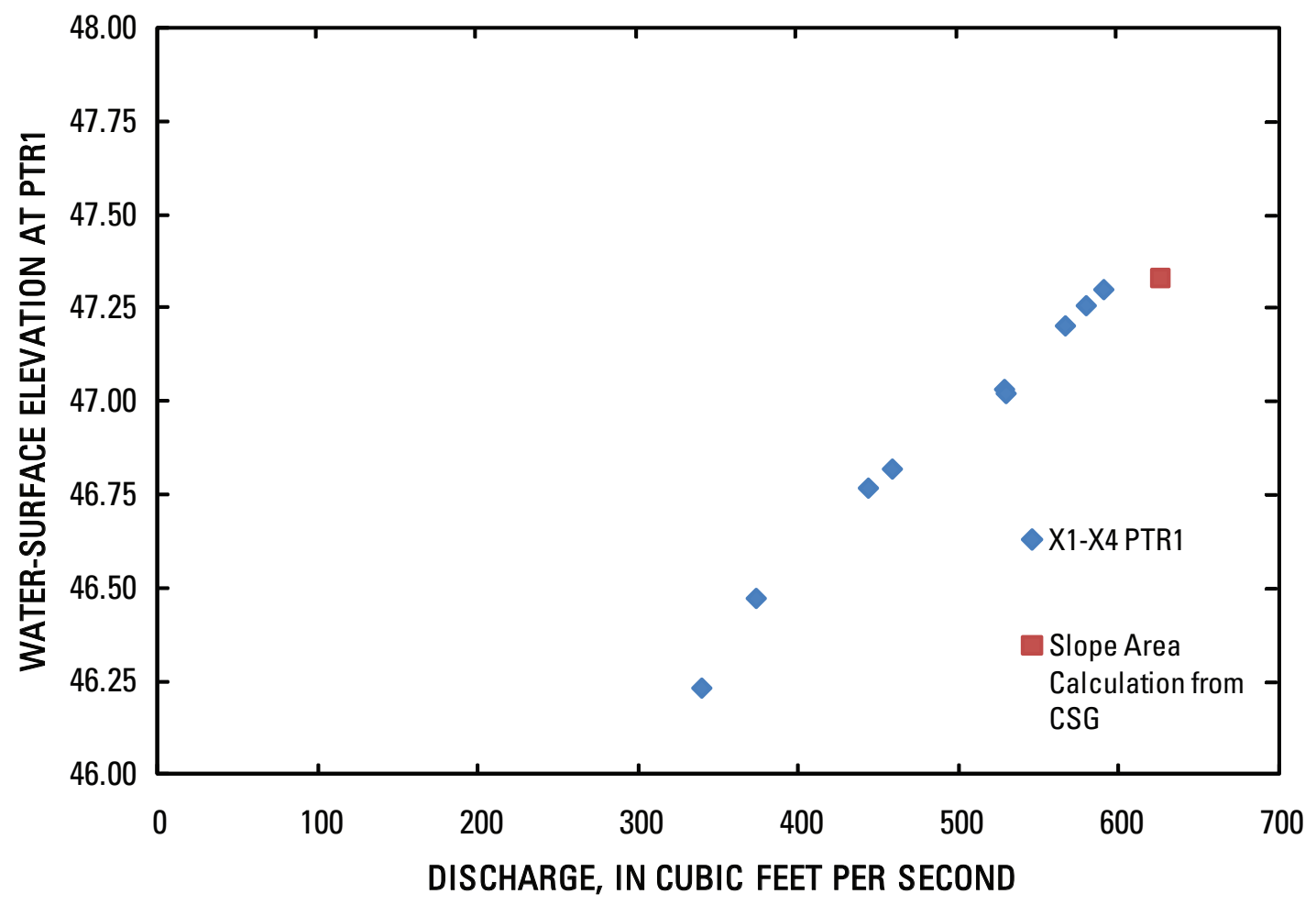

Figure 24. Stage-discharge relation determined with discharges computed from the averaged pressuretransducer data and crest-stage gage data for the 0ctober 9, 2003, event. 


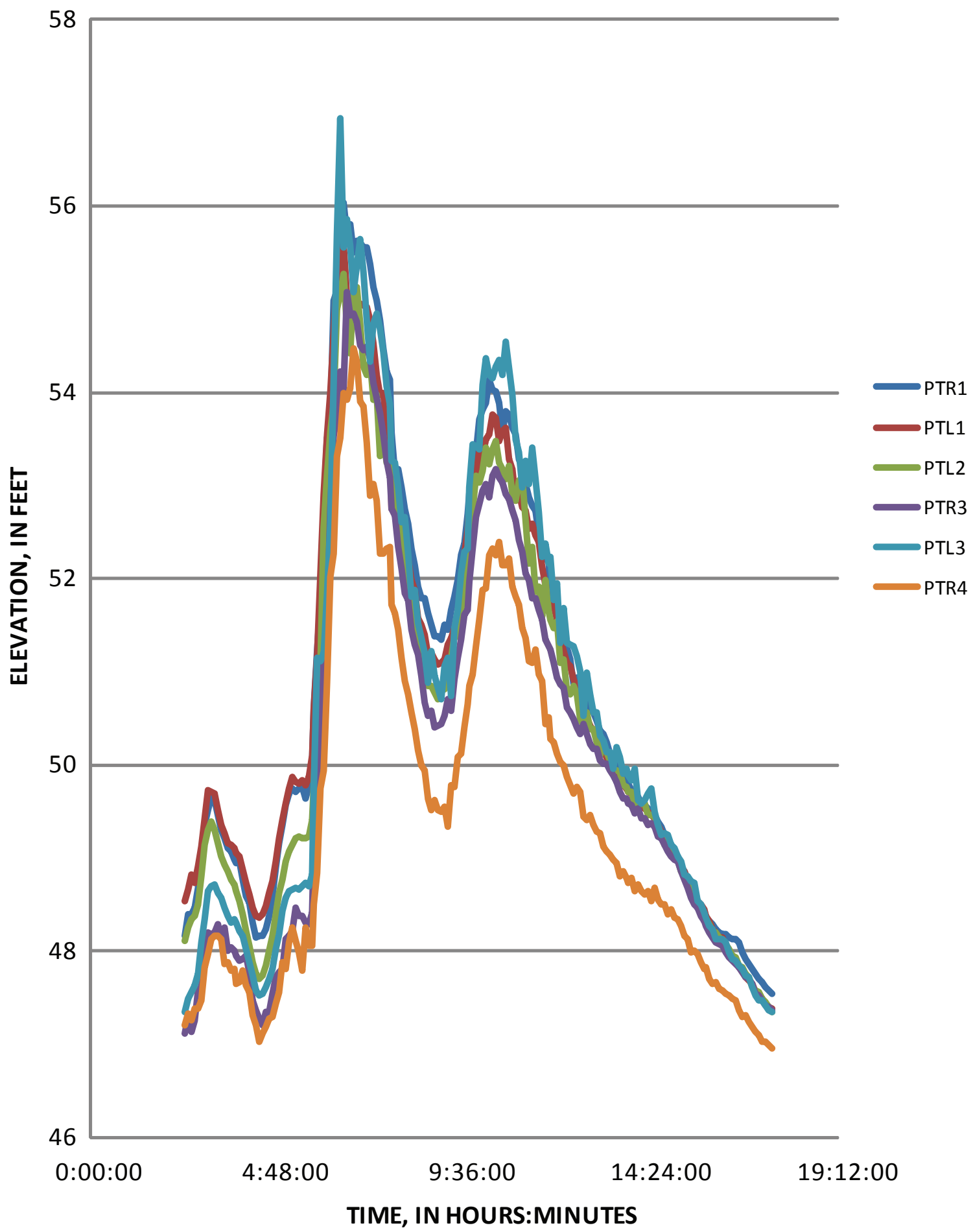

Figure 25. July 27, 2006, stage hydrographs for six pressure transducers. Right-bank pressure transducers are indicated by $R$ in the legend label; left-bank pressure transducers are indicated by $L$ in the legend label; the number in the legend label corresponds to the cross-section number. 


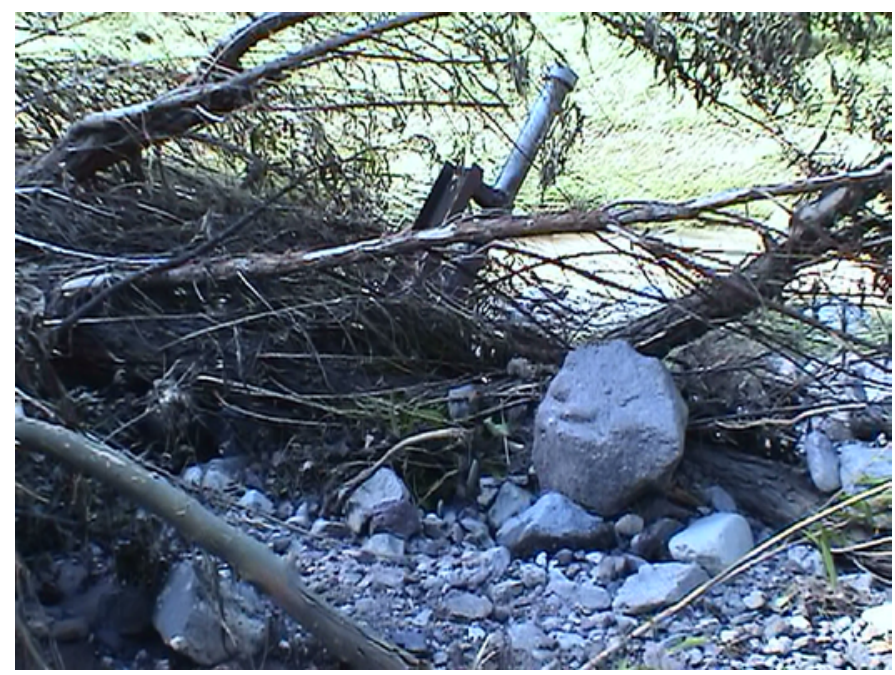

Figure 26. Right-bank pressure transducer in cross section 1 (PTR1) after the July 27, 2006, flow event.

and, therefore, that combination of cross sections could not be used to compute discharge. The discharges computed with rightbank elevations ranged from $7,818 \mathrm{ft}^{3} / \mathrm{s}$ to $12,409 \mathrm{ft}^{3} / \mathrm{s}$ (table $6)$. The most consistent results came from the multiple crosssection reaches $\mathrm{X} 1-\mathrm{X} 3, \mathrm{X} 2-\mathrm{X} 4$, and $\mathrm{X} 1-\mathrm{X} 4$.

Slope-Area Computation of Peak Discharge using PT Data and Analysis of PT Data

The peak discharge was computed using the slope-area method and peak PT elevations from the left (table 7) and right (table 8) banks. The results of the left-bank slope-area

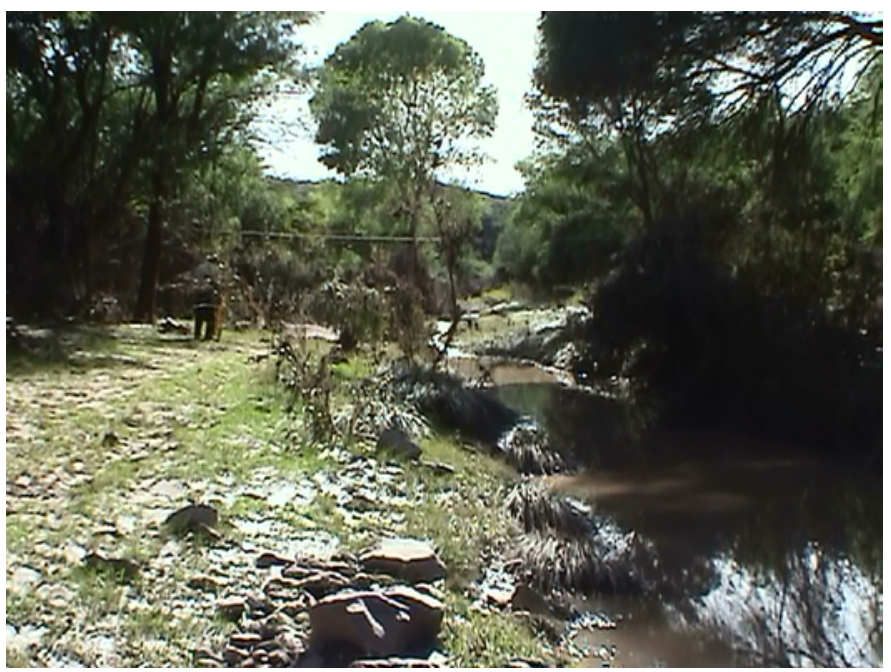

Figure 27. View looking upstream from cross section 3 on the right bank after the July 27,2006 , event. The floodway is mostly clear of obstacles.

computation of discharge showed that only one subreach, $\mathrm{X} 1-\mathrm{X} 2$, could be used in the analysis as a result of the debris pile downstream. The fall between $\mathrm{X} 1-\mathrm{X} 2$ was $0.33 \mathrm{ft}$ and the computed discharge was $8,466 \mathrm{ft}^{3} / \mathrm{s}$.

The peak stage values from the right bank produced a small range in computed discharge of $9,138 \mathrm{ft}^{3} / \mathrm{s}$ to $10,589 \mathrm{ft}^{3} / \mathrm{s}$ (table 8 ). The discharge computed using stage values from the right bank (X1-X4) of 9,621 $\mathrm{ft}^{3} / \mathrm{s}$ was considered the discharge most likely to be accurate from the slope-area computations, because it uses the longest reach and incorporates more channel data than the other cross-section combinations.

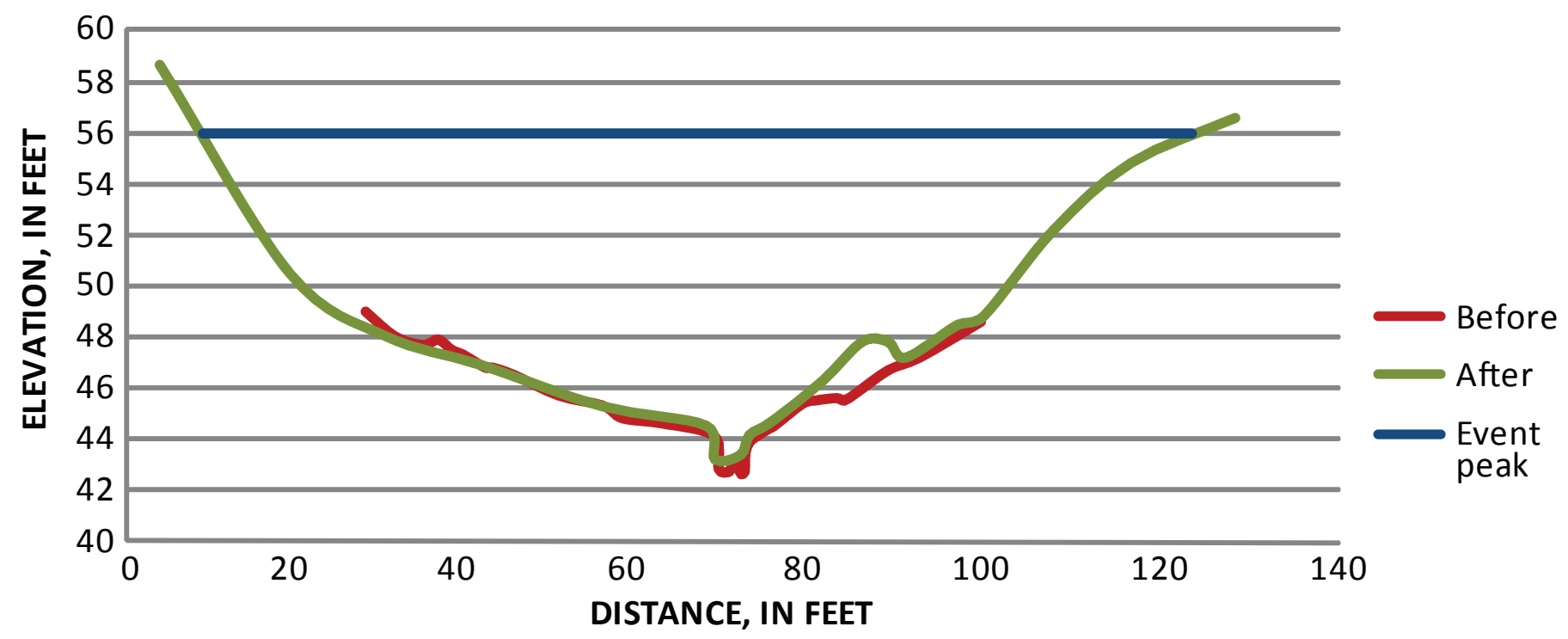

Figure 28. Channel surveys in cross section 1 before and after the July 27, 2006, event. The blue line shows the water-surface elevation at the peak discharge. At the peak discharge, the difference in cross-section areas is 2 percent. 


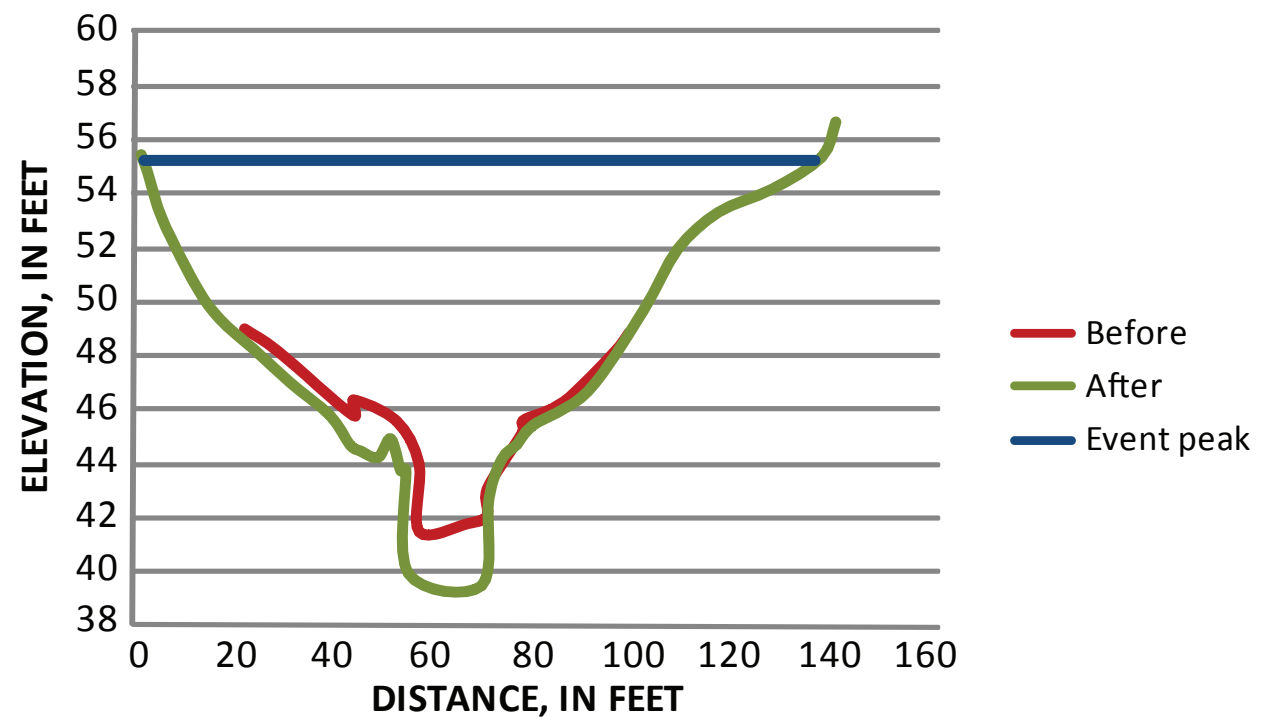

Figure 29. Channel surveys in cross section 2 before and after the July 27, 2006, event. The blue line shows the water-surface elevation at the peak discharge. At the peak discharge, the difference in cross-section areas is 8 percent.

\section{Evaluation of the Pressure-Transducer Data}

Data from the six working PTs were evaluated to determine the optimum combination for discharge computations. PTL3 was not used because of the elevated stage effects from the accumulated debris (fig. 32). The remaining five PTs were PTR1, PTR3, and PTR4 from the right bank and PTL1 and PTL2 from the left bank. Because the right bank high-water marks and pressure-transducer peaks produced a narrower range of discharges in computing the slope-area discharges, the right bank PTs were used along with PTL2, which was the only sensor available for $\mathrm{X} 2$, for the final discharge computation. PTL1 was not used in the computation of discharge, but, because it was the only PT not displaced during the event, it was used for the stage record in developing the event-rating curve and the event-discharge hydrograph.

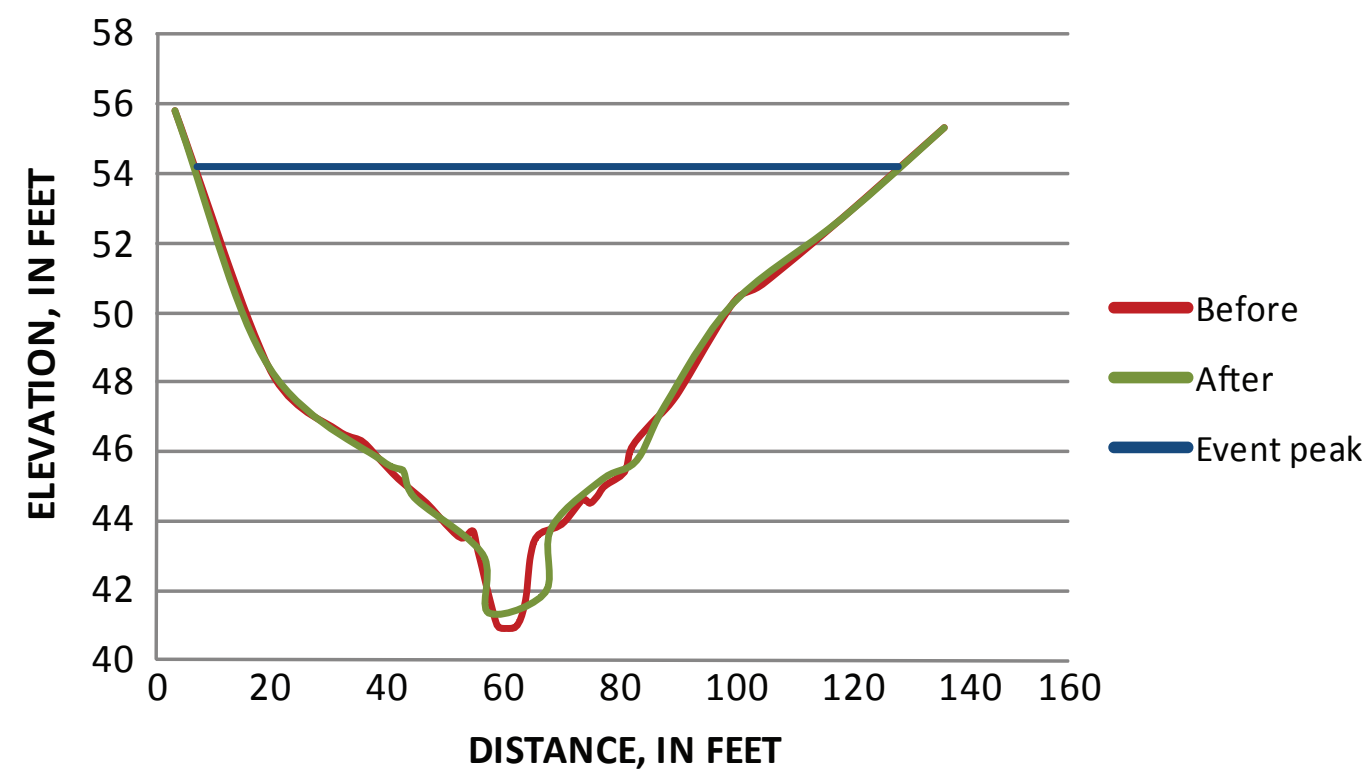

Figure 30. Channel surveys in cross section 3 before and after the July 27, 2006, event. The blue line shows the water-surface elevation at the peak discharge. At the peak discharge, the difference in cross-section areas is 0.5 percent. 
Stage hydrographs from PTR1, PTL2, PTR3, and PTR4 (fig. 33) were selected to compute discharge. The CSGs attached to these PTs were rotated to about a $45^{\circ}$ angle from vertical just after the flow peak and, consequently, discharge values were not computed after the peak. The event-rating curve was developed from discharge values computed using stage values that were recorded prior to the PTs being displaced.

\section{Development of Stage-Discharge Relation}

The stage-discharge relation was developed from stage values from PTL1 and discharge values computed with stage values recorded before the PTs were knocked over (fig. 34). A log function fit to the stage-discharge points has a $R^{2}$ of 0.9957, indicating that the stage-discharge relation fits the data closely with little scatter.

\section{Transfer of the CSA Stage-Discharge Relation to the Babocomari River near Tombstone Streamflow-Gaging Station}

The July 27, 2006, flood removed most of the large trees that were growing in the channel reach above and below the Babocomari River near Tombstone streamflow-gaging station, about $0.25 \mathrm{mi}$ above the CSA site (fig. 8). The large trees in the channel bottom were the controls for the medium to high flows near the gage (fig. 35). This is a common condition at many USGS streamgages in Arizona. Periods of low or no flow allow dense vegetation growth in the channel that can significantly modify the channel hydraulic properties.

During the July flood, nearly all of the vegetation in the channel near the gage was removed near the flood peak and during the recession. In contrast, the same flood only caused minor changes in the downstream CSA reach. The stagedischarge relation for the Babocomari River near Tombstone gage depends on the condition of vegetation in the channel and was altered by the removal of vegetation during the July 27, 2006, flood. Consequently, a new stage-discharge relation was developed for the gage. The stage-discharge relation will return to its pre-flood form as the vegetations grow back in the channel.

The stage hydrograph from the Babocamari River near Tombstone gage was compared with the stage hydrograph from PTL1 (fig. 36). The two hydrographs matched until just after the peak, when the gage hydrograph diverges from the PTL1 hydrograph, most likely as a result of the scouring of vegetation from the gage reach. On the recession, the gage hydrograph drops more than the PTL1 hydrograph by as much as $3 \mathrm{ft}$.

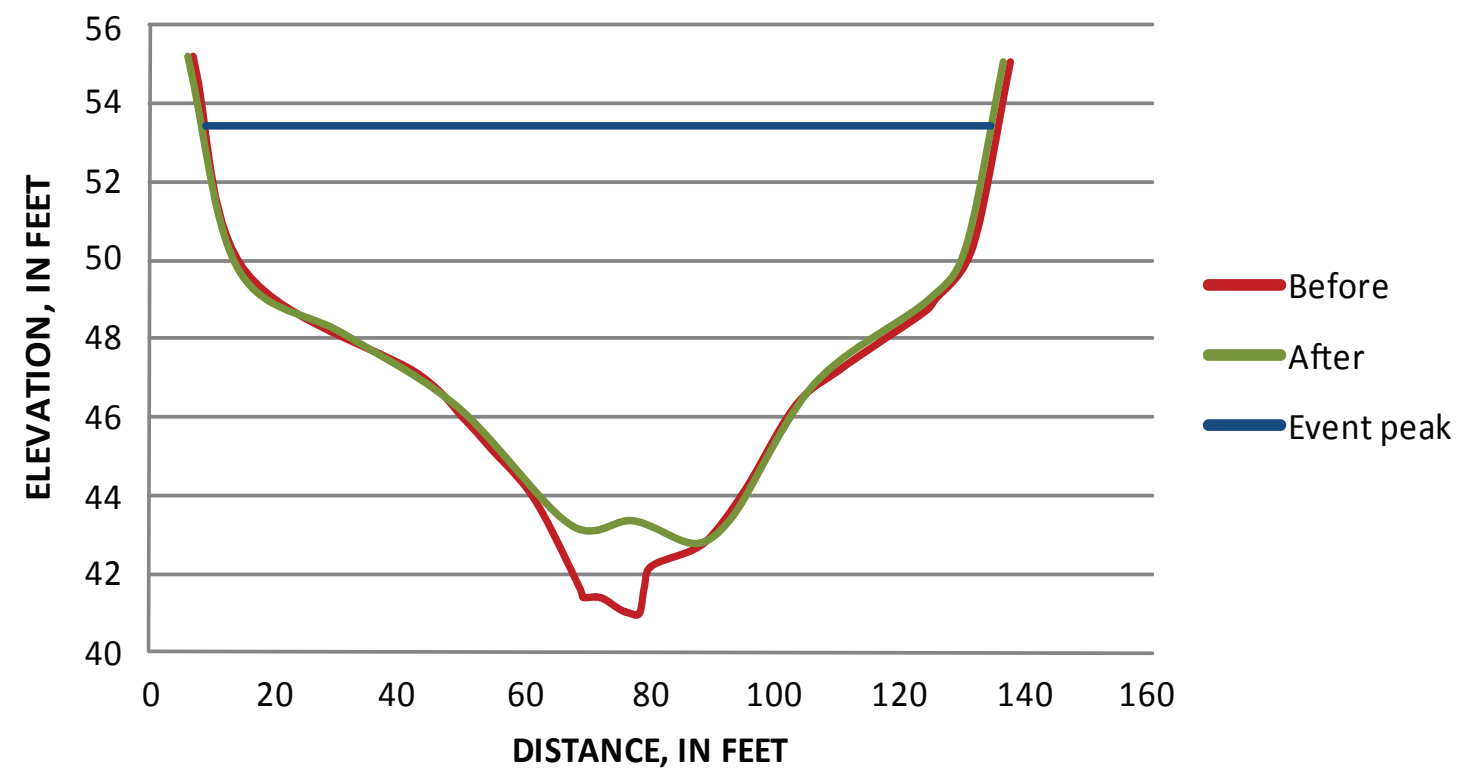

Figure 31. Channel surveys in cross section 4 before and after the July 27, 2006, event. The blue line shows the water-surface elevation at the peak discharge. At the peak discharge, the difference in cross-section areas is 4 percent. 
Table 4. Water-surface elevations from surveyed high-water marks and pressure transducers from the July 27, 2006, event.

\begin{tabular}{ccc} 
Pressure transducer & $\begin{array}{c}\text { High-water mark found } \\
\text { near PT (ft) }\end{array}$ & $\begin{array}{c}\text { Peak recorded by the } \\
\text { PT (ft) }\end{array}$ \\
\hline PTR1 & 56.57 & 56.06 \\
PTL1 & N/A & 55.60 \\
PTR2 & 56.71 & N/A \\
PTL2 & N/A & 55.27 \\
PTR3 & 55.30 & 55.08 \\
PTL3 & 55.79 & 56.95 \\
PTR4 & 55.06 & 54.47 \\
PTL4 & 55.19 & N/A \\
\hline
\end{tabular}

Table 5. Peak discharge computed using surveyed left-bank high-water marks for the July 27, 2006, event.

\begin{tabular}{ccc}
\hline Reach & Fall (ft) & Discharge $\left(\mathbf{f t}^{3} / \mathbf{s}\right)$ \\
\hline $\mathrm{X} 3-\mathrm{X} 4$ & 0.60 & 12,044 \\
\hline
\end{tabular}

Table 6. Peak discharges computed using surveyed right-bank high-water marks for the July 27, 2006, event.

\begin{tabular}{ccc}
\hline Reach & Fall (ft) & Discharge $\left(\mathbf{f t}^{3} / \mathbf{s}\right)$ \\
\hline X1-X2 & -0.14 & NA \\
X2-X3 & 1.41 & 12,409 \\
X3-X4 & 0.24 & 7,818 \\
X1-X3 & 1.27 & 10,791 \\
X2-X4 & 1.65 & 11,230 \\
X1-X4 & 1.51 & 10,089 \\
\hline
\end{tabular}

Table 7. Peak discharge computed with the left-bank pressure transducers for the July 27 , 2006, event.

\begin{tabular}{ccc}
\hline Reach & Fall (ft) & Discharge $\left(\mathbf{f t}^{3} / \mathbf{s}\right)$ \\
\hline $\mathrm{X} 1-\mathrm{X} 2$ & 0.33 & 8,466 \\
\hline
\end{tabular}


Table 8. Peak discharge computed with the right-bank pressure transducers for the July 27, 2006, event.

\begin{tabular}{ccc}
\hline Reach & Fall (ft) & Discharge $\left(\mathbf{f t}^{\mathbf{3}} \mathbf{s}\right)$ \\
\hline $\mathrm{X} 1-\mathrm{X} 3$ & 0.98 & 9,138 \\
$\mathrm{X} 3-\mathrm{X} 4$ & 0.61 & 10,589 \\
$\mathrm{X} 1-\mathrm{X} 4$ & 1.59 & 9,621 \\
\hline
\end{tabular}

Stage-discharge relations were developed for the gaging station for conditions before and following the vegetation scour using the stage values from the gaging station with corresponding discharge values that were computed using the CSA method (fig. 37). Travel time between the two locations was small and neglected in developing the rating curves.

\section{Conclusions}

The CSA method uses continuously recording pressure transducers to extend slope-area methods for computing peak discharge to entire event hydrographs. The method was initially implemented on the Babocomari River in Arizona in
2002. The pressure transducers provide records of stage that are input to the slope-area SAC program (Fulford, 1994) with cross-section and roughness information to compute discharge hydrographs. The CSA method can produce the event-peak stage and discharge, continuous-discharge hydrographs for an event, and a stage-discharge relation for the site. The SAC program provides considerable flexibility in computing discharge, including the specification of a stage-dependent $n$.

Discharges calculated with the CSA method are subject to the same error sources as indirect measurements. Surveying errors are typically small, and significant survey errors are usually evident if standard surveying practice is followed. Accuracy of the roughness parameter depends on available information and the judgment of the user, as with any indirect

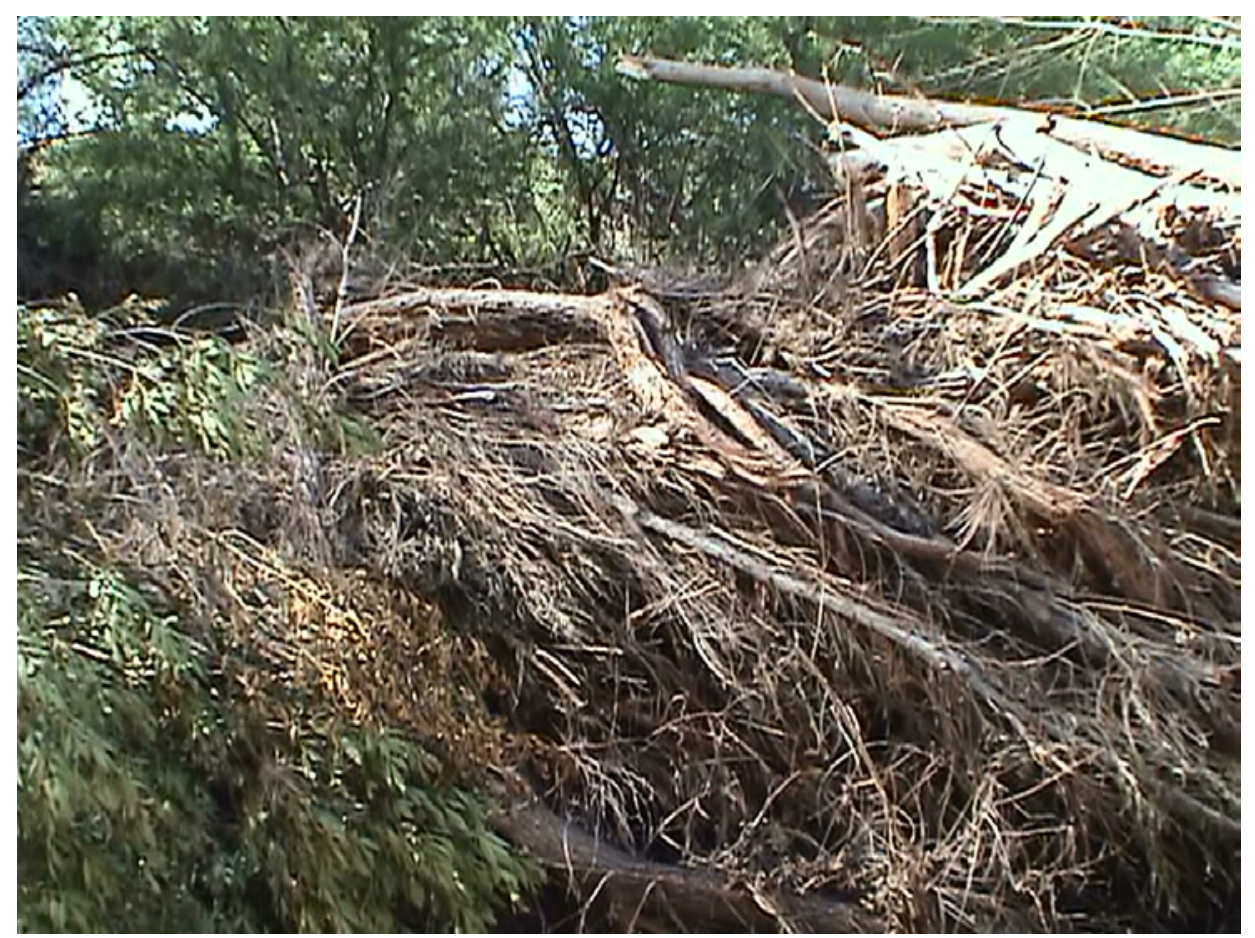

Figure 32. Debris pile near left bank in cross section 3 after the July 27, 2006, event. 


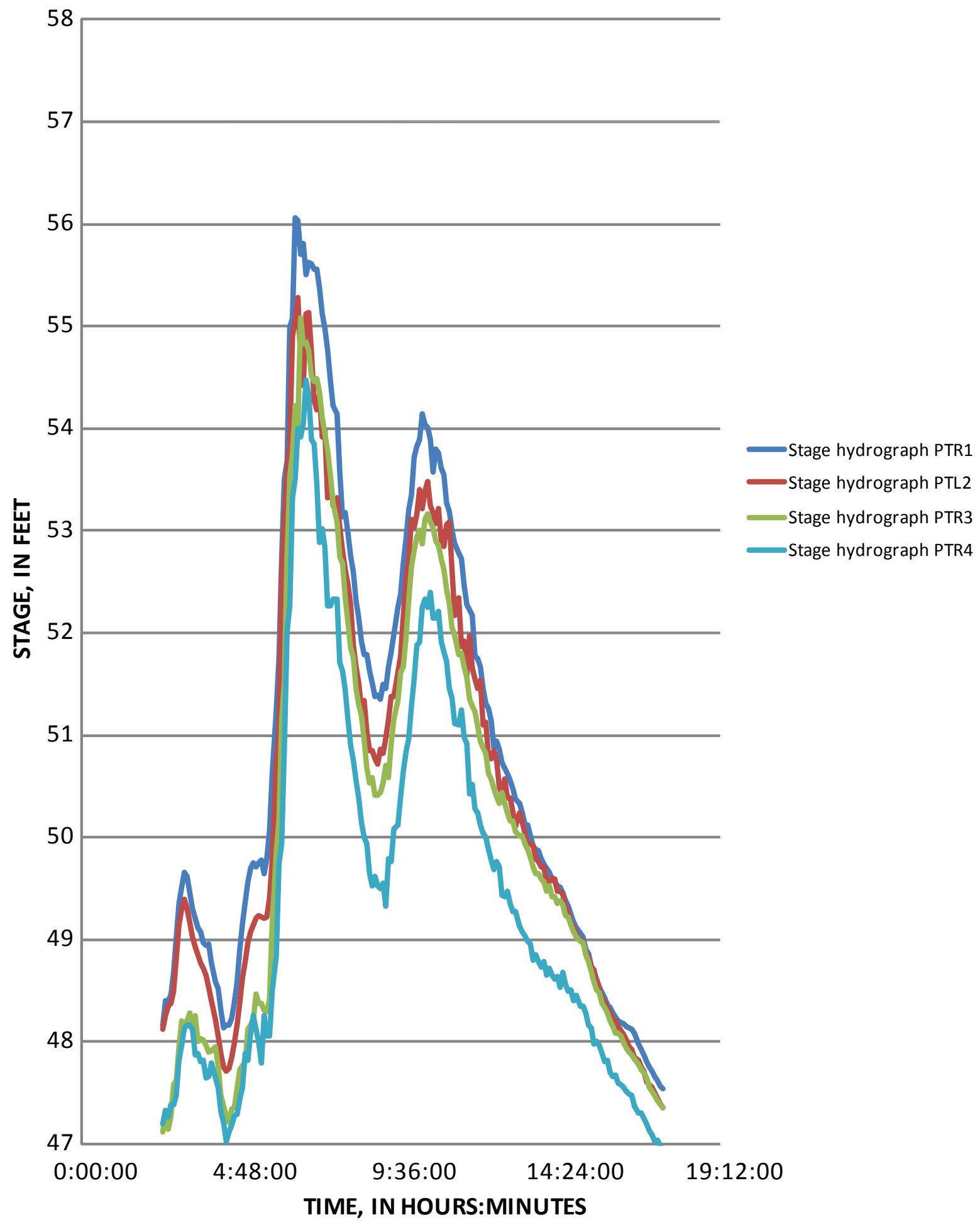

Figure 33. Stage hydrographs of the four pressure transducers that were used to compute discharge for the July 27 , 2006, event. 
measurement. The CSA method adds more information regarding a flow event but requires a corresponding amount of data evaluation, especially if the flow was sufficient to rearrange the channel or damage instruments. The continuous record of stage at multiple locations offers the opportunity to decipher the short history of a flow event in a way that is not possible with a slope-area method but at the cost of sorting through a larger volume of information.

In the study on the Babocomari River, comparisons to slope-area computations were made by using the high-water marks recorded by the CSGs or high-water marks surveyed in the CSA cross sections. The computed discharge was then compared to a discharge computed using the peak values recorded by the CSA PTs. Only two events are discussed in detail in this report, but similar applications were completed for all the flow events that produced good results. On occasion, PTs or high-water marks were affected by local conditions, such as debris piles, that degrade the accuracy of computed discharges. The data were not used where this occurred.

Ongoing experiments in CSA applications are refining optimum installation designs of the pressure transducers. The main consideration when installing a PT is stability of the base. The CSG design by Rantz (1982) is excellent at collecting the crest elevations. These types of gages are installed in areas out of the main area of flow that have slower velocities. To collect streamflow data at lower discharges, the PTs need to be installed nearer the deeper parts of the channel in the main areas of flow. The design of the PT installation in the Babocomari River performed well for the medium-flow ranges, as in the first four flow events. At discharges closer to the peak discharge of $9,600 \mathrm{ft}^{3} / \mathrm{s}$, the bases of the CSG gages

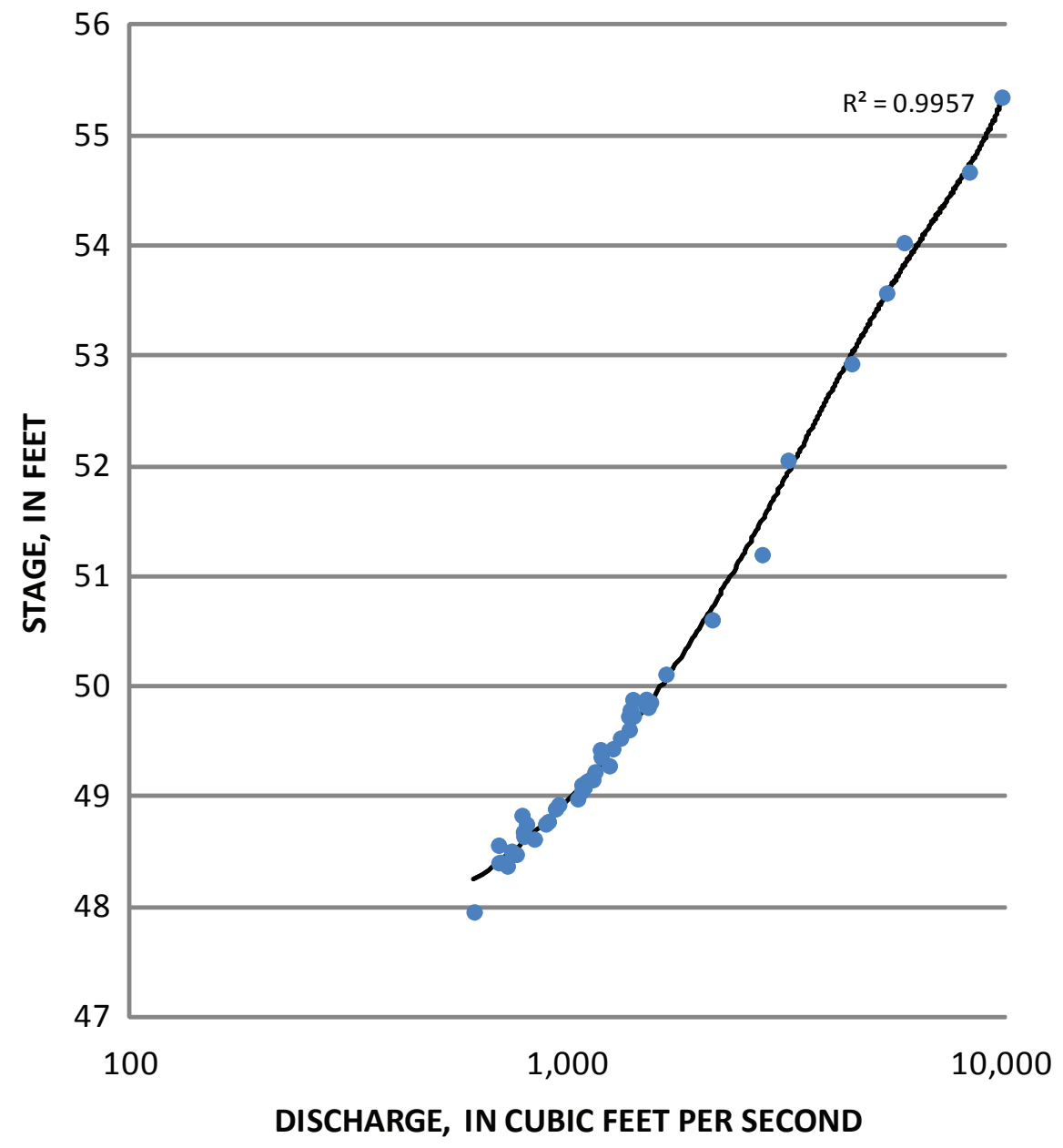

Figure 34. Stage values from the left-bank pressure transducer in cross section 1 and the corresponding discharge computed with stage data in X1-X4 during the July 27, 2006 , event are shown as dots. All stage and discharges shown occurred prior to the rotation of the pressure transducers. The solid line is a cubic polynomial fitted to the stage-discharge relation. 

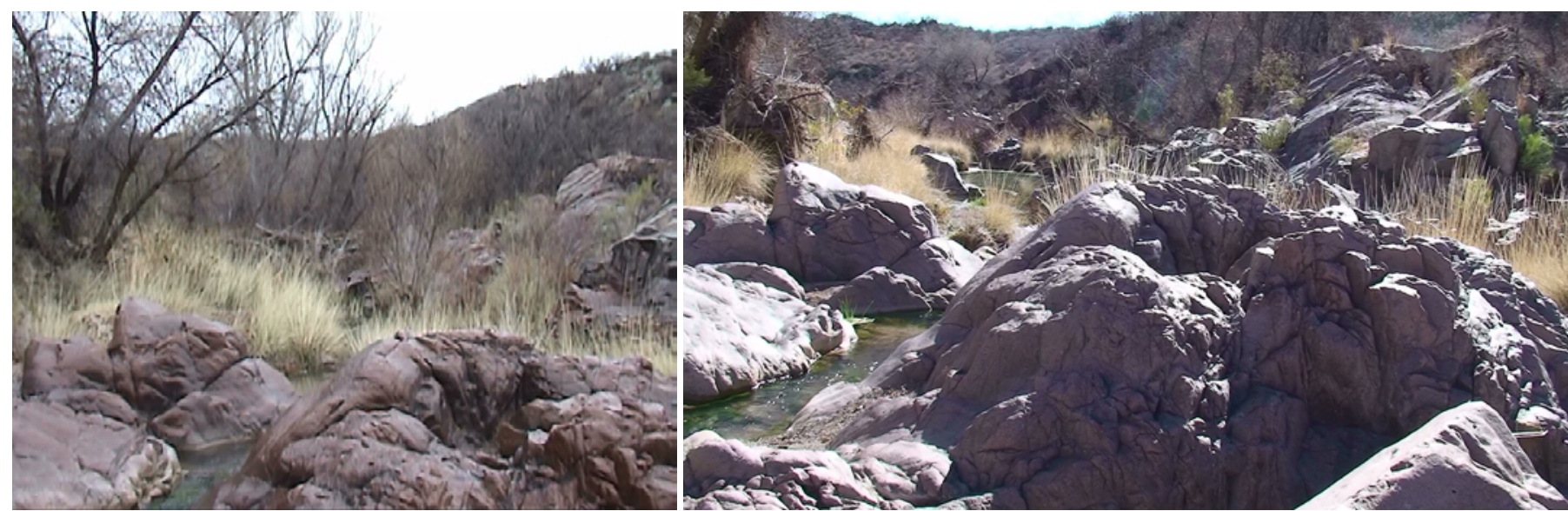

Figure 35. Reach below the Babocomari River near the Tombstone stream gage was heavily vegetated prior to the July 27, 2006, event (left). Much of that vegetation was gone after the event (right). The rock in the right foreground of the left photograph is the same as the rock occupying the right lower quadrant of the right photograph.

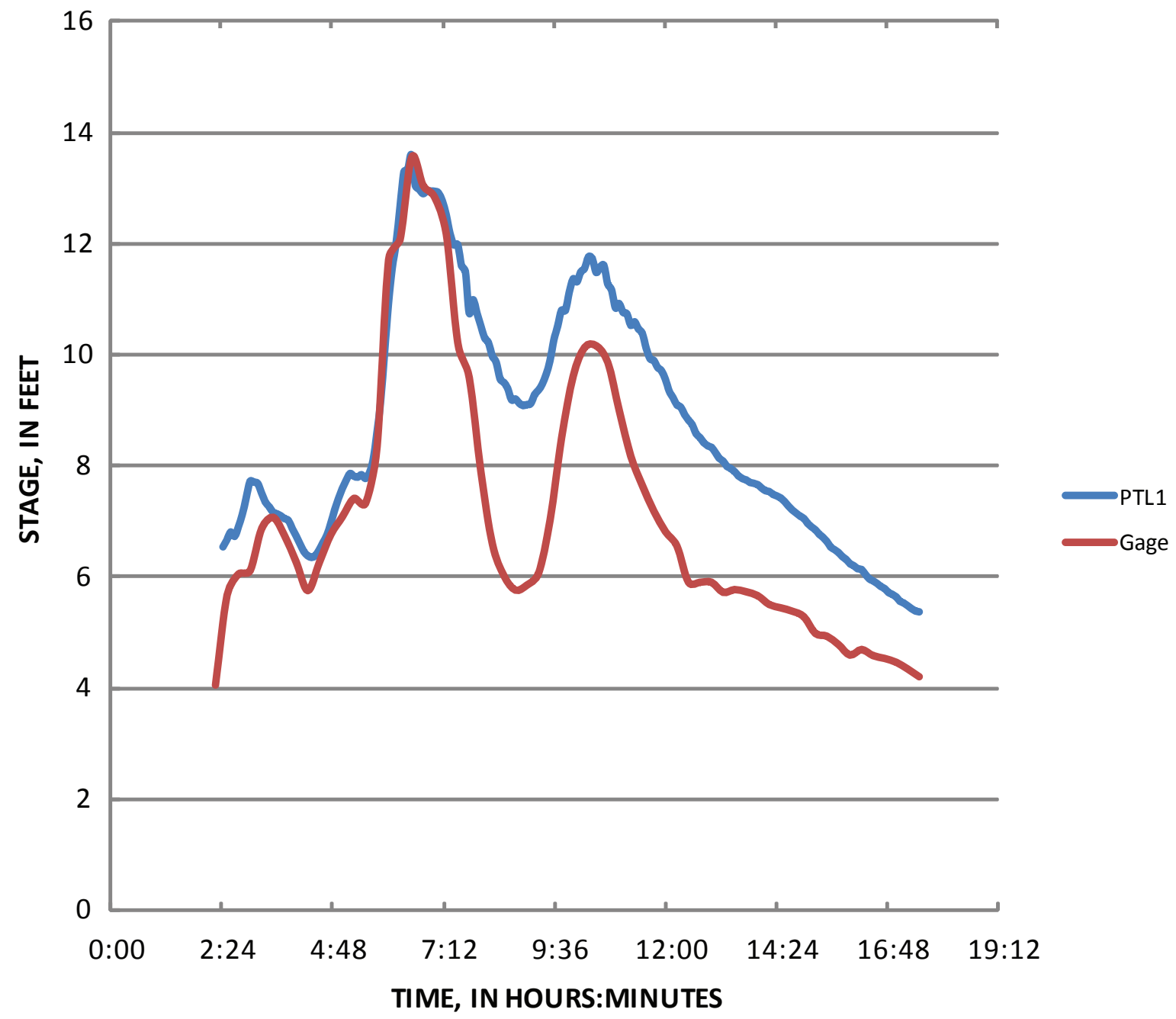

Figure 36. Stage hydrographs from the Babocomari River near Tombstone gage and the left-bank pressure transducer in cross section 1 (PTL1) during the July 27, 2006, event. Stages from the two sites were adjusted to coincide on the rising limb. 


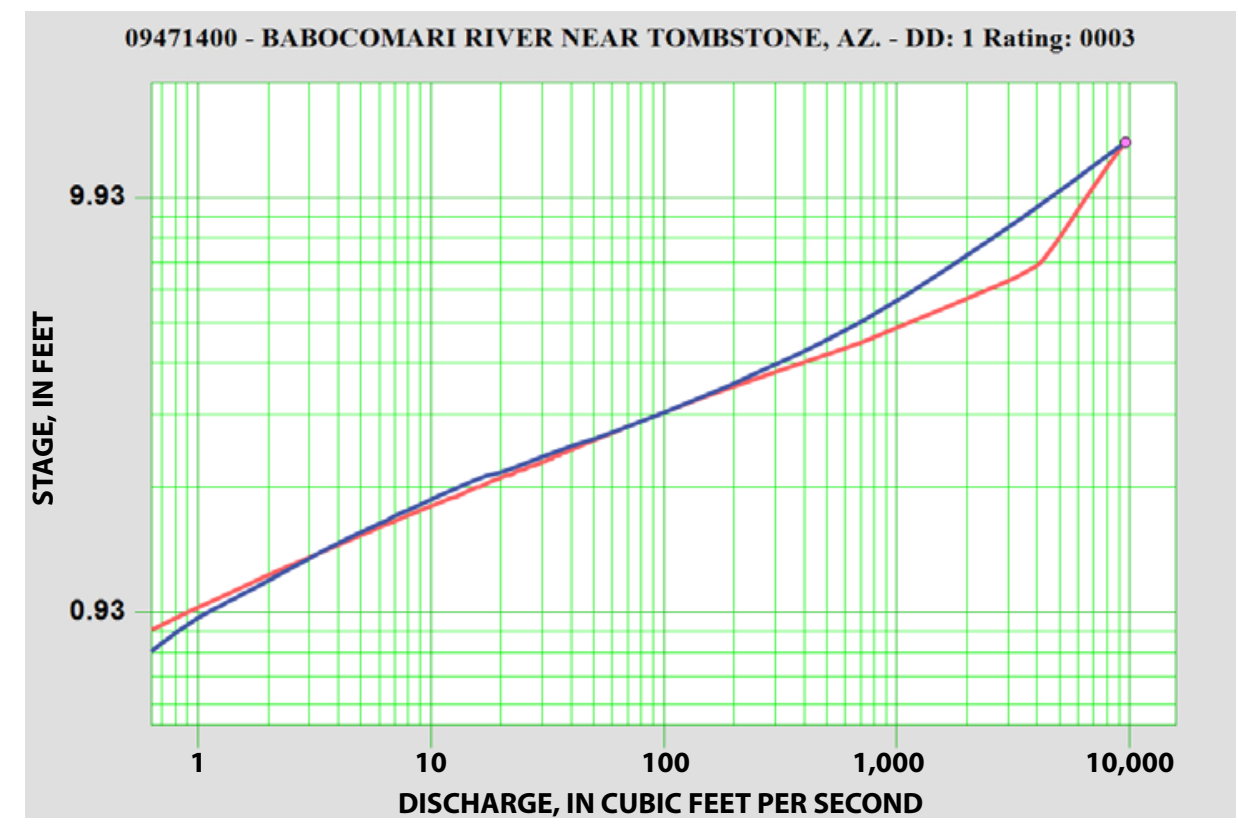

Figure 37. Stage-discharge relations before and after the July 27,2006 , event. The blue line represents conditions prior to the peak and included the effects of the dense vegetation. The red curve represents the condition after vegetation was scoured.

were scoured out, causing the CSA gage to rotate. Future installations of CSA gages should utilize shorter pipes that will collect less debris, and pipes should be angled at $45^{\circ}$ to allow them to better shed debris. This design will survive large flows but will lose the ability to record the crest elevation of a flood on the CSGs.

\section{References Cited}

Aldridge, B.N., and Garrett, J.M., 1973, Roughness coefficients for stream channels in Arizona: U.S. Geological Survey Open-File Report 73-3, 87 p.

Benson, M.A., and Dalrymple, T., 1967, General field and office procedures for indirect discharge measurements: U.S. Geological Survey Techniques of Water-Resources Investigations, book 3, chap. A1, 12 p. (http://pubs.er.usgs.gov/ usgspubs/twri/twri03A1).

Dalrymple, T., and Benson, M.A., 1967, Measurement of peak discharge by the slope-area method: U.S. Geological Survey Techniques of Water-Resources Investigations, book 3, chap. A2, 12 p. (http://pubs.usgs.gov/twri/twri3-a2/pdf/ twri_3-A2_a.pdf).

Fulford, J. M., 1994, User's guide to SAC, a computer program for computing discharge by slope-area method: U.S. Geological Survey Open File Report 94-360, 31 p.

Phillips, J.V., and Thomas, B.E., 2005, Hydrologic conditions in Arizona during 1999-2004- A historical perspective: U.S. Geological Survey Fact Sheet 2005-3081, 4 p.
Phillips, J.V., and Tadayon, S., 2006, Selection of Manning's roughness coefficient for natural and constructed vegetated and non-vegetated channels, and vegetation maintenance plan guidelines for vegetated channels in central Arizona: U.S. Geological Survey Scientific Investigations Report 2006-5108, $41 \mathrm{p}$.

Pool, D.R., and Coes, A.L.,1999, Hydrogeologic investigations of the Sierra Vista subwatershed of the upper San Pedro Basin, Cochise County, southeast Arizona: U.S. Geological Survey Water-Resources Investigations Report 99-4197, 41 p.

Rantz, S.E., 1982, Measurement and computation of streamflow, Volume 1- Measurement of stage and discharge: U.S. Geological Water-Supply Paper 2175, 284 p.

Stewart, A. M., Callegary, J.B., Smith, C.F., Wiele, S.M., Cordova, J.T., Fritzinger, R.A., and Gupta, H.V., 2008, Use of the Continuous Slope-Area Method to Estimate Runoff Through Ephemeral Stream Channels in SE Arizona, Eos Trans. AGU 89(53), Fall Meet. Suppl., Abstract H11E-0823.

Thomsen, B.W., and Hjalmarson, H.W., 1991, Estimated Manning's roughness coefficient for stream channels and flood plains in Maricopa County, Arizona: Phoenix, Flood Control District of Maricopa County report, $126 \mathrm{p}$.

Waltemeyer, S.D., 2005, Automated crest-stage gage application in ephemeral streams in New Mexico: U.S. Geological Survey Fact Sheet 2005-3136, 4 p.

Wiele, S.M. and Smith, J.D., 1996, A reach-averaged model of diurnal discharge wave propagation down the Colorado River through the Grand Canyon: Water Resources Research, v. 32, no. 5, p. 1375-1386. 


\section{Appendix 1. Stage data and computed discharge for five runoff events in the Babocomari River.}

August 3, 2002 runoff event on the Babocomari River

\begin{tabular}{ccccc}
\hline \multirow{2}{*}{$\begin{array}{c}\text { Date and } \\
\text { time }\end{array}$} & \multicolumn{4}{c}{ Right Bank } \\
\cline { 2 - 5 } & PTage, in feet \\
\cline { 2 - 5 } PTR2 & PTR3 & PTR4 \\
\hline 8/3/02 12:50 & 46.37 & 46.19 & 45.63 & 45.43 \\
8/3/02 12:55 & 46.41 & 46.20 & 45.73 & 45.56 \\
8/3/02 13:00 & 46.47 & 46.35 & 45.84 & 45.64 \\
8/3/02 13:05 & 46.72 & 46.61 & 46.10 & 45.90 \\
8/3/02 13:10 & 46.78 & 46.72 & 46.18 & 45.98 \\
8/3/02 13:15 & 46.86 & 46.88 & 46.29 & 46.10 \\
8/3/02 13:20 & 47.09 & 47.00 & 46.47 & 46.28 \\
8/3/02 13:25 & 47.14 & 47.16 & 46.51 & 46.30 \\
8/3/02 13:30 & 47.16 & 47.11 & 46.53 & 46.21 \\
8/3/02 13:35 & 47.07 & 47.04 & 46.49 & 46.23 \\
8/3/02 13:40 & 46.87 & 46.79 & 46.29 & 46.02 \\
8/3/02 13:45 & 46.74 & 46.63 & 45.98 & 45.78 \\
8/3/02 13:50 & 46.62 & 46.39 & 45.77 & 45.56 \\
8/3/02 13:55 & 46.53 & 46.29 & 45.65 & 45.39 \\
\hline
\end{tabular}

\begin{tabular}{ccccc}
\hline \multirow{2}{*}{$\begin{array}{c}\text { Date } \\
\text { and time }\end{array}$} & \multicolumn{4}{c}{ Left Bank } \\
\cline { 2 - 5 } & \multicolumn{4}{c}{ Stage, in feet } \\
\cline { 2 - 5 } PTL1 & PTL3 & PTL4 \\
\hline 8/3/02 12:50 & NA & 46.46 & 45.77 & 45.31 \\
8/3/02 12:55 & NA & 46.46 & 45.79 & 45.41 \\
8/3/02 13:00 & NA & 46.46 & 45.94 & 45.52 \\
8/3/02 13:05 & NA & 46.70 & 46.16 & 45.78 \\
8/3/02 13:10 & NA & 46.81 & 46.24 & 45.86 \\
$8 / 3 / 0213: 15$ & NA & 46.98 & 46.38 & 45.97 \\
8/3/02 13:20 & NA & 47.16 & 46.55 & 46.15 \\
$8 / 3 / 0213: 25$ & NA & 47.21 & 46.63 & 46.19 \\
8/3/02 13:30 & NA & 47.28 & 46.71 & 46.21 \\
8/3/02 13:35 & NA & 47.16 & 46.64 & 46.17 \\
8/3/02 13:40 & NA & 46.93 & 46.44 & 45.97 \\
8/3/02 13:45 & NA & 46.70 & 46.22 & 45.66 \\
8/3/02 13:50 & NA & 46.47 & 45.97 & 45.45 \\
8/3/02 13:55 & NA & 46.41 & 45.84 & 45.33 \\
\hline
\end{tabular}

Note: PTL1 was not inundated

\begin{tabular}{|c|c|c|c|c|c|}
\hline \multirow{2}{*}{$\begin{array}{l}\text { Date and } \\
\text { time }\end{array}$} & \multicolumn{4}{|c|}{ Average stage, in feet } & \multirow{2}{*}{ Computed discharge, $\mathrm{ft}^{3} / \mathrm{s}$} \\
\hline & $\overline{X 1}$ & $\overline{X 2}$ & $\overline{X 3}$ & $X 4$ & \\
\hline $8 / 3 / 0212: 50$ & & 46.32 & 45.70 & 45.37 & 431 \\
\hline 8/3/02 12:55 & & 46.33 & 45.76 & 45.48 & 428 \\
\hline 8/3/02 13:00 & & 46.41 & 45.89 & 45.58 & 458 \\
\hline 8/3/02 13:05 & & 46.65 & 46.13 & 45.84 & 528 \\
\hline 8/3/02 13:10 & & 46.77 & 46.21 & 45.92 & 566 \\
\hline 8/3/02 13:15 & & 46.93 & 46.33 & 46.04 & 620 \\
\hline 8/3/02 13:20 & & 47.08 & 46.51 & 46.22 & 675 \\
\hline $8 / 3 / 0213: 25$ & & 47.19 & 46.57 & 46.24 & 724 \\
\hline 8/3/02 13:30 & & 47.20 & 46.62 & 46.21 & 750 \\
\hline 8/3/02 13:35 & & 47.10 & 46.56 & 46.20 & 702 \\
\hline 8/3/02 13:40 & & 46.86 & 46.37 & 45.99 & 620 \\
\hline 8/3/02 13:45 & & 46.67 & 46.10 & 45.72 & 551 \\
\hline $8 / 3 / 0213: 50$ & & 46.43 & 45.87 & 45.51 & 471 \\
\hline 8/3/02 13:55 & & 46.35 & 45.74 & 45.36 & 447 \\
\hline
\end{tabular}


July 25, 2003 runoff event on the Babocomari River

\begin{tabular}{ccccc}
\hline \multirow{2}{*}{$\begin{array}{c}\text { Date } \\
\text { and } \\
\text { time }\end{array}$} & \multicolumn{4}{c}{ Right bank } \\
\cline { 2 - 5 } & \multicolumn{4}{c}{ Stage, in feet } \\
\cline { 2 - 5 } 7/25/03 19:10 & 46.25 & 45.73 & 45.57 & 44.17 \\
$7 / 25 / 0319: 15$ & 46.92 & 46.76 & 46.09 & 45.80 \\
$7 / 25 / 0319: 20$ & 47.03 & 46.78 & 46.06 & 46.12 \\
$7 / 25 / 03 ~ 19: 25$ & 46.867 & 46.67 & 46.001 & 45.97 \\
$7 / 25 / 03 ~ 19: 30$ & 46.674 & 46.432 & 45.887 & 45.683 \\
$7 / 25 / 03 ~ 19: 35$ & 46.425 & 46.119 & 45.573 & 45.239 \\
\hline
\end{tabular}

\begin{tabular}{cllll}
\hline & \multicolumn{4}{c}{ Left bank } \\
\cline { 2 - 5 } $\begin{array}{c}\text { Date } \\
\text { and } \\
\text { time }\end{array}$ & \multicolumn{4}{c}{ Stage, in feet } \\
\cline { 2 - 5 } PTL 2 & PTL 4 & PTL 6 & PTL 8 \\
\hline $7 / 25 / 03 ~ 19: 10$ & 47.346 & 46.412 & 45.74 & 45.255 \\
$7 / 25 / 03 ~ 19: 15$ & 47.345 & 46.766 & 46.107 & 45.646 \\
$7 / 25 / 03 ~ 19: 20$ & 47.343 & 46.822 & 46.333 & 46.017 \\
$7 / 25 / 03 ~ 19: 25$ & 47.347 & 46.713 & 46.219 & 45.872 \\
$7 / 25 / 03 ~ 19: 30$ & 47.349 & 46.522 & 46.027 & 45.619 \\
$7 / 25 / 03 ~ 19: 35$ & 47.352 & 46.415 & 45.746 & 45.289 \\
\hline
\end{tabular}

\begin{tabular}{cccccc}
\hline \multirow{2}{*}{$\begin{array}{c}\text { Date and } \\
\text { time }\end{array}$} & \multicolumn{3}{c}{ Average stage, in feet } & Computed discharge, $\mathbf{f t}^{\mathbf{3}} / \mathbf{s}$ \\
\cline { 2 - 5 } & $\mathbf{X 1}$ & $\mathbf{X 2}$ & $\mathbf{X 3}$ & $\mathbf{X 4}$ & \\
\hline 7/25/03 19:10 & 46.80 & 46.07 & 45.65 & 44.71 & 430 \\
7/25/03 19:15 & 47.13 & 46.76 & 46.10 & 45.73 & 527 \\
7/25/03 19:20 & 47.19 & 46.80 & 46.20 & 46.07 & 508 \\
$7 / 25 / 0319: 25$ & 47.11 & 46.69 & 46.11 & 45.92 & 491 \\
$7 / 25 / 0319: 30$ & 47.01 & 46.48 & 45.96 & 45.65 & 468 \\
7/25/03 19:35 & 46.89 & 46.27 & 45.66 & 45.26 & 429 \\
\hline
\end{tabular}

October 9, 2003 runoff event on the Babocomari River

\begin{tabular}{|c|c|c|c|c|c|c|c|c|c|}
\hline \multirow{3}{*}{$\begin{array}{l}\text { Date } \\
\text { and } \\
\text { time }\end{array}$} & \multicolumn{4}{|c|}{ Right bank } & \multirow{3}{*}{\multicolumn{2}{|c|}{$\begin{array}{l}\text { Date } \\
\text { and } \\
\text { time }\end{array}$}} & \multirow{2}{*}{\multicolumn{3}{|c|}{$\begin{array}{l}\text { Left bank } \\
\text { Stage, in feet }\end{array}$}} \\
\hline & \multicolumn{4}{|c|}{ Stage, in feet } & & & & & \\
\hline & PTR1 & PTR2 & PTR3 & $\begin{array}{l}\text { PTR4 } \\
\end{array}$ & & & PTL 2 & $\begin{array}{l}\text { PTL } 4 \\
\end{array}$ & PTL \\
\hline 10/9/03 19:35 & 46.231 & 45.657 & 45.578 & $\overline{44.244}$ & $\overline{10 / 9}$ & $/ / 03$ 19:35 & 47.339 & 46.405 & 45.72 \\
\hline 10/9/03 19:40 & 46.817 & 46.506 & 46.136 & 45.599 & $10 / s$ & /03 19:40 & 47.337 & 46.549 & 46.07 \\
\hline 10/9/03 19:45 & 47.03 & 46.781 & 46.349 & 46.118 & $10 / s$ & /03 19:45 & 47.339 & 46.883 & 46.42 \\
\hline 10/9/03 19:50 & 47.254 & 46.907 & 46.386 & 46.3 & $10 / s$ & /03 19:50 & 47.452 & 47.145 & 46.63 \\
\hline 10/9/03 19:55 & 47.297 & 46.995 & 46.384 & 46.338 & $10 / 5$ & /03 19:55 & 47.493 & 47.103 & 46.62 \\
\hline 10/9/03 20:00 & 47.2 & 46.975 & 46.296 & 46.172 & $10 / 5$ & /03 20:00 & 47.369 & 47.039 & 46.53 \\
\hline 10/9/03 20:05 & 47.019 & 46.693 & 45.995 & 45.885 & $10 / 5$ & /03 20:05 & 47.34 & 46.788 & 46.33 \\
\hline 10/9/03 20:10 & 46.766 & 46.475 & 45.893 & 45.481 & $10 / 5$ & /03 20:10 & 47.34 & 46.442 & 46.07 \\
\hline \multirow[t]{12}{*}{ 10/9/03 20:15 } & 46.471 & 46.172 & 45.655 & 45.08 & $10 / 5$ & /03 20:15 & 47.34 & 46.405 & 45.82 \\
\hline & \multirow{2}{*}{$\begin{array}{l}\text { Date and } \\
\text { time }\end{array}$} & \multicolumn{5}{|c|}{ Average stage, in feet } & \multirow{2}{*}{\multicolumn{3}{|c|}{ Computed discharge, $\mathrm{ft}^{3} / \mathrm{s}$}} \\
\hline & & $\mathrm{X1}$ & $\mathrm{X} 2$ & $\bar{x}$ & & $\mathrm{X} 4$ & & & \\
\hline & 10/9/03 19:35 & 46.231 & 46.031 & 45.6 & & 44.7575 & & 340 & \\
\hline & 10/9/03 19:40 & 46.817 & 46.5275 & 46.1 & & 45.5715 & & 459 & \\
\hline & 10/9/03 19:45 & 47.1845 & 46.832 & 46.3 & & 46.09 & & 529 & \\
\hline & 10/9/03 19:50 & 47.353 & 47.026 & 46. & & 46.2635 & & 580 & \\
\hline & 10/9/03 19:55 & 47.395 & 47.049 & 46.5 & & 46.2885 & & 591 & \\
\hline & 10/9/03 20:00 & 47.2845 & 47.007 & 46.4 & & 46.147 & & 567 & \\
\hline & $10 / 9 / 0320: 05$ & 47.1795 & 46.7405 & 46. & & 45.8445 & & 530 & \\
\hline & 10/9/03 20:10 & 46.766 & 46.4585 & 45.9 & & 45.4395 & & 444 & \\
\hline & 10/9/03 20:15 & 46.471 & 46.2885 & 45.7 & & 45.182 & & 374 & \\
\hline
\end{tabular}


August 15, 2005 runoff event on the Babocomari River

\begin{tabular}{|c|c|c|c|c|}
\hline \multirow{3}{*}{ Minutes } & \multicolumn{4}{|c|}{ Left bank } \\
\hline & \multicolumn{3}{|c|}{ Stage, recorded in feet } & \multirow{2}{*}{ Computed discharge, $\mathrm{ft}^{3} / \mathrm{s}$} \\
\hline & $\overline{\text { PTL1 }}$ & PTR2 & PTL3 & \\
\hline 0 & 47.375 & 47.035 & 46.332 & 607 \\
\hline 5 & 47.55 & 47.159 & 46.486 & 664 \\
\hline 10 & 47.499 & 47.138 & 46.431 & 650 \\
\hline 15 & 47.441 & 47.075 & 46.381 & 627 \\
\hline 20 & 47.365 & 47.013 & 46.321 & 602 \\
\hline 25 & 47.569 & 47.271 & 46.548 & 678 \\
\hline 30 & 47.723 & 47.343 & 46.685 & 728 \\
\hline 35 & 47.785 & 47.465 & 46.861 & 746 \\
\hline 40 & 47.818 & 47.524 & 46.945 & 748 \\
\hline 45 & 47.834 & 47.51 & 46.891 & 764 \\
\hline 50 & 47.839 & 47.471 & 46.912 & 759 \\
\hline 55 & 47.824 & 47.474 & 46.878 & 756 \\
\hline 60 & 47.812 & 47.411 & 46.85 & 749 \\
\hline 65 & 47.765 & 47.409 & 46.835 & 737 \\
\hline 70 & 47.728 & 47.372 & 46.8 & 720 \\
\hline 75 & 47.66 & 47.341 & 46.752 & 695 \\
\hline 80 & 47.609 & 47.228 & 46.689 & 668 \\
\hline 85 & 47.567 & 47.15 & 46.623 & 653 \\
\hline 90 & 47.492 & 47.046 & 46.52 & 623 \\
\hline 95 & 47.45 & 46.916 & 46.46 & 600 \\
\hline 100 & 47.406 & 46.826 & 46.422 & 580 \\
\hline 105 & 47.39 & 46.739 & 46.351 & 572 \\
\hline 110 & 47.56 & 47.242 & 46.611 & 662 \\
\hline 115 & 47.856 & 47.684 & 46.877 & 801 \\
\hline 120 & 48.06 & 47.912 & 47.064 & 897 \\
\hline 125 & 48.137 & 47.988 & 47.205 & 918 \\
\hline 130 & 48.133 & 48.008 & 47.237 & 909 \\
\hline 135 & 48.134 & 48.014 & 47.278 & 900 \\
\hline 140 & 48.093 & 47.969 & 47.25 & 879 \\
\hline 145 & 48.025 & 47.955 & 47.187 & 857 \\
\hline 150 & 47.958 & 47.808 & 47.105 & 823 \\
\hline 155 & 47.856 & 47.661 & 47.021 & 770 \\
\hline 160 & 47.846 & 47.534 & 46.895 & 772 \\
\hline 165 & 47.747 & 47.549 & 46.823 & 749 \\
\hline 170 & 47.697 & 47.415 & 46.736 & 723 \\
\hline 175 & 47.629 & 47.303 & 46.671 & 690 \\
\hline 180 & 47.575 & 47.226 & 46.608 & 667 \\
\hline 185 & 47.516 & 47.174 & 46.526 & 648 \\
\hline 190 & 47.459 & 47.045 & 46.512 & 613 \\
\hline 195 & 47.406 & 46.899 & 46.488 & 578 \\
\hline
\end{tabular}


July 27, 2006 runoff event on the Babocomari River

\begin{tabular}{|c|c|c|c|c|c|}
\hline \multirow{2}{*}{ Time } & \multicolumn{4}{|c|}{ Stage, recorded in feet } & \multirow{2}{*}{$\begin{array}{c}\text { Discharge, in cfs } \\
\text { CSA Discharge }\end{array}$} \\
\hline & PTR1 & PTL2 & PTR3 & PTR4 & \\
\hline $2: 15: 00$ & 46.726 & 46.479 & 45.633 & 44.333 & 383 \\
\hline 2:20:00 & 47.664 & 47.486 & 46.888 & 46.356 & 645 \\
\hline 2:25:00 & 48.164 & 48.12 & 47.122 & 47.202 & 706 \\
\hline 2:30:00 & 48.398 & 48.252 & 47.298 & 47.334 & 807 \\
\hline 2:35:00 & 48.399 & 48.346 & 47.138 & 47.258 & 806 \\
\hline 2:40:00 & 48.459 & 48.373 & 47.264 & 47.379 & 821 \\
\hline $2: 45: 00$ & 48.675 & 48.497 & 47.575 & 47.381 & 981 \\
\hline $2: 50: 00$ & 49.023 & 48.806 & 47.623 & 47.478 & 1,139 \\
\hline $2: 55: 00$ & 49.352 & 49.146 & 47.954 & 47.824 & 1,311 \\
\hline 3:00:00 & 49.507 & 49.307 & 48.203 & 47.969 & 1,427 \\
\hline 3:05:00 & 49.663 & 49.393 & 48.181 & 48.132 & 1,455 \\
\hline $3: 10: 00$ & 49.619 & 49.305 & 48.208 & 48.157 & 1,423 \\
\hline 3:15:00 & 49.465 & 49.165 & 48.287 & 48.162 & 1,352 \\
\hline 3:20:00 & 49.301 & 49.021 & 48.134 & 48.128 & 1,216 \\
\hline $3: 25: 00$ & 49.208 & 48.927 & 48.249 & 47.867 & 1,281 \\
\hline 3:30:00 & 49.109 & 48.853 & 48.002 & 47.887 & 1,155 \\
\hline 3:35:00 & 49.078 & 48.775 & 48.033 & 47.8 & 1,171 \\
\hline $3: 40: 00$ & 48.976 & 48.724 & 48.013 & 47.819 & 1,103 \\
\hline $3: 45: 00$ & 48.944 & 48.647 & 47.958 & 47.652 & 1,121 \\
\hline 3:50:00 & 48.963 & 48.535 & 47.899 & 47.664 & 1,103 \\
\hline 3:55:00 & 48.77 & 48.404 & 47.912 & 47.787 & 949 \\
\hline 4:00:00 & 48.59 & 48.21 & 47.953 & 47.641 & 891 \\
\hline 4:05:00 & 48.516 & 48.056 & 47.767 & 47.559 & 839 \\
\hline 4:10:00 & 48.308 & 47.881 & 47.478 & 47.314 & 768 \\
\hline 4:15:00 & 48.141 & 47.75 & 47.372 & 47.204 & 700 \\
\hline 4:20:00 & 48.161 & 47.711 & 47.273 & 47.027 & 739 \\
\hline 4:25:00 & 48.163 & 47.746 & 47.21 & 47.114 & 712 \\
\hline 4:30:00 & 48.235 & 47.847 & 47.343 & 47.181 & 753 \\
\hline 4:35:00 & 48.386 & 47.997 & 47.355 & 47.274 & 806 \\
\hline 4:40:00 & 48.584 & 48.166 & 47.536 & 47.296 & 925 \\
\hline 4:45:00 & 48.899 & 48.392 & 47.73 & 47.431 & 1,088 \\
\hline 4:50:00 & 49.156 & 48.626 & 47.767 & 47.558 & 1,196 \\
\hline 4:55:00 & 49.363 & 48.778 & 47.803 & 47.89 & 1,218 \\
\hline 5:00:00 & 49.56 & 48.966 & 48.123 & 47.816 & 1,435 \\
\hline 5:05:00 & 49.692 & 49.073 & 48.169 & 48.088 & 1,445 \\
\hline 5:10:00 & 49.749 & 49.142 & 48.215 & 48.257 & 1,443 \\
\hline 5:15:00 & 49.715 & 49.212 & 48.464 & 48.121 & 1,558 \\
\hline $5: 20: 00$ & 49.749 & 49.233 & 48.375 & 47.991 & 1,585 \\
\hline 5:25:00 & 49.771 & 49.222 & 48.376 & 47.787 & 1,641 \\
\hline $5: 30: 00$ & 49.64 & 49.21 & 48.308 & 48.249 & 1,423 \\
\hline 5:35:00 & 49.785 & 49.225 & 48.293 & 48.06 & 1,557 \\
\hline $5: 40: 00$ & 50.072 & 49.403 & 48.409 & 48.058 & 1,743 \\
\hline $5: 45: 00$ & 50.611 & 49.775 & 49.138 & 48.498 & 2,224 \\
\hline $5: 50: 00$ & 51.245 & 50.732 & 49.866 & 48.834 & 2,988 \\
\hline $5: 55: 00$ & 51.755 & 51.082 & 50.172 & 49.742 & 3,302 \\
\hline 6:00:00 & 52.724 & 52.546 & 51.135 & 49.933 & 4,749 \\
\hline 6:05:00 & 53.509 & 53.121 & 51.53 & 50.889 & 5,546 \\
\hline $6: 10: 00$ & 53.678 & 53.581 & 52.752 & 52.018 & 6,020 \\
\hline $6: 15: 00$ & 54.986 & 53.877 & 53.522 & 52.261 & 8,481 \\
\hline 6:25:00 & 56.055 & 55.055 & 54.226 & 53.507 & 10,097 \\
\hline
\end{tabular}




\section{Appendix 2. Input files to the SAC program used in the continuous slope-area calculations of discharge for five events on the Babocomari river. These files are templates. The stages are replaced when computing the hydrograph with stages from the CSA pressure transducers. Documentation of the SAC program can be found in Fulford (1994).}

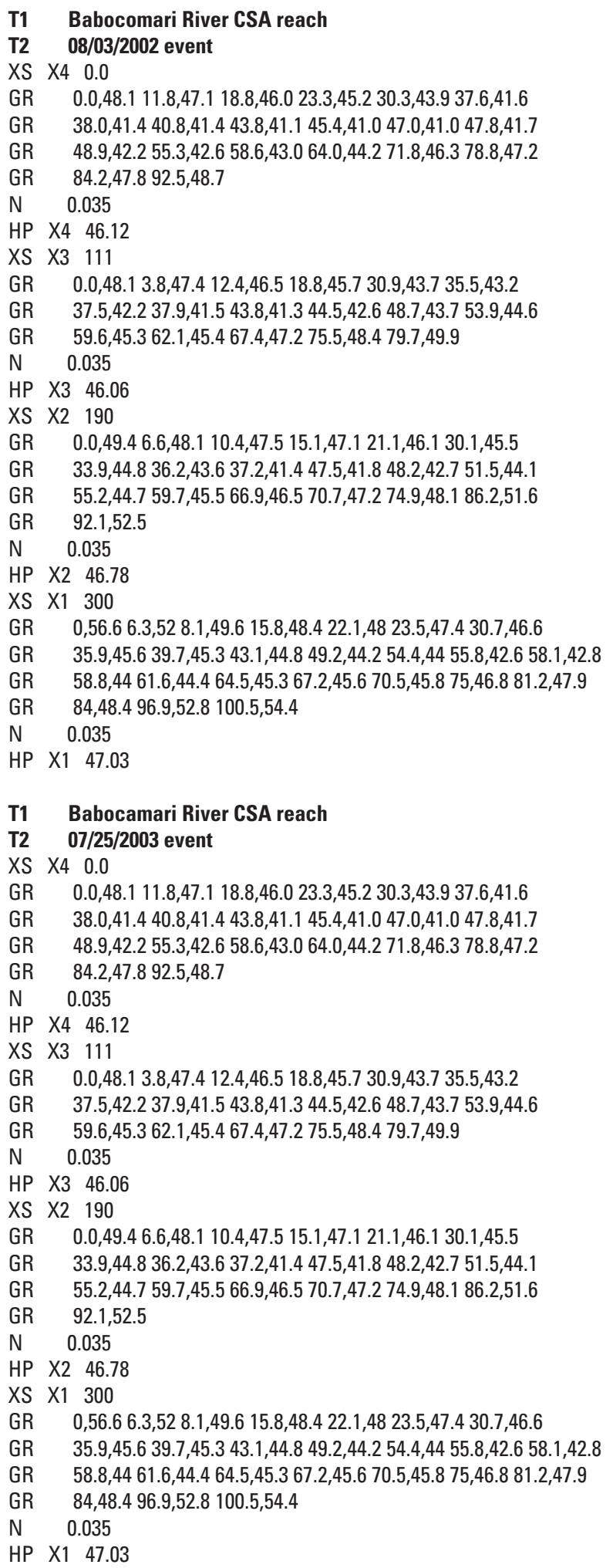




\section{Babocomari River CSA reach}

T2 7/27/2006 event

XS X4 0.0

GR $\quad 006.00,055.19014 .00,049.78041 .80,047.10048 .80,046.00$

GR $\quad 053.30,045.20060 .30,043.90067 .60,041.60068 .00,041.40$

GR $\quad 070.80,041.40073 .80,041.10075 .40,041.00077 .00,041.00$

GR $\quad 077.80,041.70078 .90,042.20085 .30,042.60088 .60,043.00$

GR $\quad 094.00,044.20101 .80,046.30108 .80,047.20114 .20,047.80$

GR $\quad 122.50,048.70124 .00,048.99130 .00,050.33136 .00,055.06$

N $\quad 0.040$

HP X4 44.333

XS X3 $\quad 115$

GR $\quad 003.00,055.79019 .80,048.30031 .50,046.60035 .70,046.30$

GR $\quad 038.70,045.80042 .20,045.20047 .20,044.50050 .50,043.90$

GR $\quad 053.30,043.50055 .30,043.70056 .20,043.10059 .50,041.00$

GR $\quad 061.10,040.90063 .10,041.00064 .50,041.70065 .40,043.00$

GR $\quad 066.80,043.60070 .90,043.90074 .50,044.60075 .80,044.50$

GR $\quad 077.10,044.70078 .40,045.00081 .90,045.40083 .10,046.10$

GR $\quad 086.60,046.80091 .00,047.60101 .00,050.28106 .10,050.80$

GR $\quad 120.00,052.69138 .00,055.30$

N $\quad 0.040$

HP X3 45.633

XS X2 188

GR $\quad 001.70,055.50003 .00,054.83006 .00,053.06012 .60,050.62$

GR $\quad 017.20,049.42022 .00,048.97028 .50,048.16043 .50,045.77$

GR $\quad 044.00,046.35052 .00,045.57056 .50,043.97056 .50,041.47$

GR $\quad 066.00,041.77070 .00,042.07070 .50,043.07077 .00,045.17$

GR $\quad 077.50,045.58085 .00,046.27095 .00,048.09098 .00,048.82$

GR $\quad 098.00,048.82101 .00,049.75107 .70,052.00115 .80,053.37$

GR $\quad 126.40,054.23136 .20,055.41139 .00,056.71$

N $\quad 0.040$

HP X2 46.479

XS X1 301

GR $\quad 004.00,058.65019 .00,050.48027 .60,049.00031 .10,048.00$

GR $\quad 034.30,047.70036 .00,047.90037 .50,047.50038 .90,047.30$

GR $\quad 041.40,046.80042 .20,046.80044 .80,046.50049 .90,045.70$

GR $\quad 055.00,045.27057 .30,044.80061 .90,044.60067 .90,044.10$

GR $\quad 068.40,042.80069 .60,042.70070 .10,043.10070 .70,042.80$

GR $\quad 071.00,042.60071 .40,042.70071 .80,043.80074 .80,044.50$

GR $\quad 078.20,045.40079 .50,045.50082 .00,045.60082 .90,045.50$ 
This page intentionally left blank 
Produced in the Western Region, Menlo Park, California Manuscript approved for publication, August 9, 2010

Layout and design by Stephen L. Scott 
8

흘 